\title{
Long-Term Instrumentation, Information, and Control Systems (II\&C) Modernization Future Vision and Strategy
}

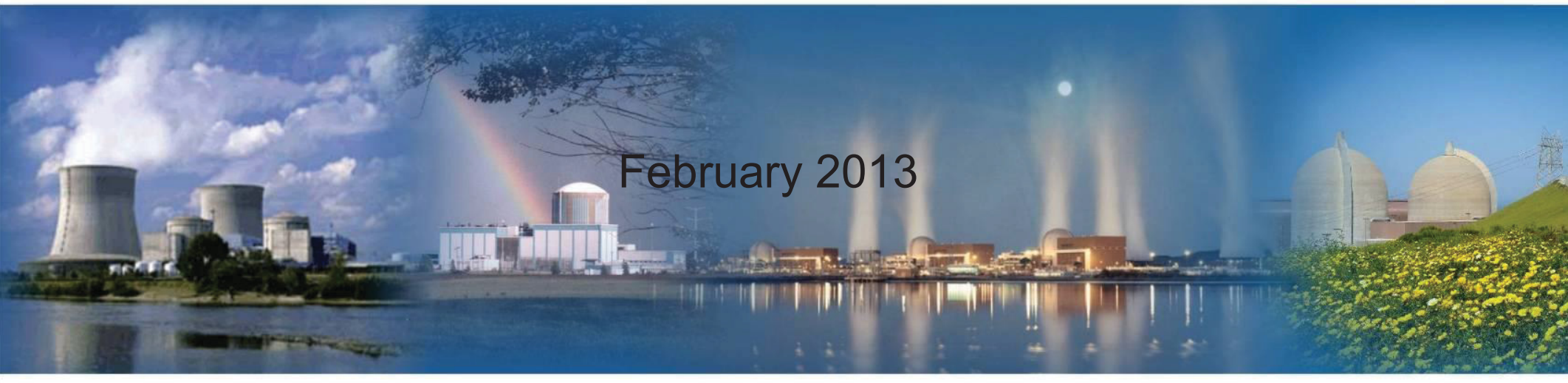

The INL is a U.S. Department of Energy National Laboratory operated by Battelle Energy Alliance 


\section{DISCLAIMER}

This information was prepared as an account of work sponsored by an agency of the U.S. Government. Neither the U.S. Government nor any agency thereof, nor any of their employees, makes any warranty, expressed or implied, or assumes any legal liability or responsibility for the accuracy, completeness, or usefulness, of any information, apparatus, product, or process disclosed, or represents that its use would not infringe privately owned rights. References herein to any specific commercial product, process, or service by trade name, trade mark, manufacturer, or otherwise, does not necessarily constitute or imply its endorsement, recommendation, or favoring by the U.S. Government or any agency thereof. The views and opinions of authors expressed herein do not necessarily state or reflect those of the U.S. Government or any agency thereof. 


\title{
Long-Term Instrumentation, Information, and Control Systems (II\&C) Modernization Future Vision and Strategy
}

\author{
Ken Thomas \\ Bruce Hallbert
}

February 2013

\begin{abstract}
Idaho National Laboratory Idaho Falls, Idaho 83415

http://www.inl.gov
\end{abstract}

\author{
Prepared under Work Package L-12N060305 \\ Prepared for the \\ U.S. Department of Energy \\ Office of Nuclear Energy \\ Under DOE Idaho Operations Office \\ Contract DE-AC07-05ID14517
}




\section{EXECUTIVE SUMMARY}

Life extension beyond 60 years for the U.S operating nuclear fleet requires that instrumentation and control (I\&C) systems be upgraded to address aging and reliability concerns. It is impractical for the legacy systems based on 1970's vintage technology to operate over this extended time period. For some time, utilities have successfully engaged in such replacements when dictated by these operational concerns. However, the replacements have been approached in a like-for-like manner, meaning that they do not take advantage of the inherent capabilities of digital technology to improve business functions. And so, the improvement in I\&C system performance has not translated into bottom-line business performance improvement for the fleet.

At the same time, it is becoming increasingly difficult to maintain the legacy I\&C systems in view of reliability and component aging issues. This is compounded by related issues of the availability of spare parts, the expense of maintaining workforce skills for these declining technologies, and the everincreasing labor requirements to maintain the components and qualify replacements.

A future vision and modernization strategy for a transformed nuclear plant operating model has been developed as part of the Advanced Instrumentation, Information, and Control (II\&C) research pathway, under the Light Water Reactor (LWR) Sustainability Program. This is a research and development program sponsored by the U.S. Department of Energy (DOE), performed in close collaboration with the nuclear utility industry, to provide the technical foundations for licensing and managing the long-term, safe and economical operation of current nuclear power plants. DOE's program focus is on longer-term and higher-risk/reward research that contributes to the national policy objectives of energy security and environmental security. The Advanced II\&C research pathway is a component of DOE's focused research and development strategy that addresses key issues needed to ensure the long-term sustainability of existing commercial power reactors.

The future vision for II\&C technologies is based on a digital architecture that encompasses all aspects of plant operations and support; integrating plant systems, plant work processes, and plant workers in a seamless digital environment to enhance nuclear safety, increase productivity, and improve overall plant performance. The long-term goal is to transform the operating model of the nuclear power plants (NPP)s from one that is highly reliant on a large staff performing mostly manual activities to an operating model based on highly integrated technology with a smaller staff. This digital transformation is critical to addressing an array of issues facing the plants, including aging of legacy analog systems, potential shortage of technical workers, ever-increasing expectations for nuclear safety improvement, and relentless pressure to reduce cost.

The modernization strategy is based on research in the following major areas of enabling capability:

1. Highly integrated control rooms

2. Highly automated plant

3. Integrated operations

4. Human performance improvement for field workers

5. Outage safety and efficiency

6. Centralized On-Line Monitoring and Information Integration

Pilot projects will be conducted in each of these areas as the means for industry to collectively integrate these new technologies into nuclear plant work activities. The pilot projects introduce new digital technologies into the nuclear plant operating environment at host operating plants to demonstrate and validate them for production usage. In turn, the pilot project technologies serve as the stepping stones to the eventual seamless digital environment of the future vision. 


\section{CONTENTS}

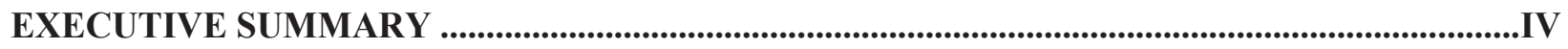

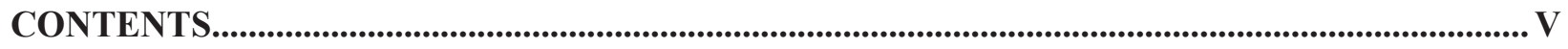

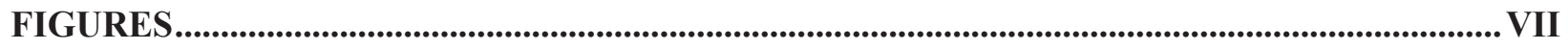

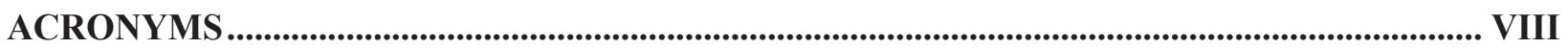

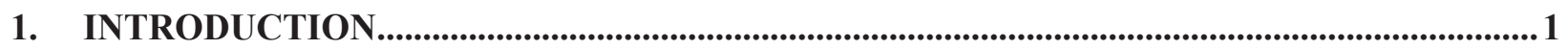

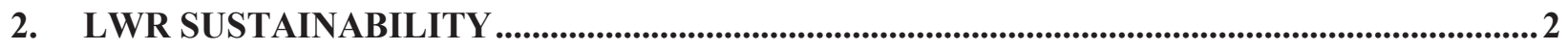

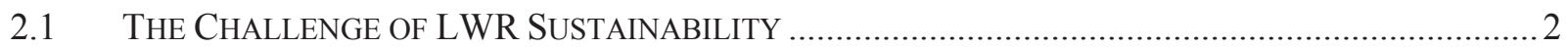

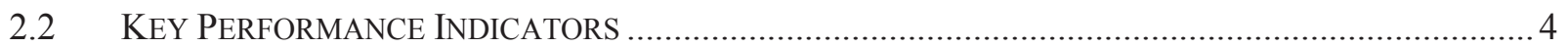

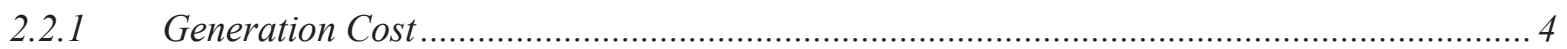

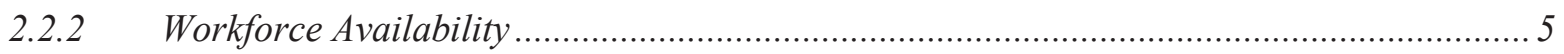

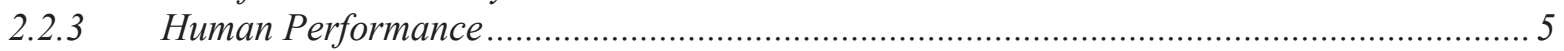

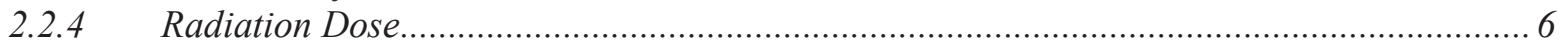

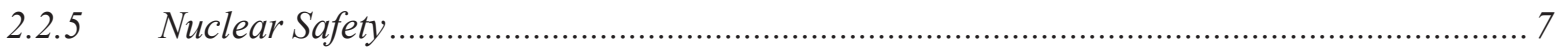

2.2.6 Long-Term Plant Asset Management .............................................................................. 7

2.3 THE CURRENT INDUSTRY APPROACH TO II\&C MODERNIZATION.............................................. 8

2.4 OPPORTUNITY FOR FUTURE PERFORMANCE IMPROVEMENT …...........................................

3. LONG-TERM II\&C MODERNIZATION: FUTURE VISION AND STRATEGY .................. 10

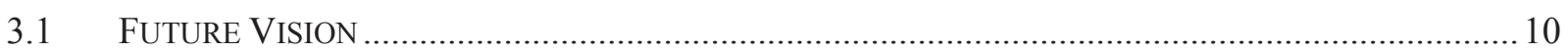

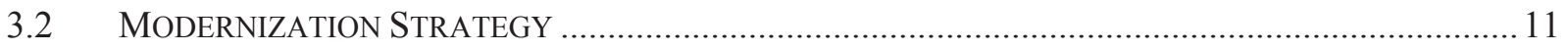

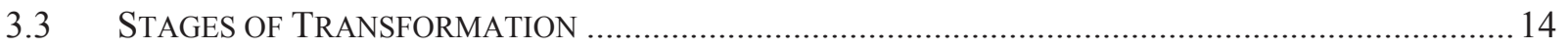

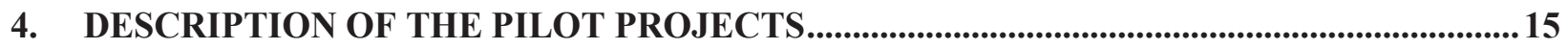

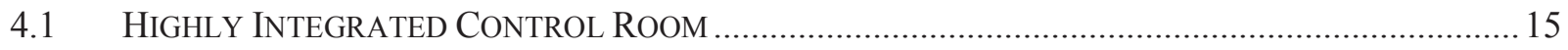

4.1.1 Applying Digital Upgrades in an Analog Control Room ........................................... 16

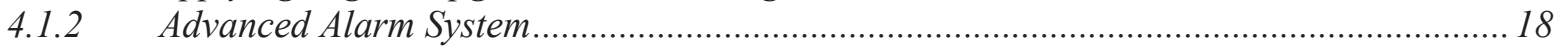

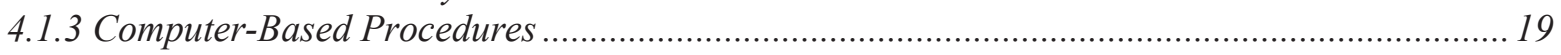

4.1.4 Computerized Operations Support Systems ............................................................... 20

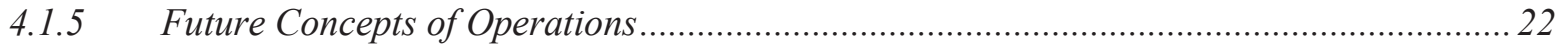

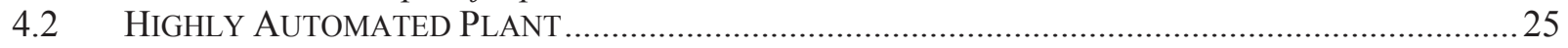

4.2.1 Digital Architecture for a Highly Automated Plant ...................................................... 25

4.2.2 Automating Manually Performed Plant Activities ...................................................... 26

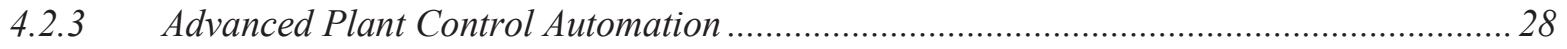

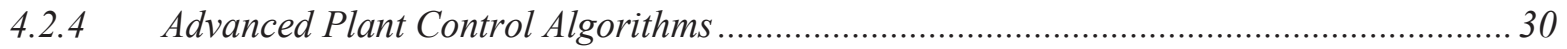

4.3 HumAn PERFORMANCE IMPROVEMENT For NUCLEAR POWER PlANT FIELD WORKERS ..........31

4.3.1 Mobile Technologies for Nuclear Power Plant Field Workers........................................ 32

4.3.2 Automated Work Packages ..................................................................................... 34

4.3.3 Augmented Reality for Nuclear Power Plant Field Workers ............................................ 36

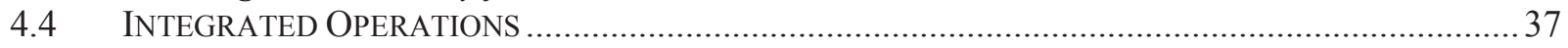

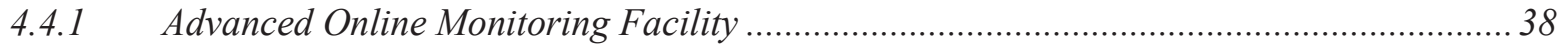

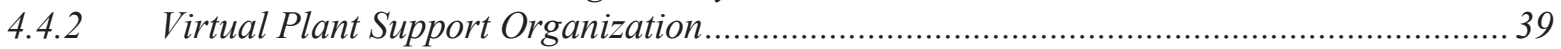

4.4.3 Management Decision Support Center ...................................................................... 42 


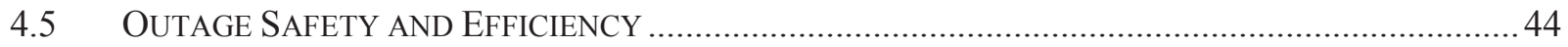

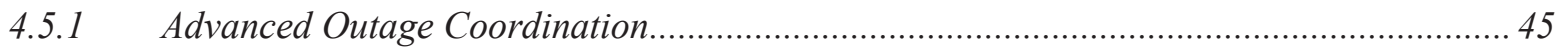

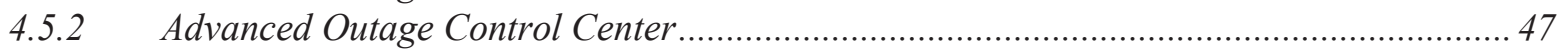

4.5.3 Outage Risk Management Improvement ...................................................................... 48

4.6 CENTRALIZED ON-LINE MONITORING AND INFORMATION INTEGRATION ..............................49

4.6.1 On-Line Monitoring of Active Components ................................................................. 52

4.6.2 On-Line Monitoring of Passive Components/Structures ..................................................5 53

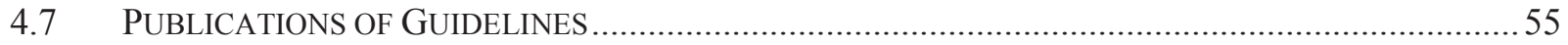

5. RESEARCH AND DEVELOPMENT SUPPORT FUNCTIONS ...........................................56

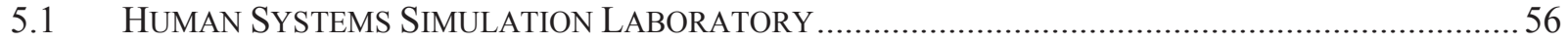

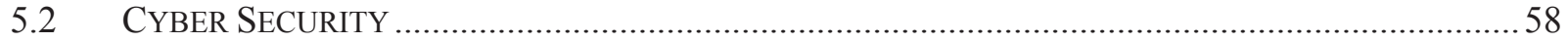

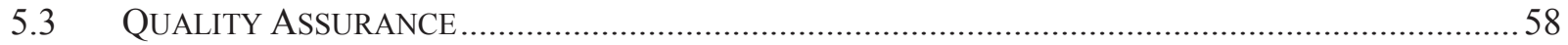

6. RESEARCH AND DEVELOPMENT COOPERATION ......................................................59

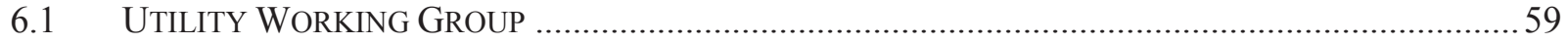

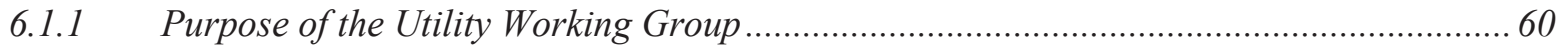

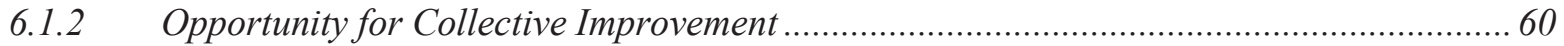

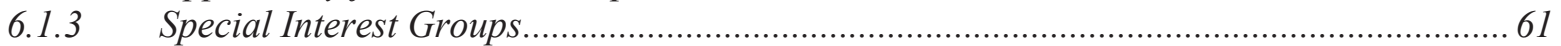

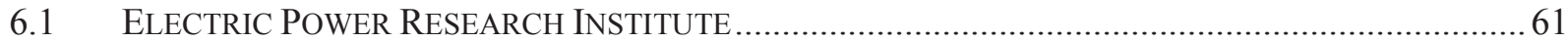

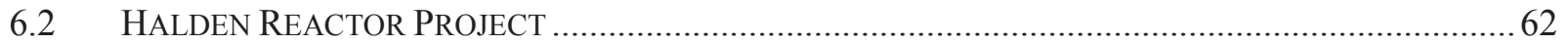

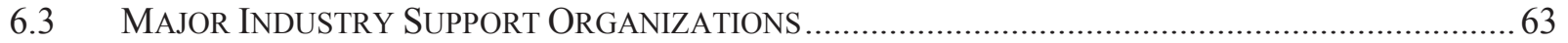

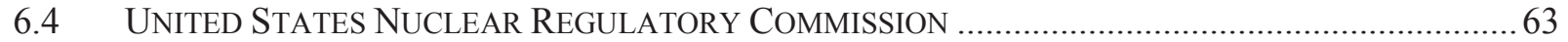

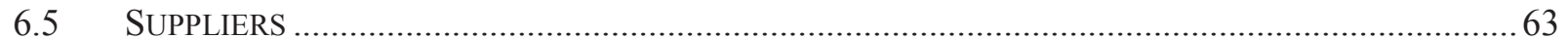

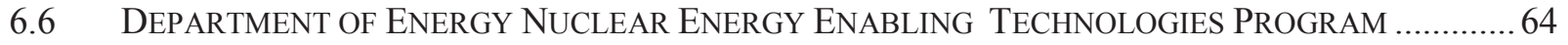

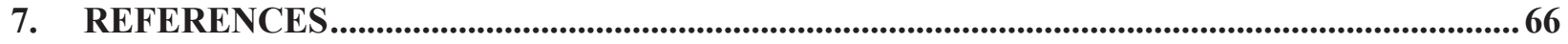

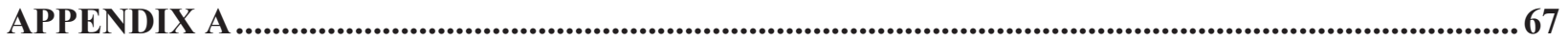




\section{FIGURES}

Figure 1 Performance Based on CurRent Operating Model ................................................... 9

Figure 2 PERformance IMPROVEMENT BASEd ON A Digital TRANSFORMATION OF THE OPERATING

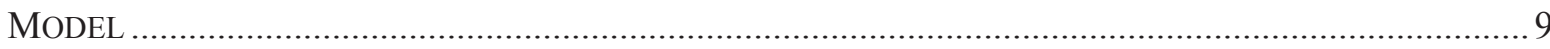

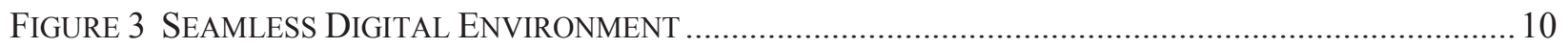

FIGURE 4 SUMMARY OF THE PILOT PROJECTS FOR THE II\&C SYSTEMS TECHNOLOGIES R\&D PATHWAY

Figure 5 StAges of TRANSFORMATION IN THE AdVANCED II\&C LONG-TERM ViSION ......................... 15

FIGURE 6 OPERATOR WORKSHOP CONDUCTED IN THE HSSL IN SUPPORT OF A NUCLEAR UTILITY

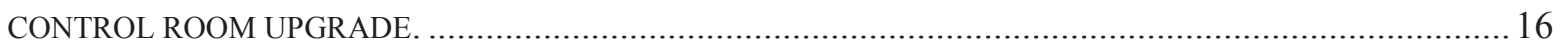

FIGURE 7 HUMAN FACTORS STUDIES FOR COMPUTER-BASED PROCEDURES FOR FIELD OPERATORS .........20

FIGURE 8 OPERATOR AT CATAWBA NUCLEAR STATION USING HAND-HELD TECHNOLOGY FOR

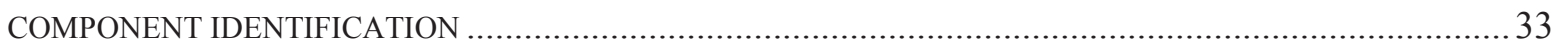

FIGURE 9 CATAWBA OPERATORS DEMONSTRATE THE USE OF COMPUTER TABLET-BASED WORK

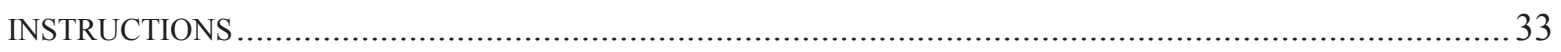

FigURE 10 REMOTE COLLABORATION TECHNOLOGY IN USE DURING A REFUELING OUTAGE AT BYRON

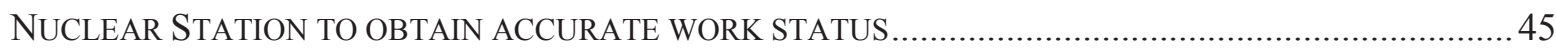

FIGURE 11 OPERATOR USES HAND-HELD TECHNOLOGY TO VERIFY CORRECT COMPONENT IDENTIFICATION AT BYRON NUCLEAR STATION.

Figure 12 FleEt-wide Prognostics And Health Management In AN ONLINE Monitoring ENVIRONMENT (DIAGRAM COURTESY OF EPRI)

FIGURE 13 HUMAN SYSTEMS SIMULATION LABORATORY USED TO EVALUATE ADVANCED CONTROL ROOM TECHNOLOGIES

FIGURE 14 HUMAN SYSTEMS SIMULATION LABORATORY CONFIGURED WITH BENCH-BOARD STYLE CONTROL BAYS FOR REALISTIC SIMULATION OF CURRENT LIGHT WATER REACTOR CONTROL ROOMS 


\section{ACRONYMS}

BWR boiling-water reactor

CBP computer-based procedures

DOE Department of Energy

DOE-NE Department of Energy-Office of Nuclear Energy

EPRI Electric Power Research Institute

HFE human factors engineering

HMI human-machine interface

HSSL Human Systems Simulation Laboratory

I\&C instrumentation and control

II\&C Instrumentation, Information, and Control

INL Idaho National Laboratory

INPO Institute of Nuclear Power Operations

LWR Light Water Reactor

LWRS Light Water Reactor Sustainability

NEI Nuclear Energy Institute

NPP Nuclear Power Plant

NRC U.S. Nuclear Regulatory Commission

O\&M operating and maintenance

OCC outage control center

PWR pressurized-water reactor

R\&D Research and Development

SSC systems, structures and components

SOER Significant Operating Experience Report

UWG Utility Working Group 


\section{Introduction}

A future vision and strategy for long-term modernization of instrumentation, information, and control (II\&C) systems for the operating U.S. LWR fleet to address aging issues for these systems is herein provided to ensure long-term sustainability, to enhance nuclear safety, and to improve operational performance. The strategy addresses two essential elements: 1) to ensure that legacy analog II\&C systems are not life-limiting issues for the LWR fleet, and 2) to implement digital technology in a manner that enables broad innovation and business improvement in the nuclear plant operating model. Both of these elements undergird the long-term sustainability of the nation's LWR fleet, which is vital to the future energy and environmental security of the United States.

Digital II\&C technologies are deployed in power generation settings worldwide. The United States' nuclear power sector differs from these other settings in several key respects: analog systems that have been operated beyond their intended service lifetimes dominate II\&C systems in place today; regulatory uncertainty and associated business risk concerns are dominant contributors to the status quo; and current NPP operating models have not evolved to take full advantage of digital technologies to achieve performance gains. As a consequence, digital technologies are largely implemented as point solutions for performance and aging concerns of individual II\&C components. This reactive approach is characterized by planning horizons that are short and typically only allow for "like-for-like" replacements to be made. This results in a fragmented, non-optimized approach that is driven by immediate needs. As a long-term strategy, this is not sustainable in light of the evolution of II\&C technology, availability of skills needed to maintain the legacy technology, and high costs and uncertainties associated with doing so.

In order to be successful in supporting long-term operational goals enabled by new types of II\&C systems, a new approach is needed to develop and deploy advanced II\&C. The new deployment activities must address the limitations of current industry trends and factors. At a minimum, some demonstration projects are needed to validate the new operational concepts and create confidence in the new technology. Facilities for research and tests to support these needs are simply lacking in the United States and elsewhere. Also, little experience currently exists in using these kinds of facilities to demonstrate new technologies and produce data that can be used to formulate a regulatory technical basis for digital technology. Rather, most attempts to introduce digital technologies are performed on an as-needed basis by individual utilities. Some of these efforts have resulted in lengthy and very costly efforts and have had a chilling effect on other utilities considering a wide-scale digital implementation.

Because these technology replacements are made "like-for-like"- analog to digital without enhanced capability - the replacements do not displace any of the old costs, but rather add to them. Therefore, digital technologies do not positively impact the current operating models of the utilities or foster needed business innovation.

A technology-driven approach in this research and development (R\&D) area alone will be insufficient to yield the type of transformation that is needed to secure the LWR fleet as a long-term source of economical energy; a new approach is needed to achieve the business innovation that is made possible by digital technologies. An effective R\&D initiative must engage the perspectives of all stakeholders (i.e., asset owners, regulators, vendors, and $R \& D$ organizations) in order to define and initiate relevant $R \& D$ activities.

The pursue this future vision of a transformed nuclear plant operating model based on an integrated digital environment, the Advanced II\&C Systems Technologies Pathway was initiated as part of the LWR Sustainability Program. The LWR Sustainability Program is a research and development program (R\&D) sponsored by the Department of Energy (DOE), performed in close collaboration with industry R\&D and improvement programs, to provide the technical foundations for licensing and managing the long-term, safe and economical operation of current nuclear power plants. DOE's program focus is on longer-term 
and higher-risk/reward research that contributes to the national policy objectives of energy security and environmental security. [1] A description of the LWR Sustainability Program is found in INL/EXT-1123452, entitled Light Water Reactor Sustainability Program Integrated Program Plan.

To this end, a future vision and strategy for the modernization of II\&C systems for the LWR fleet has been developed to serve as a roadmap for the demonstration and deployment of new digital technologies that collectively form a platform to integrate plant systems, plant processes, and plant workers. The strategy is based on a series of pilot projects over a twelve-year period to introduce these technologies into actual nuclear plant operations by host nuclear utilities. Supporting this development is a competent R\&D staff at the DOE National Laboratories working in leading research facilities capable of conducting high-fidelity simulations of plant operational activities.

\section{LWR Sustainability}

\subsection{The Challenge of LWR Sustainability}

The U.S. Department of Energy's Nuclear Energy Research and Development Roadmap describes four objectives to ensure nuclear energy remains a viable energy option for the United States. These objectives deal with current reactors, new reactors, new fuel cycles, and nuclear proliferation. [2] The Light Water Reactor Sustainability (LWRS) Program is the primary programmatic activity that deals with current reactors, stated as follows:

Develop technologies and other solutions that can improve the reliability, sustain the safety, and extend the life of the current reactors.

Recognizing that the industry has been successful in extending the original 40 year license periods for much of the LWR fleet to 60 years, the focus of this program is on life extension beyond 60 years. This is essential to national energy policy goals of maintaining diversity in the electric generation mix and reducing greenhouse gases.

The challenge of LWR sustainability is two-fold. First, component aging issues that could be lifelimiting to the LWR fleet must be successfully resolved from a technical and regulatory standpoint. These issues primarily concern the large components and structures in a nuclear plant that would be difficult or cost-prohibitive to replace. Examples include the reactor building base mat, the containment structure, and the plant cabling system.

Second, the business model for operating a nuclear power plant must remain viable in the face of an increasingly-competitive electric generation market, most recently affected by the abundance of relatively-cheap natural gas. The business model must remain competitive even while absorbing the cost of investments in technologies to ensure extended life of these critical plant components and structures.

The importance of a viable business model was recently underscored by the announcement of the second-quarter 2013 closing of the Kewaunee Nuclear Station by Dominion Resources for economic reasons, as outlined in the following excerpt from the news release: [3]

"This was an extremely difficult decision, especially in light of how well the station is running and the dedication of the employees," said Thomas F. Farrell II, Dominion chairman, president and CEO. "This decision was based purely on economics. Dominion was not able to move forward with our plan to grow our nuclear fleet in the Midwest to take advantage of economies of 
scale. In addition, Kewaunee's power purchase agreements are ending at a time of projected low wholesale electricity prices in the region. The combination of these factors makes it uneconomic for Kewaunee to continue operations."

This announcement confirms that even a well-running nuclear plant might not be able to withstand competitive pressures in the electric generation market, particularly in the absence of economies of scale typically found in fleet operations. It is clear that addressing long-term aging issues for major plant components and structures is not by itself sufficient to ensure the sustainability of the LWR fleet.

Life extension for a current LWR plant depends on obtaining a license renewal based on the requirements found in the Code of Federal Regulations 10 CFR 54. More specifically, the structures and components addressed in the regulations are the safety-related systems, structures, and components (SSCs) that are relied upon to remain functional during and following design basis events. Further, nonsafety SSCs whose failure could prevent the accomplishment of the safety functions are also included in the scope.

Paragraph 54.21 of this regulation lists certain SSCs that are subject to an aging management review as part of the license extension process. Instrumentation, information, and control components that are part of this list are as follows: electrical cables and connections, cable trays, and electrical cabinets, motors, diesel generators, the control rod drive, pressure transmitters, pressure indicators, water level indicators, switchgears, transistors, batteries, breakers, relays, switches, power inverters, circuit boards, battery chargers, and power supplies. Many of these components were originally specified for a 40 year life, or shorter, so there is a concern on aging effects for these components.

In the first round of license extension for the LWR fleet, the aging II\&C components were generally resolved by describing ongoing testing programs that would identify degraded components such that they could be replaced. In fact, for II\&C components, two factors generally hold true:

- Most of these components are not expected to last the life of the plant and are subject to random, periodic failure. (As exceptions, cables and diesel generators are generally expected to last the life of the station.)

- In-service failure of these components is acceptable due to the plant design that no safety function can be impaired by a single failure. In other words, the safety systems have sufficient redundancy to withstand the random, periodic failure of any given component.

None of these components are prohibitively expensive to replace if failed or degraded. That is, the cost of replacement, at least individually, would not threaten the economic viability of the plant. However, at least one of these components, namely cables, could be financially challenging if they all had to be replaced due to common aging concerns.

A greater concern is the potential inability to acquire replacement components at a reasonable cost, in that these components are based on declining technologies in the general marketplace. The alternative is to undertake reverse engineering efforts to manufacture and qualify replacement components, which, for relatively small quantities, is very expensive compared to the original cost.

Therefore, since the II\&C components can be reasonably modernized from a cost standpoint, the opportunity in regard to sustainability is to do this in a manner that improves the business model. Digital replacements for legacy analog II\&C components have this capacity. They not only can perform the immediate control and information requirements, but they can also serve as a foundation of business improvement, providing information and innovative capabilities that greatly improve the performance of plant activities. 
Therefore, the optimum strategy to deal with aging II\&C components is to take advantage of the normal component replacement opportunities to install modern digital technologies that enable substantial business performance improvement, thereby offsetting future operating costs and lowering the cost of generation. The following section describes how digital technology can impact the key performance indicators of the nuclear power plant operating model.

\subsection{Key Performance Indicators}

The key performance indicators of the nuclear power plant business model that must be addressed for long-term sustainability are generation cost, workforce availability, human performance, radiation dose management, nuclear safety, and long-term plant asset management. The following sections describe how each of these indicators impacts the overall business performance of the plant and how digital technology can enable substantial improvement.

\subsubsection{Generation Cost}

Going forward, nuclear energy will have to be cost-competitive with other forms of energy production in order for utilities to make the required investments for extended life, including the upgrades of II\&C systems. The prospects for a long-term abundant supply of shale natural gas have recently increased this generation cost pressure. Furthermore, new generation forms such as renewables will eventually benefit from a declining cost of infrastructure as technology improvements and economies of scale lower costs on a unit basis of production.

Nuclear generation could be at a disadvantage if it continues to rely on an operating model that requires a large plant staff. Approximately $70 \%$ of a typical nuclear plant's operating and maintenance $(\mathrm{O} \& \mathrm{M})$ cost is labor. Labor will continue to be a rising cost, particularly in that the future workforce will require considerable specialized in-house training to maintain competency in the legacy plant technologies that are no longer taught in technical schools. Digital technology provides the opportunity to transform the operating model of the NPPs from one based on a large staff performing mostly manual activities to an operating model based on highly integrated technology with a smaller staff.

In addition to labor costs, the LWR fleet is faced with significant plant investment requirements as they deal with aging issues for plant components and structures. Not the least of these is the projected cost of replacing II\&C systems as they become increasingly difficult to maintain at the required levels of reliability. Recent upgrades in the industry have come at considerable cost due to technical complexity and regulatory uncertainty. Therefore, wide-scale modernization of the legacy I\&C systems could prove to be cost-prohibitive unless the technology is implemented in a manner that enables significant business innovation as a means of off-setting the cost of upgrades.

Increasing a nuclear plant's capacity factor has a favorable impact on unit generation cost, because fixed costs are spread over a larger volume of production. Over the past three decades, there has been steady improvement in the average capacity factors of the LWR fleet from a starting point below $70 \%$ to about $90 \%$. Now, however, the rate of improvement is essentially flat. The largest opportunities for capacity factor improvement are in reductions to forced loss rate and length of refueling outages. Improvement in forced loss rate will be a function of improved equipment reliability, robustness of plant II\&C systems to cope with plant upsets, and human performance. Further improvement in refueling outages will be largely achieved with better command and control capabilities, real-time collaboration technologies, and improved situational awareness 


\subsubsection{Workforce Availability}

Nuclear generation is labor-intensive due to the vast number of operational and support activities that must be continually performed, mostly in a manual mode. The work is accomplished using an in-house workforce of operators and technologists with specialized expertise in the existing systems and facilities. And, many different types of expertise are required to be available directly on site or close by, due to the typically short time available to correct problems in order to avoid shut-downs or restore regulatory compliance.

Going forward, there are concerns whether the nuclear industry will even be able to attract the needed engineers and technicians into careers centered in these legacy technologies. It will likely have to offer salary and benefits premiums to retain them, further exacerbating the cost of labor. Moreover, a large staff has a compounding effect of requiring proportionately higher organizational support in the form of additional supervisors and managers, human resource specialists, trainers, etc.

On a societal level, it is expected that future workers will change jobs far more frequently. Also, typical company talent management programs actually encourage lateral job changes to broaden employees for future advancement. These factors will limit the depth of expertise in the plant staff and result in a shortage of critical experts in those disciplines that require years of experience to fully master. The outcome will be a less-effective workforce in addressing time-critical problems.

Digital technology can substantially address this escalating issue of staff cost by enabling a shift from a labor-intensive operating/support model to one that is technology-based. It can do so by displacing many of the repetitive, tedious activities that are currently performed manually. This, in turn, will greatly reduce the dependence on maintaining such a large skilled workforce. Further, it can enable many activities to be performed remotely, thus reducing the need for specialized experts to be on site. Rather, the nuclear utilities can outsource this support to companies with greater expertise and experience. In this way, the nuclear power plants can maintain a smaller, more generalized workforce, trained more for operational and general support roles rather than specialized technical roles.

\subsubsection{Human Performance}

Many industries have greatly reduced their reliance on human performance to conduct high risk activities. Examples include advanced flight management systems for airliners, numeric control for high precision manufacturing, and advanced medical diagnosis and treatment systems for doctors. These digital applications have literally transformed how these activities are conducted, yielding amazing improvement in accuracy, quality, and efficiency.

On the contrary, for current nuclear plants, many critical activities are still performed manually due to the technological limitations of the legacy plant systems and support facilities. A reliance on human skill and decision-making is still the norm for most plant operational and support activities.

Even so, nuclear plant operators have been quite successful in improving human reliability through a variety of techniques and job aids. These have included human performance tools such as communication standards, self-checking, questioning attitude, etc. Also, a concerted focus on correct worker behaviors and adherence to formal work expectations has produced significant improvement over what the industry experienced in its early years; namely, frequent operational transients and nuclear safety challenges due to human error.

In addition to error reduction, the nuclear plants have employed a number of barriers to prevent errors from causing operational events. These have included independent verifications, enhanced job oversight, pre-job briefings, and others. In spite of these barriers, there is still a residual level of human error that is challenging nuclear safety and production. In fact, human error rates in the nuclear plants have been 
essentially flat for several years, after a period of notable improvement. For example, in 2010, there was a sharp increase in nuclear safety challenges caused by human error as compared to recent years.

Also, the by-product of this approach to human performance is that work processes have become overly-complex. The time and number of workers to perform plant support activities have significantly increased, and worker satisfaction has been eroded. In short, the cost of human error prevention has become a significant and growing part of the already high cost of labor in the nuclear plant cost structure.

Nominal human reliability (for action errors) is generally assumed to be at an error rate in the $1.0 \mathrm{E}-03$ range [4], whereas the reliability of well-designed and maintained digital systems can approach fault rates in the $1.0 \mathrm{E}-05$ to $1.0 \mathrm{E}-06$ range. When operators are left in essentially the same role even with the addition of digital systems, the human function remains the weakest link in the human-machine system in terms of overall reliability. Shifting the operator from an active control function to one of monitoring a control system could potentially improve reliability of the operation by orders of magnitude.

To overcome this practical limit in human performance, a paradigm shift is needed in the operating/support model from one that is labor-based to one that is technology-based. The new paradigm would harness the ever-improving reliability of technology, which far exceeds human ability both in speed and accuracy. Substantial performance improvement would be possible.

In short, humans are much better suited to reasoning and cognitive activities, leaving the repetitive tasks to machines. The new paradigm optimizes the use of human resources by putting them in roles suited to what they do best. The new paradigm does not de-value human performance; rather it augments human performance with technology to increase overall plant performance and reduce labor costs.

\subsubsection{Radiation Dose Management}

There will continue to be a strong industry emphasis in the future on reducing radiation dose for plant workers. The nuclear industry has made great strides in reducing cumulative dose for plant workers and continues to set challenging goals for improvement. Also, the recent accident at the Fukushima - Daiichi nuclear plant in Japan highlighted the need to consider ways to reduce dose for plant workers under potential accident conditions.

The nuclear industry relies on a concept in reducing dose known as ALARA - "as low as reasonably achievable." This concept operates on the principles of managing "time, distance, and shielding" for exposed workers to reduce dose. Up to now, most dose improvement has come from reducing time and increasing shielding at the job site. Distance from the radiation source has been harder to manage because work must be performed "hands-on" at the components.

Digital technologies can substantially help in this regard by indirectly "managing distance." Automation of manually-performed tasks will reduce the number of workers required to be in radiation areas, relying instead on technologies that enable either remote or automated operations. This includes workers directly performing the tasks, or other support workers such as Radiation Protection technicians being able to monitor the job remotely.

For plant workers required to be in the radiation areas, technologies are emerging that will allow a worker to "see" radiation fields using handheld or heads-up displays. These technologies can greatly improve a worker's ability to minimize dose by avoiding high dose and contaminated areas. The technology would also alert workers to changing radiological conditions. 


\subsubsection{Nuclear Safety}

The U.S. nuclear industry has achieved an outstanding record on nuclear safety due to its commitment to excellence, high standards, and transparency as an industry. It stands out among all technology-based industries as the clear leader in public health and safety, and is often cited as the model for engendering a pervasive safety culture throughout its operating companies and support organizations.

However, perceptions on nuclear safety among the public and key decision-makers always prove to be tenuous and readily influenced by recent events - even if they occur outside the United States such as the accident at the Fukushima-Daiichi nuclear plant in Japan. It is difficult to make investment decisions that will stand for decades in an environment of fluctuating public and political opinion about the safety and acceptability of nuclear generation.

Also, if the nuclear power industry is successful in building a new generation of nuclear plants, especially those relying on passive safety systems, there could be an emerging perception that the existing plants are not as safe as the new ones. This could have implications for effort to extend the life of the current LWR fleet. Therefore, the industry should not be complacent with the present high levels of nuclear safety, but should strive for even greater nuclear safety margins.

While the industry would never put a price tag on safety, there is a measurable cost to challenges to nuclear safety in terms of recovery actions, cause analysis and corrective actions, regulatory scrutiny, effect on INPO ratings, etc. Some utilities estimate that up to $30 \%$ of their technical staff is consumed in event recovery and corrective action program activities. There may be a large potential to save costs in this area if safety challenges are reduced.

The long-term operation of the LWR fleet is absolutely dependent on public confidence in the safety of the plants. Therefore, it is imperative that as legacy II\&C systems are replaced, they are implemented in a manner that increases overall nuclear safety, addressing equipment reliability, human performance, operational challenges, and accident response capability.

\subsubsection{Long-Term Plant Asset Management}

Asset management has become a key focus for nuclear power plants, especially in view of extended operating licenses. Many of the key components and structures were designed for a 40 year plant life, which has now been extended to 60 years for many of the U.S. plants and may possibly be extended to 80 years if subsequent license renewal beyond 60 years is pursued. It is essential that the major plant components be maintained in good operating condition over these extended periods of operations. Otherwise, the replacement or rehabilitation of these assets could collectively be proven to be costprohibitive and preclude extended life.

One particular class of assets of concern is the large array of II\&C systems. These cannot be allowed to run to the point of reliability problems due to aging and lack of support.

Modern digital diagnostic and monitoring technologies can play a significant role in protecting these assets by identifying when and where intervention is needed. Also, they can play a critical role in justifying the extended life of the assets on a technical basis. [5]

There are numerous areas of the plants that can benefit from these technologies, including concrete, cables, high performance metals, power equipment (motors, transformers), and underground piping. With on-line diagnostic technologies, these components and structures can be monitored by remote technical resources, relieving the operating plant of having to have these types of experts on site. These technologies can also enable significant cost reductions by shifting from periodic to condition-based maintenance. [6] 


\subsection{The Current Industry Approach to II\&C Modernization}

The commercial nuclear industry has taken a very conservative approach in the application of digital technology. While, the LWR fleet has indeed had a number of successful digital upgrades to the legacy analog II\&C systems, the tendency has been to directly replace the analog function of the previous systems without taking advantage of the inherent capabilities that digital systems have. While this approach has resolved the immediate aging and reliability problems, it has not resulted in additional business improvement gains that are possible with this technology.

However, it is understandable why nuclear utilities would pursue a "like-for-like" replacement strategy with digital upgrades. They are saddled with significant barriers to making large changes in the operating/support model for the plants, as follows:

- There is enormous investment in the work process infrastructure (training, procedures, task qualifications, etc.,) to support the labor-centric approach to operating the plant and it is very expensive to change these documents and revalidate them.

- The plant operators are highly acclimated to the current layout of the main control room and related control functions. Significant changes in the layout of the control boards and operator interface protocols could create human factors challenges.

- The NRC-approved safety analysis of these plants credits the current design of the plant systems. The pursuit of licensing changes for digital technology exposes the utilities to substantial risks in new regulatory requirements, cost increases, and schedule delays.

While the approach of like-for-like replacement has been the path of least cost and risk, it has served to reinforce the old operating/support model rather than leading to a transformed model that evolves with ever-improving technology. Therefore, the investment in II\&C upgrades has not translated to bottom-line performance improvement for the operating plants, other than addressing the immediate equipment reliability issues. In this sense, digital technology has been a net cost adder because the investment and additional maintenance costs have not been offset by business innovation leading to lower operating costs. The cost of upgrading legacy II\&C systems has limited the rate of digital conversion and made many of the potential projects marginal. In a larger sense, this represents an ongoing opportunity cost to provide a technological enabler of transformative business innovation for future performance improvement in the LWR fleet.

\subsection{Opportunity for Future Performance Improvement}

Today, nuclear generation is a vital component of the nation's energy supply, providing safe, reliable, carbon-free electricity at a relatively low cost. This is largely due to the impressive performance improvement that the industry has achieved over the past 15 or so years. It was in the mid-1990s that there was an acceleration of the standardization of plant processes and the conduct of operations. This was due to the concerted efforts of the utilities and the Institute of Nuclear Power Operations (INPO) to set challenging performance targets and to undergird these efforts with comprehensive process templates and human performance expectations. 
As a result, performance improvement has been evident in virtually every aspect of plant operations notably in the areas of capacity factor, scram rate, forced loss rate, dose, refueling outage length, and overall cost performance. And this has been achieved while substantially improving nuclear safety performance.

This has also resulted in a fairly standard operating model for the U.S. LWR fleet, based on these process and human performance standards. Operating experience and lessonslearned have been effectively incorporated throughout the industry such that there is now considerable uniformity in how nuclear operations and support activities are conducted from one nuclear utility to the next.

However, sustainability of this performance improvement is an ongoing concern. Every means or methodology of accomplishing an end is subject to the classic " $\mathrm{S}$ " curve in the relationship between effort and performance, as illustrated in Figure 1 . This has certainly proven to be true with respect to performance improvement in the LWR fleet based on the current operating model.

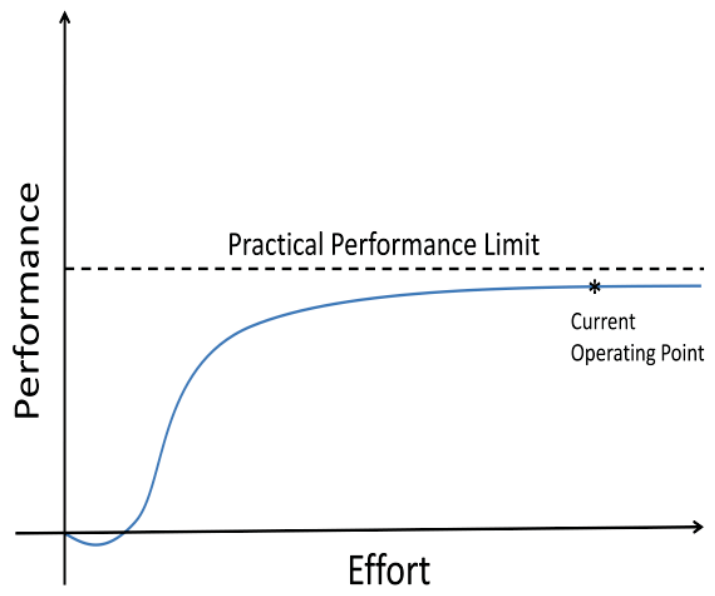

Figure 1 Performance Based on Current Operating Model

In the early years of the operating model, the industry was below the knee of the curve and enjoyed highly-leveraged returns relative to effort. This roughly corresponded to the time period between the mid-1990s and the mid-2000s. As the operating model matured, much of the "low-hanging fruit" was exhausted and it became impossible to maintain the rate of improvement. Again, this has been evident in the performance from the mid-2000s to the present, in which the rate of improvement has greatly slowed or even flattened, as evident in fleet capacity factors, scram rates, and forced loss rates.

As further indication, it is generally acknowledged by nuclear utility staff that more and more complexity has been added to the plant processes, with only small increments of performance improvement to show for it. It confirms that the industry's operating model is well out on the flat part of the curve and that it has been substantially exploited of its performance improvement potential. If so, the industry is in need of a new operating model that provides an expanded basis for further performance improvement.

A new operating model would be one that has shifted from a labor-centric basis to a technology-centric basis. And digital technology is the foremost enabler of such a shift. Indeed, it has the potential to transform virtually every aspect of nuclear plant operations and support as the unexploited capabilities of digital II\&C systems, along with the emerging technologies that enhance human effectiveness, are combined to create a new paradigm for the plant operating model.

Such a development would draw a new performance curve and move the operating point back below the knee of the curve to once again enable highly-leveraged performance improvement for reasonable effort, as illustrated in Figure 2.

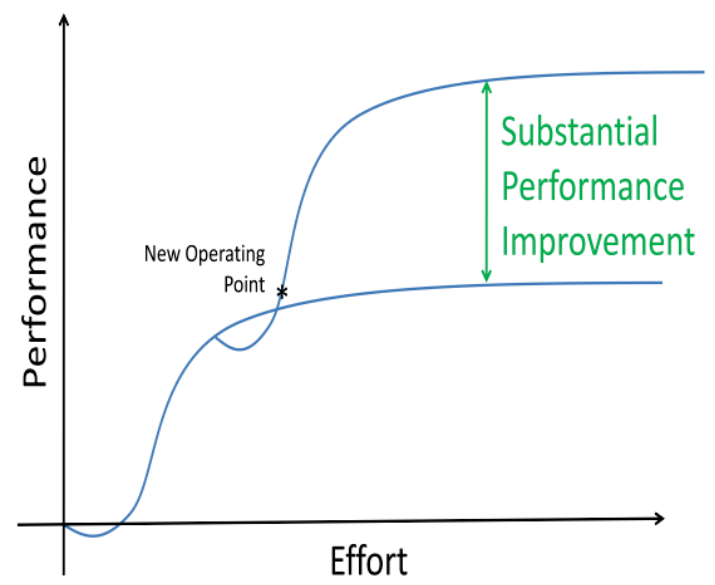

Figure 2 Performance Improvement Based on a Digital Transformation of the Operating Model 


\section{Long-Term II\&C Modernization: Future Vision and Strategy}

To address the sustainability of the LWR fleet and the challenges reflected in the industry's key performance indicators, a long-term future vision for the modernization of II\&C systems is set forth. A strategy to achieve this vision is described that defines the activities and deliverables of the research program. Then, the stages of transformation to achieve this future vision are presented as a timeline to fully assimilate the digital technologies into the emerging NPP operating model.

\subsection{Future Vision}

The future vision for this research program is an enhanced NPP operating model, achieved through the integration of plant systems, plant processes, and plant workers through the application of digital technology (Figure 3). This results in a seamless digital environment that encompasses all aspects of plant operations and support, thereby enhancing nuclear safety, increasing productivity, and improving overall plant performance. The long-term goal is to transform the current operating model of the NPPs from one that is highly reliant on a large staff performing mostly manual activities to an operating model based on highly integrated technology with a smaller staff. This digital transformation is critical to addressing the array of challenges facing the LWR operating fleet, including aging of the legacy analog systems, potential shortage of technical workers, everincreasing expectations for nuclear safety improvement, and relentless pressure to reduce cost.

In more specific terms, the future vision can be described in two

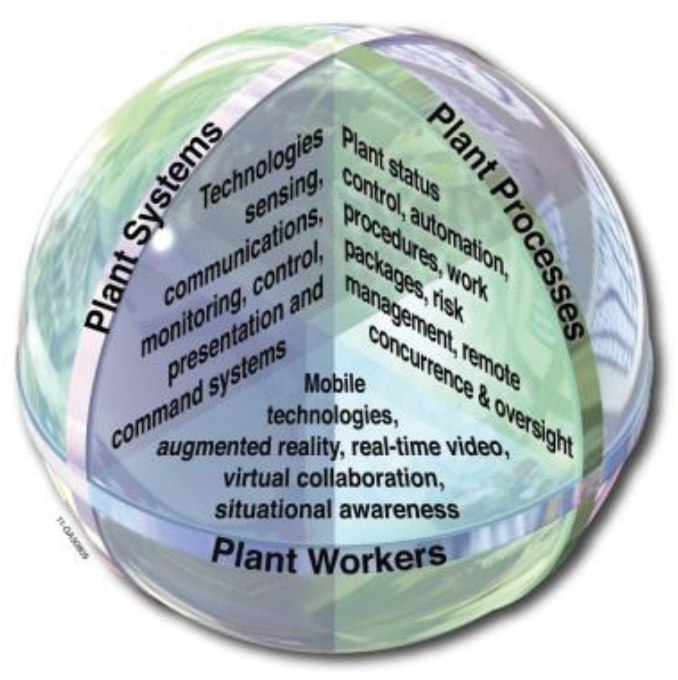

Figure 3 Seamless Digital Environment broad outcomes that together represent the integration of plant systems, plant processes, and plant workers. The first broad outcome is a focus on plant operations through the modernization of the control rooms. This entails the upgrade of the legacy control systems and operator interfaces to modern digital systems that are software-based rather than large arrays of discrete panelmounted analog devices. The endpoint for control room modernization would be either a Fully-Integrated Control Room (meaning all digital-based operator workstations positioned in front of large multi-function displays) or an Advanced Hybrid Control Room (meaning a significant number of advanced digital systems with some legacy analog technology left in place, arranged in a combination of operator workstations and control panels). Both of these concepts are encompassed in the term Highly-Integrated Control Room.

The second broad outcome is the digital integration of all important plant support functions in a manner that directly interfaces with control room functions as appropriate. This can be pictured as plant support technologies wrapped around the control room technologies and connected at the points of required process and human-system interfaces. The term Integrated Operations is used to describe this network of capabilities, which often involve centralized and remote functions participating directly in the operational and support activities through advanced technology.

The modernization of the II\&C systems of the LWR fleet with digital technology, along with significant business improvement capabilities built around them, enables the following performance goals: 
- II\&C systems provide enhanced, accurate, and dependable plant control functions and operator information, thereby resolving the aging and reliability concerns of their predecessor legacy analog systems.

- The margins of nuclear safety are increased by the inherent reliability and precision of digital technology.

- Worker productivity is substantially enhanced through the automation of manual tasks, improvements in communications and coordination, and the immediate availability of utility and industry experts through real-time distance collaboration.

- Human performance is greatly improved through advanced worker technologies and automated processes.

- Radiation dose is minimized by reductions in the time and effort to conduct plant activities in radiation areas, and through new capabilities for workers to visualize radiation fields in their work areas using augmented reality technologies.

- Plant cost performance is improved through increased capacity factors and reduced operating costs.

\subsection{Modernization Strategy}

As described in Section 2.3, nuclear utilities have been reluctant to upgrade their II\&C systems other than when necessitated by performance and maintainability problems, and then typically as direct, likefor-like, replacements for their current analog systems. The inherent capabilities in these digital systems to support business improvement have been largely unexploited. Many of the projects to date have been costly, risky, and subject to schedule delays. Therefore, without a vibrant modernization strategy that uses these inherent capabilities to improve plant performance and thereby offsets the upgrade costs, utilities might defer these needed investments until such time that the business case for additional life extension collapses due to an insufficient cost recovery period. Put another way, nuclear utilities might opt to run these plants as long as they can cope with the inevitable problems of their legacy II\&C systems, as well as the other challenges of the future work environment. They would then possibly retire these plants early, without pursuing additional life extension. This, of course, would be counter to the purpose and goals of the Light Water Reactor Sustainability Program.

To avoid this undesirable outcome, two complementary objectives must be achieved as part of the modernization strategy.

1. Reduce the technical, financial, and regulatory risk of upgrading the aging II\&C systems to support extended plant life beyond 60 years, thereby ensuring that legacy analog II\&C systems are not life-limiting issues for the LWR fleet.

2. Provide the technological foundation for a new nuclear plant operating model that improves plant performance and addresses the challenges of the future business environment.

These objectives are incorporated into a planned set of tasks that together comprise the II\&C modernization strategy in support of the long-term future vision as follows:

1. Identify the business innovations and underlying technologies that enable II\&C modernization and address the issues represented in the industry's key performance indicators. 
2. Sponsor and engage a Utility Working Group (UWG) composed of II\&C and business innovation leaders from the nuclear utilities to advise the research program on nuclear plant requirements and to serve as a peer review group for developed technologies and related business innovations. (See Section 6.1, Utility Working Group)

3. Conduct pilot projects at host nuclear plants (members of the UWG) to demonstrate and validate the business innovations and associated technologies, thereby reducing the risk of full-scale implementation by nuclear utilities.

4. Use DOE Laboratory facilities, such as the Human Systems Simulation Laboratory (HSSL), to conduct high-risk or unique program-related research and to demonstrate technologies and concepts that cannot be implemented at host nuclear plants until they are proven and validated. (See Section 5.1, Human Systems Simulation Laboratory)

5. Develop and validate the overall plant information architecture that integrates these technologies into a seamless digital environment that supports the new operating model.

6. Communicate the work of this research program to all stakeholders, particularly decision makers for plant life extension beyond 60 years.

7. Engage the major industry support organizations of the Electric Power Research Institute (EPRI), the Institute of Nuclear Power Operations (INPO), and the Nuclear Energy Institute (NEI) to ensure coordination of efforts and collaboration on development where beneficial.

8. Maintain open communications with the U.S. Nuclear Regulatory Commission (NRC) regarding the regulatory acceptability of the technologies and associated operational concepts.

9. Engage the supplier community in promoting the development of commercial products for the demonstrated technologies supporting the desired business innovations.

10. Develop a business case for the transformed nuclear plant operating model by extrapolating projected savings from the technologies and operational concepts demonstrated in the pilot projects. Validate these projected savings with multiple utilities.

Pilot projects have been defined to produce the fundamental technologies for the transformed plant activities. They are conducted at host utilities as the means for industry to collectively integrate new technologies into nuclear plant work activities one at a time, spread over many plants and utilities, to the benefit of all. The pilot projects introduce new digital technologies into the nuclear plant operating environment to demonstrate and validate them for eventual production usage. In turn, the pilot project technologies serve as the stepping stones to the eventual seamless digital environment as described in the future vision.

A total of 20 pilot projects have been defined, grouped into six broad areas of enabling capability as follows:

1. Highly integrated control rooms

2. Highly automated plant

3. Integrated operations

4. Human performance improvement for field workers

5. Outage safety and efficiency

6. Centralized On-Line Monitoring and Information Integration 
Each of these areas of enabling capability represents an important outcome in modernizing the LWR fleet and ensuring a sound basis of long-term safe and economical operations. Together, they integrate the plant systems, plant work processes, and activities of the plant workers to ensure maximum efficiency and accuracy in plant operations and support. The pilot projects have been scheduled over a twelve-year period as depicted in Figure 4 below.

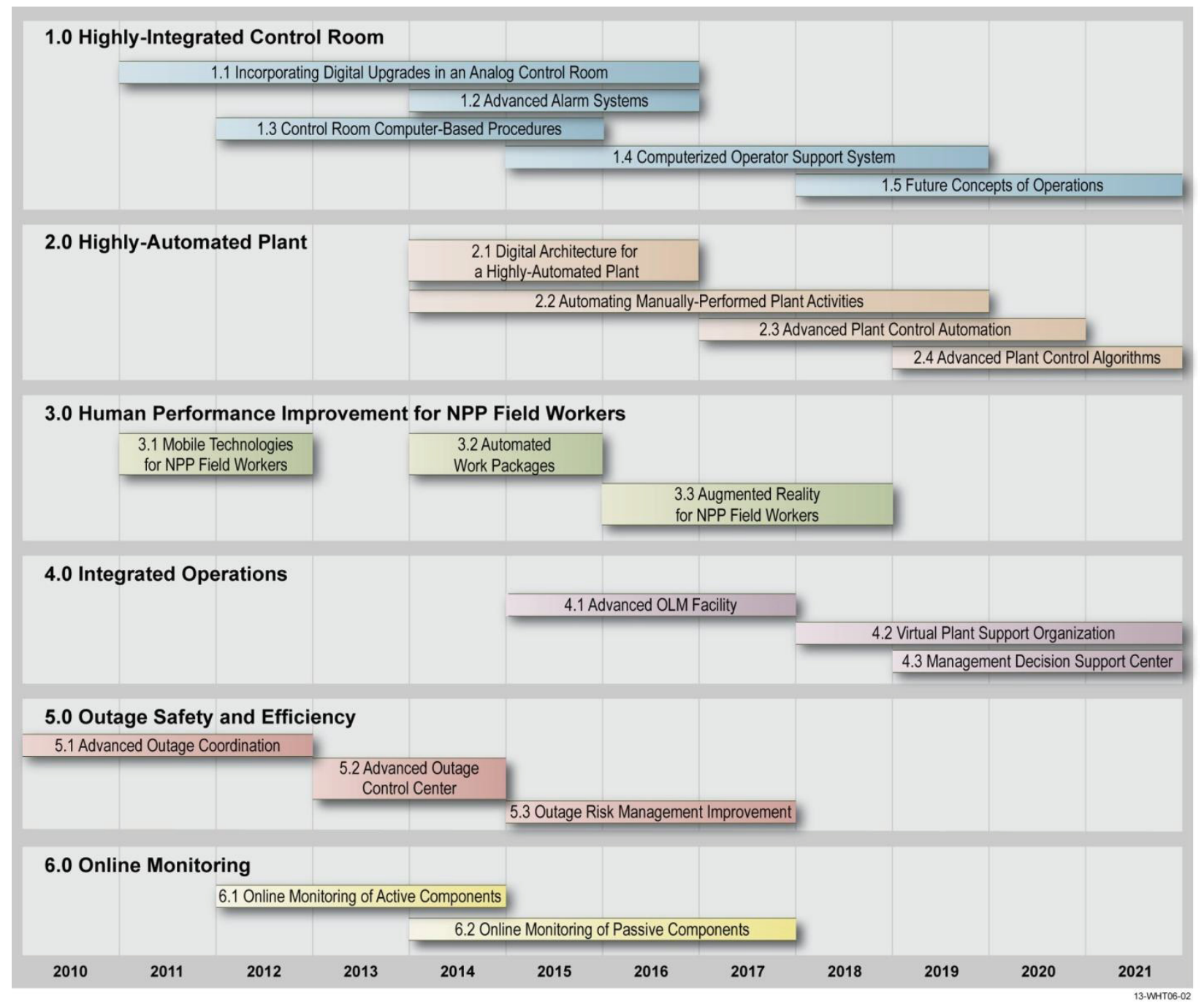

Figure 4 Summary of the pilot projects for the II\&C Systems Technologies R\&D Pathway

A science-based approach is used to develop the pilot project technologies, moving from bench-scale studies in the laboratory to full-scale demonstrations in an NPP setting. The products of the pilot projects are formal research reports that can be cited in regulatory filings, vendor specifications, utility feasibility studies, etc. These reports have the needed rigor to serve as cited works to validate the soundness of conducting nuclear plant activities based on the technologies and operational concepts. In some cases, guideline documents for utility implementation are produced. It should be noted that actual commercial products for the technologies are not developed as part of this research program. Rather, this role is left to the nuclear industry suppliers of these types of technologies.

To develop the new technologies and operational concepts of the pilot projects, DOE provides the structured research program and expertise in plant systems and processes, digital technologies, and human factors science as it applies to nuclear plant human performance. The utilities, through their participation 
in the industry working group associated with this research program, develop a collective vision of this digital operating environment and set the priority and timing of developments by their individual sponsorship of pilot projects.

This II\&C modernization strategy is differentiated from other industry initiatives addressing the legacy II\&C systems in that the technologies are actually demonstrated in NPPs, under controlled circumstances, to validate them. And where technologies cannot practically be demonstrated in a NPP until they are validated (e.g. control room changes), INL has state-of-the-art test and evaluation facilities, such as the HSSL and a virtual reality cave, to provide a high-fidelity environment for validation studies.

Each of the pilot projects contributes directly to one or more of the performance goals described in the future vision in Section 3.1. Appendix A depicts these contributions in chart form. Taken as a whole, the resulting improved plant performance has the potential to substantially offset the required investment for II\&C modernization.

\subsection{Stages of Transformation}

The transformation of the nuclear plant operating model to that which is described as the future vision will take more than a decade to fully assimilate the pilot project technologies into the plant operations and business processes. The rate of transformation is a function of how the pilot projects are defined and sequenced, such that later combinations of these technologies create new capabilities that address the requirements of more complex nuclear plant work activities. The stages of transformation are depicted in Figure 5 below.

The first stage involves the development of enabling capabilities that are needed to motivate the first movers in the industry to adopt new digital technologies. The pilot projects serve to introduce new technologies to the nuclear plant work activities and validate them as meeting the special requirements of the nuclear operating environment. They must be demonstrated to not only perform the intended functions with the required quality and productivity improvements, but they must also fit seamlessly into the established cultural norms and practices that define the safety culture of nuclear power industry. This stage is characterized as new digital technologies improving the quality and productivity of work functions as they are now defined.

The outcomes of the first stage are Control Room Digital Upgrades, Collaborative Technologies, and On-Line Monitoring Technologies. The Human Systems Simulation Laboratory (HSSL) is a key development focus of this stage to enable studies and validations of main control room simulation as well as distributed command and control center (e.g. outage control center) simulation. (Refer to Section 5.1, Human Systems Simulation Laboratory)

The second stage occurs when the enabling capabilities are combined and integrated to create new functionality. This is something of an aggregation stage; however, it includes the introduction of even more enabling capabilities as further advancements are made. The pilot project technologies have been formulated in anticipation of this integration stage such that they will work in cooperation with each other to support large organizational functions. This stage is characterized as the reformulation of major organizational functions based on an array of integrated technologies.

The outcomes of the second stage are the Early Hybrid Control Room, Automated Work Activities, Advanced Outage Management, and Centralized On-Line Monitoring Facilities.

The third stage occurs when there is substantial transformation of how the nuclear plant is operated and supported based on all major plant functions being embedded in a seamless digital environment. 
Again, this transformation is enabled by both newly-developed technologies and the continued creation of new capabilities based on previously-developed technologies. This stage is characterized as a transformation of the nuclear plant organization and plant operating model based on advanced digital technologies that redefines and focuses the roles of plant workers and support organizations on valueadded tasks rather than organizational and informational interfaces.

The outcomes of the third stage are the Highly-Integrated Control Room and Integrated Operations.

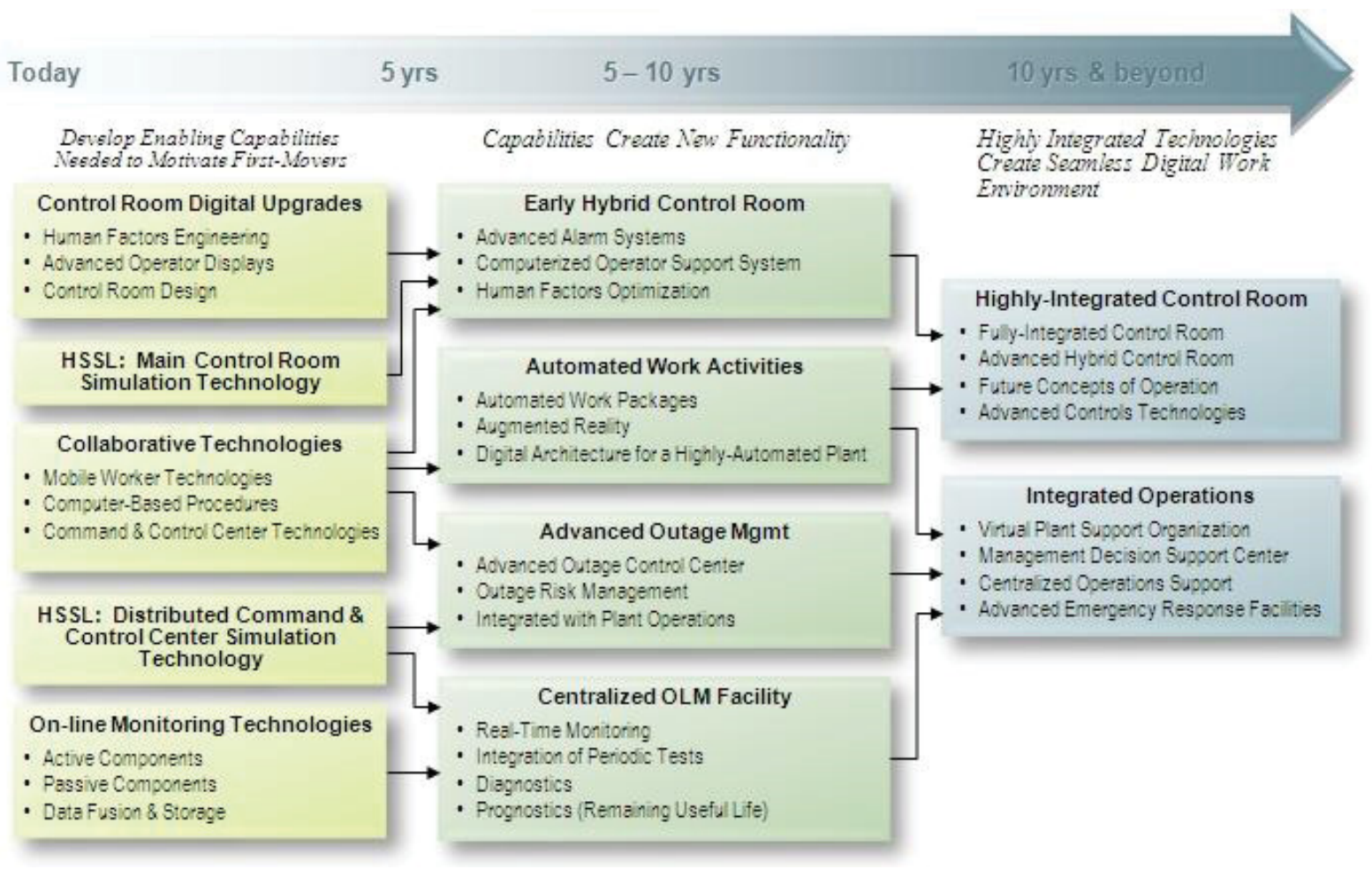

Figure 5 Stages of Transformation in the Advanced II\&C Long-Term Vision

\section{Description of the Pilot Projects}

For each of the areas of enabling capability, the current performance issues and needs are described, followed by a description of how technology developments can improve performance. Each of the pilot projects is then described in terms of activities and deliverables, including a concise summary of each project.

\subsection{Highly Integrated Control Room}

Control rooms for NPPs reflect the technology available at the time they were designed. For the current fleet, the control rooms consist of an expansive set of control boards to accommodate the hundreds of discrete controls and indications required by analog technologies. In addition, the control rooms are typically ringed with overhead alarm panels, consisting of hundreds of individual alarm windows each dedicated to a particular alarm condition. The complexity and sheer number of devices presents quite a challenge to the operators. 
Digital technology has been slowly introduced into U.S. operating NPPs over the past couple of decades. However, it has had little impact on the design and layout of the control rooms themselves. Rather, it has been blended into the larger population of analog controls in order to preserve the general arrangement of functions that are familiar to the operators. A major upgrade of a control room has not yet been undertaken in the U.S. fleet.

Research projects by the LWRS Program will be a significant national resource to guide the modernization of U.S. NPP controls rooms as the legacy II\&C systems of these plants are inevitably converted to digital technology. HSSL is a world-class facility capable of supporting the technical and human factors studies needed to ensure that new control room concepts are sound and will uphold all nuclear safety requirements. In addition, the LWRS Program has an agreement in place for access to control room modernization technology developed by the Halden Reactor Project, which has played a key role in several of the European control room upgrades. The LWRS Program is well-positioned to provide the enabling science behind a much-needed modernization of the LWR fleet control rooms.

\subsubsection{Applying Digital Upgrades in an Analog Control Room}

More and more digital conversions of analog II\&C systems will be undertaken by U.S. nuclear utilities as concerns over reliability and obsolescence continue to accrue. These new systems typically come with an advanced operator interface that is quite different than the analog control devices of the legacy systems. This always raises the question of how to incorporate this new technology into the existing control room and the impact on operator performance and regulatory requirements. One strategy has been to preserve the same operator interfaces of the old analog controls with the same or similar board-mounted discrete control and indication devices, in lieu of modern human systems interfaces. While this has minimized the cost of changes to operator procedures and training, it has diminished the value and potential benefits of the digital technology.

In other cases, dedicated human systems interfaces are incorporated into the control boards in the general area where the former analog controls were located. However, this sometimes introduces different types of operator interface, such as integrated flat-panel displays,

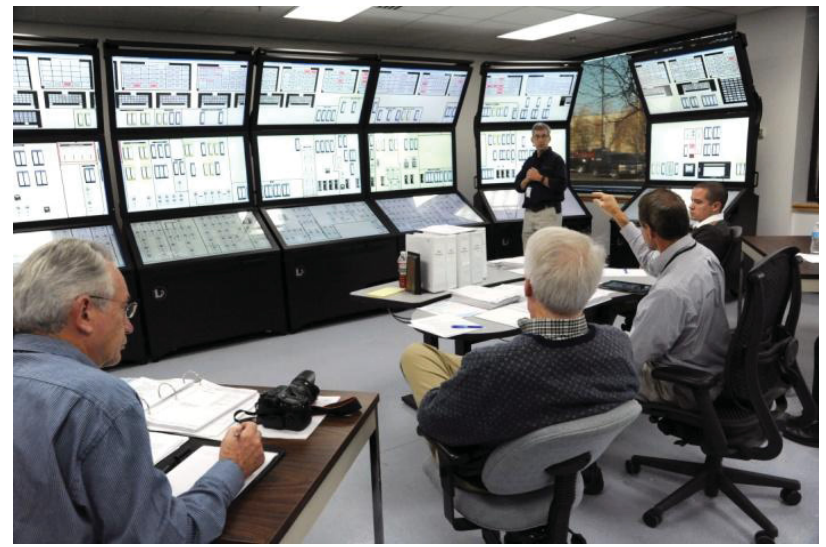

Figure 6 Operator workshop conducted in the HSSL (reconfigurable simulator) in support of a nuclear utility control room upgrade. large screen overview displays, touch panels, track balls, a standard computer mouse, and multiple keyboards. Obviously, this impacts training and can result in changes to operator and team performance if not properly implemented. Further, many plants plan to implement these modifications over time, which results in hybrid control rooms mixing analog and digital human systems interfaces. This also can impact an end-state control room vision of a totally integrated control room unless the interim digital control panels are eventually integrated into a final design.

The prospect of multiple, disparate digital interfaces in the control room will drive the need to readdress the control room layout in a more holistic manner in order to provide the operators with a consistent, uniform interface for the various digital systems. Such upgrades to the control room are unprecedented in the U.S. nuclear utility industry and will involve first-of-a-kind technical developments and regulatory submittals.

One major consideration of a control room upgrade is application of human factors principles. Expertise in control room human factors has been substantially lost in the nuclear utility staffs since the 
days of the TMI-2 Action Plan in the late 1980s. Furthermore, the scientific underpinnings of human factors have substantially improved since that time and regulatory requirements and guidance is evolving. National laboratories maintain considerable expertise in human factors principles and application and have reconfigurable simulator and visualization technology. They also offer much-needed expertise to the initial efforts to upgrade control rooms using digital technology, especially for safety-related systems. National laboratories are involved with leading international efforts in this area and have agreements to leverage the expertise in modernizing control rooms that has been developed in other countries; in particular, the control room upgrades that have been undertaken in Europe.

Specifically, there is a need to develop standardized operator interface screens and control board layout guidelines based on human factors engineering (HFE) principles and regulatory guidance. Otherwise, the large-scale upgrade of the control rooms could create new operator performance problems and negate the benefits of the new technology. HFE studies will be conducted in the HSSL to address human factors issues for control room operators as shown in Figure 6.

This project will develop principles that can be used in guidelines for design and layout of highlyintegrated control rooms and for standardized operator interface screens, according to HFE principles. These activities will support the development of a Human Factors Engineering Plan, which will provide the basis of determining whether modernized control rooms will perform within acceptable limits and thereby support safe operation of the plant.

Pilot Project No: 1.1 Title: Incorporating Digital Upgrades in an Analog Control Room

Purpose: $\quad$ To develop HFE guidance for implementation of a hybrid and fully integrated control room as new digital technologies and operator interface systems are introduced into a traditional control room.

Scope: Install the host utility's plant simulator and control room layout in the INL HSSL, conduct human factors studies on function and layout options for incorporation of new digital technology and develop associated guidance.

Deliverables: - (2012) Develop a digital, full-scale mockup in HSSL of a conventional NPP control room (Complete).

- (2013) Publish a reference human factors engineering plan for an optimized, human-factored control board layout for integrating digital operator interface screens with analog controls and indicators.

- (2014) Develop a strategy for migration of II\&C functions from traditional control boards to compact operator control consoles.

- (2015) Integrate computer-based procedures for reactor operators into the hybrid control room concept, including soft controls and concepts for shared procedures among control room operators and field operators.

- (2016) Develop an end-state vision and strategy, based on human factors engineering principles, for the implementation of both a hybrid and a fullyintegrated control room as new digital technologies and operator interface systems are introduced into traditional control rooms.
Schedule:
FY 2011 to FY 2016
Cost:
TBD
Host Utility:
Southern California Edison
Duke Energy (Progress Energy)
Project Status: In-Progress 


\subsubsection{Advanced Alarm System}

Alarm systems in NPP control rooms today are facing reliability and obsolescence issues, as well as being non-optimal for highest operator performance.

The annunciator window-based systems are capable of only indicating that a certain condition has been sensed and cannot put this information in the context of actual plant conditions and mode of operation. In a complex event or plant transient, many superfluous or low-priority alarms are triggered due to the large number of off-normal conditions throughout the plant. However, the majority of these alarm conditions are simply symptomatic of the event or plant mode and not the cause. Some of the alarms in any given event indicate the direct cause and some do require operator actions; however, most of them do not require action or at least not until later in the recovery.

An advanced alarm system would be capable of suppressing the non-essential alarms so the operator is not distracted with superfluous information during the time-critical phase of the event. These suppressed alarms would be maintained in a separate list that could be accessed at any time the operator has need for them. The advanced alarm system also could be state-based and operating mode-sensitive, meaning that alarms that are not meaningful in the present operating state would be suppressed.

Human factors studies will be conducted to measure operator performance for selected candidate alarm system displays and to determine which presentations of alarm information result in the optimum operator performance.

As another objective of this project, research will be conducted in advanced visualization techniques to improve operator recognition and comprehension of alarm states. Traditional alarm systems rely on brief word descriptions that are typically illuminated in a flashing annunciator window or flashing alarm display. This does not take advantage of a human's inherent abilities to process information conveyed in color, pictures, graphical representations, and other visual clues. Human factors studies will be conducted to determine the optimum forms of alarms to maximize operator performance.

The project will develop a technical report with guidance for selecting candidate alarm system displays and logic based on a needs analysis and technical requirements for an operating NPP.

The HSSL will be configured to simulate control room functions and layout of the host utility control room. It will be used to conduct alarm design and validation studies on candidate alarm systems using operators from the host utility or those that are familiar with their systems and procedures. This will involve the logic of the alarms and the visual presentations of the alarm displays. Options for presentations will include use of the HSSL and advanced visualization techniques, making use of human factors studies to determine the best information presentations for peak operator performance.

\section{Pilot Project No: $\quad 1.2$ Title: Advanced Alarm Systems}

Purpose:

Scope:

Deliverables:
To improve operator performance in an event or plant transient by prioritizing alarms within the context of plant state and operating mode.

Development of candidate alarm display concepts, human factors evaluations of candidate systems in HSSL, and development of a requirements specification for an advanced alarm system.

- (2014) Develop concepts and technologies for advanced alarm management in a hybrid control room.

- (2015)Develop concepts for alarm integration into operator displays and computer-based procedures.

- (2016) Publish a technical report for an advanced alarm management system in 
an NPP control room and a methodology for integrating diverse alarms and annunciators across all systems and digital platforms.

$\begin{array}{llll}\text { Schedule: } & \text { FY 2014 to FY 2016 } & \text { Cost: } & \text { TBD } \\ \text { Host Utility: } & \text { TBD } & \text { Project Status: } & \text { Planned }\end{array}$

\subsubsection{Computer-Based Procedures}

The commercial nuclear industry conducts virtually all plant activities using standard or special procedures. This includes operational activities, abnormal or emergency actions, maintenance, testing, security measures, plant chemistry control, and radiation protection. The quality of the procedures, refined by operating experience over decades, has been an important contributing factor to the overall success of plant operational excellence and nuclear safety. Strict adherence to written procedures is a key tenet of operational standards.

Unlike many other safety-critical industries, procedures in the commercial nuclear industry are almost always paper-based procedures (PBPs). As such, these procedures remain prone to certain human errors and process deviations that continue to challenge the plants. Typical problems are as follows:

- Applying the wrong procedure for the plant situation

- Unauthorized or unintentional deviations from procedure steps

- Unexpected results from procedure actions due to coincident plant conditions/configuration

- Copy errors in transcribing plant data into the procedures

- Computational errors in processing acquired data.

These types of problems can be largely prevented using computer-based procedures (CBPs), which inherently enforce adherence expectations and perform data manipulations in a correct manner.

Furthermore, in a well-connected CBP environment using wireless technology, it is possible to track the timing of real-time actions from procedure steps in order to detect unintended interactions among procedures or with the desired plant configuration. A number of important benefits are possible with such a system as follows:

- Integration with real-time plant data and system status

- Time monitoring for time-critical actions

- Detection of undesirable interactions

- State-based and mode sensitive context

- Sequencing of steps and other procedures (workflows)

- Place-keeping

- Seamless transitions to other procedures

- Computational aids and validation of results

- Embedded job aids - reference material, training material, and operating experience reports

- Automatic information insertion and verification of plant response

- Remote concurrences and authorizations

- Soft controls - platform for the future "highly automated" plant

- Real-time task status

- Real-time risk assessment

INL has considerable expertise in CBPs, having produced papers and reference material for NRC on this topic. 
The incorporation of advanced technology, such as CBP systems, will help to manage the effects of aging systems, structures, and components. Additionally, the introduction of advanced technology will also make the existing light-water reactor fleet more attractive to the future workforce.

Further, the INL agreement with the Halden Reactor Project provides access to considerable research and products for CBPs.

In the long run, full modernization of the NPP control rooms will require the use of soft controls accessible through a CBP platform. The industry can increase its efficiency and safety by taking advantage of technological advancements, such as replacing the PBPs with CBPs, which increase usability and allow human performance aspects to be integrated into the procedure.

CBPs offer the option to move towards a more dynamic nature of how procedures are presented to the user. For example, the CBP system can display only the relevant steps based on operating mode, plant status, and task at hand. This will enable many advances in advanced controls and reduction in human error. CBPs are the foundation of many advanced operational concepts of benefit to the LWR fleet. Figure 7 shows the use of a computer-based procedure prototype demonstration at a nuclear utility.

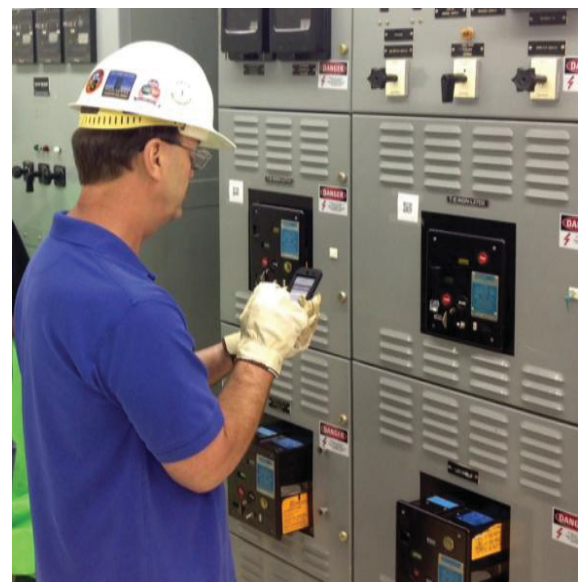

Figure 7 Human factors studies for computerbased procedures for field operators

Pilot Project No: $\quad 1.3$ Title: Control Room Computer-Based Procedures

Purpose: $\quad$ To improve operator performance by the use of CBPs in plant operational activities.

Scope: $\quad$ Working with the host utility's CBP development project to provide HFE studies regarding the procedure presentations, structure, and underlying software system to ensure that human error traps are not created.

Deliverables: $\quad$ - (2012) Complete interim report of Computer-Based Procedure System Prototype.

- (2013) Complete evaluation of final Computer-Based Procedures prototype for field workers.

- (2014) Develop concepts for use of computer-based procedures in a hybrid control room.

- (2015) Publish a technical report for computer-based procedures that enhance worker productivity, human performance, plant configuration control, risk management, regulatory compliance, and nuclear safety margin.
Schedule:
FY 2012 to FY 2015
Cost:
TBD
Host Utility:
Duke Energy,
Arizona Public Service
Project Status:
In-Progress

\subsubsection{Computerized Operations Support Systems}

Situational awareness is critical to the safe operation of NPPs. It requires an accurate understanding of the current plant state and operating configuration, the intricacies of the plant process and control systems, the physics of the plant processes (nuclear, thermal, fluid, and electrical), and the current operating margins with respect to safety and regulatory limits. Today, this enormous amount of information has to be mentally integrated by the operators to arrive at an accurate understanding of how 
the plant is operating and where it is headed. This is a daunting task for even the most experienced operators and could become a significant concern in the future as a wave of new operators replace the aging nuclear workforce.

As more and more plant information becomes available in digital form, it will be possible to provide operators with advanced information systems that aid in assessing the current plant status, safety margins, and deviations from expected operations. Further, through advanced simulation techniques, it will be possible to predict where the plant is going operationally and how long the operators have to intercede in undesirable plant trends.

A computerized operations support systems (COSS) is a collection of capabilities to assist operators in monitoring overall plant performance and making timely, informed decisions on appropriate control actions for projected plant condition. It could contain the following features:

- Advanced nuclear, thermal-hydraulic, and electrical models to assess the actual plant performance relative to the predicted plant performance and report deviations and trends to the operators. It could use directly-measured parameters and derived parameters to analyze plant performance. It could distinguish between real plant performance deviations and those due to sensor degradation.

- A faster-than-real-time simulator that could predict the effect of operator actions prior to them being taken. This would detect interactions that might not be apparent to the operator due to unusual plant configurations and other operating restrictions. It could project the timing of the gradual effect of actions on reactor power such as boration and dilution. Depending on the fidelity of the simulator, it could be very helpful in off-normal conditions where the emergency procedures cannot anticipate every combination of component unavailability.

- Learning systems that become more robust as they experience a wider variety of operational conditions. This could include systems that employ advanced algorithms to monitor many sensors and other inputs to perform monitoring of plant and subsystem performance.

- Continual reinforcement of training within the control room by providing direct reference to training material when it would not be a distraction to operational duties. This form of embedded training has been used elsewhere in other industries (notably aviation) with beneficial effect.

This pilot project will conduct research to build these aggregate plant models and connect them to current and new advanced sensors to obtain precise measurements of the current operating parameters. These models would be validated against actual plant performance at a host utility's NPP. They would be refined until they produced an accurate picture of the plant operating state and degree of deviation from expected performance.

It should be noted that this project will require a substantial cost-share on the part of the host utility. DOE's responsibility in the project will be to provide the COSS platform suitable for testing and demonstration. However, the largest portion of the work will be in modeling the host utility NPP to a degree of detail that will provide useful information to the operators. This would be the responsibility of the host utility.

Pilot Project No: $\quad 1.4 \quad$ Title: Computerized Operator Support System

Purpose: $\quad$ To demonstrate and develop guidance for an advanced COSS, providing real-time 
Scope: $\quad$ Model nuclear, thermal-hydraulic, and electrical processes of the host utility NPP, run the model in a learning state at the host NPP until it is refined to a point of high fidelity, and develop an operator interface (consistent with HFE principles) that reports plant upsets/deviations/undesirable trends and responds to operator inquiries.

Deliverables: $\quad$ - (2014) Develop concepts for using NPP full-scope simulators as operator advisory systems in hybrid control rooms and complete a technical report on prototype demonstrations in HSSL.

- (2015) Develop concepts for a real-time plant operational diagnostic and trend advisory system with the ability to detect system and component degradation and complete a technical report on prototype demonstrations in HSSL.

- (2016) Develop an operator advisory system fully integrated into a control room simulator (HSSL) that provides plant steady-state performance monitoring, diagnostics and trending of performance degradation, operator alerts for intervention, and recommended actions for problem mitigation, with application of control room design and human factors principles.

- (2017) Develop an operator advisory system that provides plant transient performance monitoring with operator alerts for challenges to nuclear safety goals.

- (2018) Develop an end-state vision and implementation strategy for an advanced computerized operator support system, based on an operator advisory system that provides real-time situational awareness, prediction of the future plant state based on current conditions and trends, and recommended operator interventions to achieve nuclear safety goals.

$\begin{array}{llll}\text { Schedule: } & \text { FY } 2014 \text { to FY } 2018 \text { Cost: }\end{array}$

Host Utility: $\quad$ TBD $\quad$ Project Status: Not started

\subsubsection{Future Concepts of Operations}

The control room staffing and protocols for the current light water reactor fleet are based on operational concepts that go back to the beginning of the industry. They are largely based on staffing requirements to handle plant emergencies. They employ protocols that reinforce command and control, rigorous formality, and operator attention-to-detail. They mandate minimum staffing present in the control room due to the need for physical proximity to the information displays and controls. These protocols are absolutely essential today because the operator is the point of integration for information about the current operating state of the plant.

While this operating model has been very successful in safe and productive operation of the LWR fleet, it drives a number of inefficiencies in staffing because operators who are monitoring the plant systems generally cannot be involved in other activities. Therefore, additional operators are required for work management functions, system tag-out developments, plant rounds and field operations, and monitoring special processes such as reactor refueling or dry cask storage loading.

In the future, it will be possible to gain significant efficiencies by employing new concepts of operation made possible by the combined technologies for control room modernization and enhanced operator performance. Specifically, there could be a reduction in the number of operators who are required to be either onsite or in the control room on a continual basis. In addition, the operating protocols could be substantially more flexible in allowing operators to conduct auxiliary tasks while maintaining 
adequate situational awareness of the operating units and being immediately available to take necessary control actions.

These future concepts of operations may alleviate the need for as large a physical presence to effectively control the plant. The new levels of automation may relieve the operators of performing tedious diagnosis and control functions, enhancing their roles to one of oversight of plant protection and control systems and intervening only as needed.

We have strong precedents for this concept in aviation today. Pilots do not have to actually be in the cockpit to fly an airplane (for example, unmanned aerial vehicles have systems that can perform real-time flight control functions by responding to broader directions and objectives set by a remote pilot). A similar concept is employed in virtually all modern aircraft cockpits, where the flight controls, avionics, and navigation systems are coupled under a flight management system that automatically directs the flight according to the flight plan and pre-determined instructions of the pilot, freeing the pilot to stay in an oversight mode of ensuring that all systems are operating correctly and that the flight is proceeding as planned.

The idea of using technology to reduce control room staffing or to permit plant control from outside the control room using advanced display and communication technologies will be highly controversial, notwithstanding the potential efficiency gains. This concept will run against the grain of deeply held beliefs on the conduct of nuclear operations. However, there is already a provision for some of the control room staff to be out of the control room provided they can return within a set time (e.g., the shift technical advisor). Therefore, with no additional risk imposed, this concept can first be validated by giving these technologies to control room crew members that can already be out of the control room to determine their effectiveness in increasing situational awareness while away. The concept can slowly evolve from there as experience and human factors studies determine whether there are efficiency gains without undue concerns over loss of effectiveness of the control room crew.

These technologies and capabilities would include the following:

- Portable interface devices (e.g., tablets and heads-up displays) that will provide continual plant status and control capability anywhere in the plant.

- New control capabilities that automate large operational sequences such as power maneuvers and putting systems into service. Further, they could diagnose and manage (without manual operator actions) the early portions of transients and accidents for the time required for operators to return to the control room. These capabilities can transform required operator actions from long sequences of individual control actions to broad, high-level objective commands (e.g., "place alternate letdown in service").

- Computerized operations support systems that detect deviations and trends very early and provide much more response time to operators to react to and intervene in the situation.

- Ability of qualified operators to assist with certain tasks from where they are (i.e., at home, in remote parts of the plant facility, or at a sister nuclear unit).

- For operators in the control room, technology would enable them to participate in activities that would today require them to be in other parts of the facility (e.g., pre-job briefings). This capability would rely on real-time video, collaboration tools, and virtual meeting software to allow participation in these activities from their normal operating station. 
The Halden Reactor Project is already experimenting with high-fidelity control room displays on portable devices such as digital tablets to study potential improvement in situational awareness for operators temporarily away from the control room. This effort, and other similar research studies, will provide insight into how these technologies can safely be used by control room crews.

This project will assess capabilities beneficial to a modernized control room and develop concepts for operating the nuclear unit in a more flexible and efficient manner. This will include a minimum presence of staffing in the control room, assessment of the control room workload based on advanced technologies, and flexibility for crew members to conduct activities outside the control room while remaining "in-theloop" through the technologies. A human factors' study of crew dynamics would be conducted, with focus on collective situational awareness.

Other future concepts of operation would be explored with the objective to enhance how the control room interacts with special-purpose control centers such as the outage control center, work execution center, technical support center, operational support center, and the emergency operations facility.

Pilot Project No: $\quad 1.5$ Title: $\quad$ Future Concepts of Operations

Purpose: $\quad$ To enhance NPP control room performance through technologies that enable operations crew efficiencies and flexibility.

Scope: $\quad$ Conduct human factors studies in a simulated modernized control room (HSSL) and locations external to the simulated control room to validate new concepts in control room protocols, staffing, operator proximity, and control room management through new technologies that provide mobile information and control capabilities.

Deliverables:

- (2018) Complete a technical report on operator attention demands and limitations on operator activities based on the current conduct of operations protocols. This report will identify opportunities to maximize operator efficiency and effectiveness with advanced digital technologies.

- (2019) Develop and demonstrate (in HSSL) prototype mobile technologies for operator situational awareness and limited plant control capabilities for NPP support systems (e.g., plant auxiliary systems operations and remote panel operations).

- (2020) Develop and demonstrate (in HSSL) new concepts for remote operator assistance in high activity periods (e.g., refueling outages) and accident/security events, allowing offsite operators to remotely perform low safety-significant operational activities, freeing the control room operators to concentrate on safety functions.

- (2021) Develop validated future concepts of operations for improvements in control room protocols, staffing, operator proximity, and control room management, enabled by new technologies that provide mobile information and control capabilities and the ability to interact with other control centers (e.g., emergency response facilities for severe accident management guidelines implementation).
Schedule:
FY 2018 to FY 2021
Cost:
TBD
Host Utility:
TBD
Project Status: $\quad$ Not started 


\subsection{Highly Automated Plant}

NPPs are perhaps the only remaining safety-critical operations that rely to a large degree on human skill to conduct routine and emergency activities. Adoption of digital technologies has transformed other high-risk industries (e.g., aviation, medical procedures, and high-precision manufacturing), with tedious control functions now performed by automation while the operator remains in an oversight, directory role.

This situation is largely due to the fact that the LWR fleet was designed in the 1970s and early 1980s and, due to technology limits at the time, most plant functions required manual control. While certain processes pertaining to reactor operations are automated (e.g., core power level with automatic rod control), the vast majority of plant controls for configuration changes or placing equipment in and out of service are manual. This over-reliance on tedious manual control on such a large scale challenges operators and results in human error rates that remain too high.

The concept of a highly-automated plant is one where the most frequent and high risk control activities are performed automatically under the direction of an operator. Because of higher reliability in well-designed automatic control systems, improvements will be realized in nuclear safety, operator efficiency, and production. The chief impediment to the widespread implementation of this concept is the cost of retrofitting new sensors, actuators, and automatic control technology to the existing manual controls. The goal of this research will be to demonstrate that the resulting improvement in safety and operating efficiencies will more than offset the cost of making these upgrades.

\subsubsection{Digital Architecture for a Highly Automated Plant}

To automate operating NPPs to their full potential, integration of digital technologies must extend beyond plant control and information systems to that of the domain of plant work processes and plant worker activities. This will require a plant digital architecture that is more encompassing than is currently available to the industry.

Even in today's more advanced plants, the digital architecture typically extends only to the major protection and integrated controls systems. Data architectures to support plant work processes are intentionally separate due to cyber security concerns. No comprehensive data schema is available that relates all plant functions in the context of their real-world relationships, thereby defining the needed data interfaces to conduct plant functions and support activities in an integrated manner. This architecture would define the following:

- Systems that need to be integrated for robust plant protection and control

- Types of data busses and interfaces

- Cyber security requirements

- Failure and recovery requirements

- Necessary segmentation of the overall architecture to ensure independence of function and defense-in-depth

- Data relationships that are required to support plant functions, plant systems, plant processes, and plant worker activity

- External interfaces to enable remote operations and support activities; either at a fleet or industry level.

This project will define an advanced information and control architecture that will accommodate the entire range of system, process, and plant worker activity to enable the highest degree of integration, thereby creating maximum efficiency and productivity. This pilot project will consider a range of open standards that are suitable for the various data and communication requirements of the seamless digital 
environment. It will map these standards into an overall architecture to support the II\&C developments of this research program.

Pilot Project No: $2.1 \quad$ Title: Digital Architecture for a Highly Automated Plant

Purpose: $\quad$ To develop an advanced digital information and control architecture to integrate plant II\&C systems, plant work processes, and plant worker mobile technologies. This architecture will serve as the foundation of the highly-automated plant. It will be based on open standards so third party organizations have direct connectivity to the plant applications when authorized by the plant owner.

Scope: $\quad$ Investigate the current state of available plant data and control architectures for each functional area of plant automation, develop a prototype architecture that bridges all of these functional areas, and develop a technical report for a production architecture that can support a highly automated plant.

Deliverables: - (2014) Publish a technical report that provides a current state and gap analysis for integrating plant information residing in plant II\&C systems, plant work processes, and information resources needed for mobile worker technologies.

- (2015) Develop a conceptual model for a digital architecture, integrating plant systems, plant processes, and mobile plant workers based on information exchange requirements that are established on open standards and consistent with design and licensing basis requirements (such as cyber security and Class IE separation). Develop a methodology for mapping NPP operational and support activities into the digital architecture.

- (2016) Publish a technical report on an advanced digital architecture, integrating plant systems, plant work processes, and plant workers in a seamless digital environment, with guidance on how to apply the architecture to an NPP's established data network systems.

$\begin{array}{llll}\text { Schedule: } & \text { FY 2014 to FY 2016 } & \text { Cost: } & \text { TBD } \\ \text { Host Utility: } & \text { TBD } & \text { Project Status: } & \text { Not started }\end{array}$

\subsubsection{Automating Manually Performed Plant Activities}

NPPs have a higher ratio of staffing to unit of power output than any other form of electrical generation. For example, an NPP will typically have ten times the amount of staffing as a similar-sized fossil generation station. Labor is the largest component of an NPP's operating and maintenance cost, typically accounting for $70 \%$ of the annual operating budget.

These high staffing requirements are due to the fact that NPPs have such a large number of systems and most operations are performed manually. Because of nuclear safety concerns, most plant manipulations have to be verified by a second person and even a third person in high-risk situations.

As current components in the plants today approach end-of-life and are faced with reliability and component aging issues, an opportunity presents itself to upgrade the systems in a manner that can reduce dependence on manual activity. Whereas this would have once been thought to be cost-prohibitive, new advances in technology now make this economically feasible. Some of these advances are as follows:

- Low-cost, highly reliable sensors and actuators (with low maintenance requirements)

- Wireless technology, avoiding the need for long runs of expensive instrument cable 
- Easy-to-maintain control technologies such as field programmable gate arrays, programmable logic controllers, and other digital control devices

- Power harvesting from ambient energy (e.g. light, heat, and vibration).

To make this automation cost effective, plant activities must be transformed so that the cost of automation is offset by reductions in the size of the plant staff required to conduct these activities. Otherwise, the technology upgrade costs would simply be added to the cost of the present plant structure of staffing and manual processes and no real efficiencies would be gained. Therefore, research is required to determine how to conduct these activities in a fundamentally different way, relying on automation to accomplish the end objectives rather than staff activity.

Examples of these kinds of opportunities are as follows:

- Replacement of stand-alone control loops with digital technology. A typical example would be a throttle valve control circuit, which would rely on an analog sensor/transmitter hard-wired to the control room, a controller with a set point or manual control, and an output circuit with a current loop connected to a pneumatic control loop connected to the valve's air operator. The objective would be to replace all of these analog technologies with digital equivalents, eliminating the frequent maintenance work required for these legacy technologies, while gaining improved accuracy and reliability of the digital technology.

- Elimination of manual gauges and displays that have to be locally read on a frequent basis, replacing them with wireless equivalents.

- Addition of low-cost, wireless component position indicators, eliminating time-consuming and error-prone field walk-downs of valves, breakers, and dampers to verify they are in the correct position.

- In-line chemistry instruments, eliminating field samples that have to be transported to an analysis laboratory for processing.

- Replacing local control panels with highly automated soft controls that can be operated from more convenient locations.

- Conversion of protective relays to integrated digital relay systems, eliminating tedious manual testing of these individual devices and greatly reducing the effort to periodically adjust protective relay settings.

This project will analyze the NPP current staffing and cost model in a top-down manner to identify opportunities to significantly lower operating costs through selective automation of frequently performed manual activities. It will examine the technologies from a maturity perspective and a human factors perspective. It will make broad recommendations on gradually transforming the operating model of NPPs from one that is labor centric to one that is technology centric. In making this transformation, the underlying technologies that are deployed will enable a concept of integrated operations, reducing dependence on in-plant staff through greater use of out-sourced remote operations and maintenance.

Pilot Project No: $\quad 2.2 \quad$ Title: Automating Manually Performed Plant Activities

Purpose: $\quad$ To transform the NPP operating model from a labor-centric to a technology-centric basis, thereby improving plant economics, addressing long-term staffing shortage 
Scope: $\quad$ Analyze the NPP operating model to redefine the approach to plant functional support areas, moving to highly automated operations in lieu of manually performed plant activities. Transformative technologies would be prototyped and tested at host utility NPPs as proof-of-concept. Human factors considerations would be applied to new organizational structures. Utility scale-up recommendations would be developed.

Deliverables: - (2015) For NPP operations activities, analyze the staffing, tasks, and cost models to identify the opportunities for application of digital technologies to improve nuclear safety, efficiency, and human performance based on optimum humantechnology function allocation. Demonstrate representative activities as transformed by technology with results published in a technical report.

- (2016) For NPP chemistry activities, analyze the staffing, tasks, and cost models to identify the opportunities for application of digital technologies to improve nuclear safety, efficiency, and human performance based on optimum humantechnology function allocation. Demonstrate representative activities as transformed by technology with results published in a technical report.

- (2017) For NPP maintenance activities, analyze the staffing, tasks, and cost models to identify the opportunities for application of digital technologies to improve nuclear safety, efficiency, and human performance based on optimum human-technology function allocation. Demonstrate representative activities as transformed by technology with results published in a technical report.

- (2018) For NPP radiation protection activities, analyze the staffing, tasks, and cost models to identify the opportunities for application of digital technologies to improve nuclear safety, efficiency, and human performance based on optimum human-technology function allocation. Demonstrate representative activities as transformed by technology with results published in a technical report.

- 2019) Develop and publish a transformed NPP operating model and organizational design derived from a top-down analysis of NPP operational and support activities, quantifying the efficiencies that can be realized through highly automated plant activities using advanced digital technologies.
Schedule:
FY 2014 to FY 2019
Cost:
TBD
Host Utility: $\quad$ TBD - multiple NPPs $\quad$ Project Status: $\quad$ Not started

\subsubsection{Advanced Plant Control Automation}

Because of the pervasive analog II\&C technology in the NPPs today, much of plant control is conducted by operators manually manipulating a large array of discrete control devices. The major exceptions to this are the process control systems for the reactor coolant system, heat transfer (steam generators for PWRs), and turbine-generator controls for power production. Also, the emergency core cooling system is typically auto-started on certain emergency signals, but has to be manually adjusted as the accident mitigation sequence progresses. Other plant systems are largely reliant on manual operator actions for normal and emergency operations.

By shifting the balance away from manual operator actions to more plant control automation, nuclear safety and plant production can be enhanced by reducing the opportunity for human error, while making it possible for the operator to focus on oversight of the changing plant conditions and the performance of the automatic control systems. 
Building on work from the pilot project on automating annually performed plant activities, especially the conversion of stand-alone control loops to digital technology, it will be possible to implement distributed control systems in ways that automate large sequences of commands in order to relieve the operators of tedious plant manipulations. In some cases, this will also require the upgrade of certain manually-operated components to automatic equivalents and the installation of low-cost, highly reliable sensors and actuators.

Priorities for advanced plant control automation concepts would be those activities that are frequently performed, time- and attention-intensive for the operators, and entail some nuclear safety or production risk. Examples of such activities are as follows:

- Plant heat ups and cool downs

- Automated management of plant transients

- Swapping operating trains where there are redundant systems

- Aligning systems to their test configuration

- Placing systems into service

- Conducting in-service maintenance activities such as backwashing strainers.

Human factors evaluations would be a key aspect of this project in that there are significant concerns on how this level of automation would affect operator skills and knowledge. Operator performance studies would be run in HSSL to address issues such as:

- Would an over-reliance on the automation technology be created so operators would not maintain the skills necessary for performing the actions manually if the technology failed?

- Would operators have a sufficient awareness and understanding of what the automated systems were doing during a given automated plant evolution?

- Would operators lose focus in monitoring the plant during long sequences of automated control?

- Would operators immediately recognize a control system failure even when there was no significant plant excursion?

Working with a host utility NPP, this project would use the HSSL to develop a prototype of widescale control automation and conduct the human factors studies to answer these questions. The project would develop a prioritized list of plant control functions to be included in an advanced plant control implementation for a first-mover NPP. The project would also develop a technical report for applying advanced plant controls in a manner consistent with human factors principles.

\section{Pilot Project No: $\quad 2.3$ Title: $\quad$ Advanced Plant Control Automation}

Purpose:

Scope:
To improve nuclear safety and operator human performance by automating control for frequent and safety-significant plant configuration and operating state evolutions.

Working with a host utility NPP, identify the high-priority plant evolutions to convert to an advanced plant controls concept, build this level of automation into that plant's current simulator in the HSSL, conduct required human factors evaluations to validate advanced plant automation concepts, and build a generalized business case for utilities to follow in pursuing this higher level of 
Deliverables:

- (2017) Develop concepts for advanced control automation for control room operators based on human technology function allocation developed in the pilot project for automating manually performed plant activities. Publish a technical report on candidate applications for automation reflecting design and human factors principles.

- (2018) Develop and demonstrate (in HSSL) prototype plant control automation strategies for representative normal operations evolutions (e.g., plant start-ups and shut-downs, equipment rotation alignments, and test alignments).

- (2019) Develop and demonstrate (in HSSL) prototype plant control automation strategies for representative plant transients (e.g., loss of primary letdown flow or loss of condensate pump).

- (2020) Develop the strategy and priorities and publish a technical report for automating operator control actions for important plant state changes, transients, and power maneuvers, resulting in nuclear safety and human performance improvements founded on engineering and human factors principles.

$\begin{array}{llll}\text { Schedule: } & \text { FY 2017 to FY 2020 } & \text { Cost: } & \text { TBD } \\ \text { Host Utility: } & \text { TBD } & \text { Project Status } & \text { Not started }\end{array}$

\subsubsection{Advanced Plant Control Algorithms}

Control algorithms for the current fleet of LWRs are certainly adequate and sufficient to maintain control of plant functions in all expected operating conditions and to invoke protective actions when the allowable operating limits are exceeded. However, because of the state of technology at the time these plants were designed, the control parameters were limited to those that could be cost-effectively hardwired to the control devices of any particular plant function.

This means that the controls for LWRs are not as highly integrated as desirable. In some cases, they are coupled only by the physics of the plant (e.g., controlling rod demand with turbine impulse pressure). As a result, certain control functions do not respond until the physical plant has responded to some other input or control function. This introduces delay and insensitivity for the downstream control functions.

A fully-integrated digital plant would have access to any parameter captured by its sensors, instruments, and control functions. If properly organized in a plant-wide database, any parameter could be made available to any control function as a variable in the control software, if it made logical sense to do so. This would create the potential for far more robust control functions for LWRs, including the following concepts:

- Adaptive controls to cope with sensor and control component failures

- Anticipatory signals for quicker plant responses to upsets

- New types of sensors to provide direct measures of key control parameters

- Derived values for desired parameters that cannot be directly measured.

This project will consist of a study of critical control functions in both BWR and PWR NPPs to determine how they can be made more robust and finely tuned by the addition of new control parameters. Sources for these desired parameters will be identified as available signals in the plant II\&C systems, requirements for new types of sensors, and requirements for derived parameters from other plant information. Also, adaptive control schemes for critical control functions will be developed in consideration of these same available parameters. The result will be far more robust control schemes for 
critical plant control applications; thereby improving plant reliability, minimizing plant transients, and enhancing nuclear safety.

This project will build on the work performed in the pilot project on a digital architecture of a highly automated plant, specifically in the structure of the plant-wide database to organize all of the sensor and derived parameters available to the II\&C systems. A key consideration of this database design will be the update frequency required by the advanced plant control algorithms (i.e., limits on signal latency) to keep pace with rapidly changing plant conditions.

$\begin{array}{ll}\text { Pilot Project No: } & 2.4 \quad \text { Title: Advanced Plant Control Algorithms } \\ \text { Purpose: } & \text { To improve plant performance and nuclear safety by developing advanced plant } \\ & \text { control algorithms based on more widely available plant parameters, resulting in } \\ & \text { more anticipatory, adaptive, and resilient control functions. }\end{array}$

Scope: $\quad$ Prioritize and evaluate critical control functions related to nuclear safety and plant production, identify improvements to these control functions based on the availability of all sensed and derived parameters, test these new control schemes using the HSSL reconfigurable simulator, and develop a technical report for improving these control functions in the current LWR fleet.

Deliverables: - (2019) Conduct and publish a technical report on NPP control problems due to limitations in control algorithms and, specifically, lack of needed plant parameters (sensed or derived) that would improve plant control success in both normal and degraded conditions.

- (2020) Develop and demonstrate new control algorithms based on a prototype plant-wide database of sensed and derived parameters, which is built on the digital architecture for a highly automated plant.

- (2021) Develop the strategy and priorities and publish a technical report for improving plant control algorithms, based on greater availability of sensed and derived plant parameters through the advanced digital architecture, resulting in more anticipatory, adaptive, and resilient control functions.

$\begin{array}{llll}\text { Schedule: } & \text { FY } 2019 \text { to FY 2021 } & \text { Cost: } & \text { TBD } \\ \text { Host Utility: } & \text { TBD } & \text { Project Status: } & \text { Not started }\end{array}$

\subsection{Human Performance Improvement for Nuclear Power Plant Field Workers}

Despite over a decade of strong emphasis on human performance improvement, the LWR fleet continues to be impacted by human error, resulting in plant transients, nuclear safety challenges, and equipment damage. While consequential error rates are relatively low (typically measured in the range of $10^{-4}$ consequential errors on a base of $10 \mathrm{~K}$ hours worked), the sheer number of work hours accumulated by the plant staff over time means that errors impacting plant safety and reliability still occur too frequently.

The traditional approach to improving plant worker human performance has been to focus on correcting worker behaviors. This has indeed produced substantial improvement since the time this emphasis was begun in the mid-1990s. Up to that time, there were frequent plant trips and transients due to human error such as working on the wrong component or even the wrong operating unit. These types of errors have been gradually reduced until they are relatively rare. However, other types of errors 
continue to cause or complicate nuclear safety challenges. The commercial nuclear industry received somewhat of a wake-up call in the first half of 2010 when there were a series of incidents at different NPPs, many of which were considered to be among the industry's best performers. These incidents were documented in the Institute of Nuclear Power Operations Significant Operating Experience Report (SOER) 10-2, The Thinking, Engaged Organization, which assigned a significant portion of the causes to human error and lack of operator fundamental knowledge.

The focus on correct worker behaviors typically involves analysis of the inappropriate worker actions and implementation of corrective actions in the form of additional training, procedure upgrades, job and memory aids (i.e., acronyms and neck strap cards), additional peer checking, management job observations, and so forth. While some improvement is usually obtained from these corrective actions, there is a cumulative negative effect in adding complexity to work activities that makes the work slow and cumbersome. To plant workers, the focus seemed to be more about the human performance tools (job aides) than the actual task or activity being accomplished. Job satisfaction is eroded and the added complexity becomes an enticement to take short-cuts with these additional requirements, further perpetuating the cycle of human error. Much frustration on the part of workers and their managers has resulted from the ever-increasing job expectations applied to their work activities while, in actuality, they are experiencing diminishing returns in terms of error-free performance. Some industry observers believe that a saturation point has been reached where the added complexity is contributing to the rate of human error (due to divided attention) and that we have reached the practical limits of human reliability at the present error rates.

To further improve human performance for NPP field workers, a fundamental shift in approach is needed. Digital technology can transform tedious error-prone tasks in NPP field activities, placing the worker in a more cognitive role. It has the potential to eliminate human variability in performing routine actions such as identifying the correct component to be serviced. In short, the technology can perform tasks at much higher reliability rates, while plant workers are elevated to a role of correctly applying the technology and validating the results.

\subsubsection{Mobile Technologies for Nuclear Power Plant Field Workers}

Virtually all plant work activities are conducted under the control of rigorous work processes that convey the required job quality and technical requirements. Up until now, these work processes have generally relied on printed paper to present information to the plant workers and to serve as the medium to direct the execution and documentation of the specific tasks of the work activities. However, paper as a medium has the obvious limitations of not being interactive with real-time information sources. It is inflexible in its usage, leaves room for interpretation; and is incapable of enforcing its printed requirements.

Technologies that have replaced the use of paper processes in the office environment have not been easily adapted to field worker requirements. The primary difficulty in providing plant workers with technology to improve their performance has been the fact that the workers must move about the plant in sometimes relatively inhospitable environments for digital technology (e.g., temperature extremes, radiation, radio frequency interference, and confined spaces). Also, there has been no practical way to connect these devices for real-time interactions to assist mobile workers. 
Outside the nuclear industry, the use of mobile technologies to improve human performance is much more pervasive. A rapid transformation is in progress in the use of mobile technologies to revolutionize how humans conduct their routine personal and work-related activities. These technologies range from the applications in the latest smart phones to the hand-held business technologies used to receive and track mobile objects such as overnight packages, rental cars, and warehouse inventories. What these technologies have in common is that they correctly identify the intended work object, apply the correct process steps, validate information, and post real-time work status to the corporate process systems - all from the job location.

These devices rely on wireless networks, digital processing devices, object identification capabilities (e.g., bar codes and radio frequency identification), voice command capability, and information processing software (Figure 8). In other words, many different technologies can be bundled in a single mobile device to address all aspects of a particular work activity. These technologies have also been "hardened" such that they can reliably perform in challenging environments, including those found in a NPP.

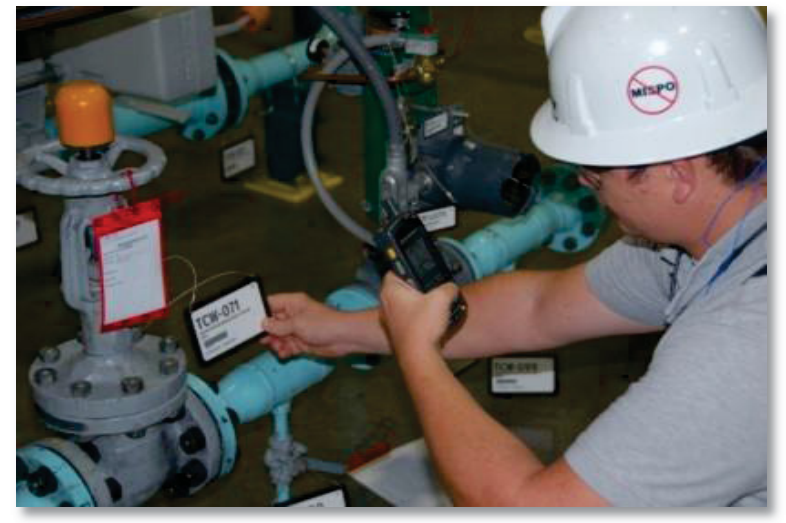

Figure 8 Operator at Catawba Nuclear Station using hand-held technology for component identification

However, it is not enough to simply provide field workers with mobile technologies. These technologies must be integrated into the plant work processes and must be able to access real-time plant information. Further, they must provide the ability for real-time interaction and collaboration with workers in other locations, in particular those who are coordinating overall plant operations, such as those in the NPP control room or outage control center. The idea is to literally embed the field worker in the digital plant processes and digital plant systems with wearable technologies, such that the worker is an integral and connected part of the seamless digital environment supporting plant operations and related activities.

These integrated technologies must first be validated using human performance evaluations to ensure they are not introducing negative factors into the work setting. It is essential that they be packaged and used in a manner that is intuitive, promotes situational awareness, and does not distract the worker from key job requirements or safety hazards in the area.

This research project will develop the basic mobile technology capabilities needed by a NPP field worker in performing typical plant work activities (Figure 9). It will include general work process instructions, component identification capability, wireless communications to transmit and receive realtime information, audio, picture and video streaming, and use of heads-up, hands-free displays for workers involved in hands-on work. It also will include human factors evaluations to ensure the technologies do not introduce negative factors that are detrimental to the job outcomes or well-being of the workers.

The initial applications of this technology will address safety tagging of components and conducting valve line-up checklists. These two initial applications typify many other plant activities such that the technologies can easily be expanded into these other uses. The project also will develop a prototype of a simplified computer-based procedure to test the suitability of the technologies to handle interactive and shared content.

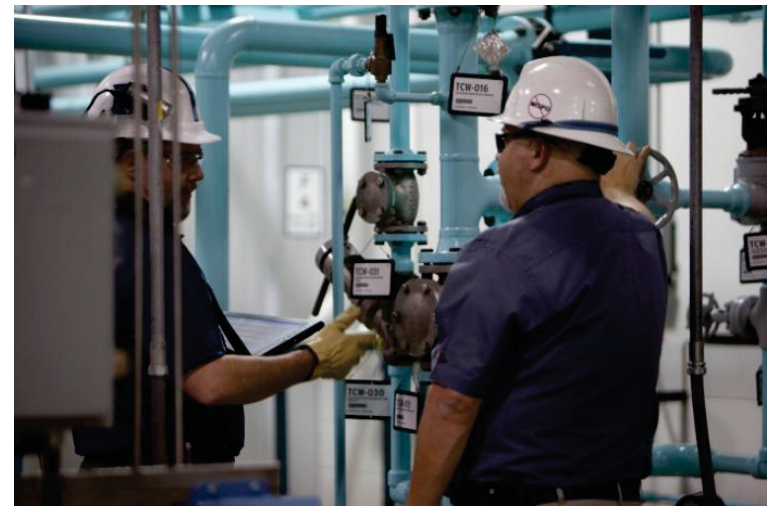

Figure 9 Catawba operators demonstrate the use of computer tablet-based work instructions 
Pilot Project No: $\quad 3.1 \quad$ Title: $\quad$ Mobile Technologies for NPP Field Workers

Purpose:

Scope:

Deliverables:

Schedule:

Host Utility:
To improve performance of NPP field workers by replacing paper-based activities with technology-based activities, thereby reducing human error, improving productivity, and providing real-time information links to work processes and control centers. In addition, by maximizing the "collective situational awareness" of the entire plant, these technological advancements will greatly improve critical decision making at all levels.

Assemble an array of mobile technologies that constitute a platform for field activities in a NPP, apply these technologies to initial applications of safety tagging and valve line-up verifications, develop a prototype computer-based procedure capability for field activities, conduct related human factors evaluations, and provide guidance for a fleet-wide scale up of the technologies.

- (2012) Publish a technical report on the research and development facility buildout and the project execution of the Mobile Technologies for NPP Field Workers pilot project.

- (2012) Publish guidance for deployment of mobile technologies for NPP field workers.

FY 2011 to FY 2012

Cost: $\quad$ (on file)

Duke Energy

\subsubsection{Automated Work Packages}

Work packages for NPP field activities are typically bulky and cumbersome. They are expensive and wasteful of paper to print, and the volume of paper can be overwhelming to transport to the job site and manage while there. Further, for activities in a radiation control zone, taking the needed and contingency paperwork to the job site often increases the amount of contaminated waste generated.

Moreover, the paper-based work processes rely on human performance to correctly obtain data, enter it into the work packages and procedures, successfully complete the steps of the process in the right sequence, and ultimately validate that the correct results have been obtained. Because of the complexity of these activities and the sheer bulk of the paperwork, errors frequently occur that cause incorrect final results, rework, time delays, excessive safety system unavailability, and, if errors go undiscovered, latent nuclear safety issues.

Based on mobile technologies for NPP plant workers developed under the first pilot project of this enabling area, it will be possible to automate large portions of plant activities in a manner that improves human performance, makes workers more productive, and enhances nuclear safety by reducing active and latent component failures. Specific capabilities would include the following:

- Organize and control the sequence of all tasks performed under the work package

- Retrieve documentation directly from the utility's document management system, eliminating reference material from the work package that often proves to be unneeded.

- Obtain plant data inputs directly from the plant systems and components, eliminating reading and transcribing errors. This data could be obtained wirelessly from the plant computer and locally by connecting directly to smart devices such as digital transmitters. 
- Insert results directly into plant work processes and plant systems. This would include system health applications, data historians, plant computer, and the work package and procedure archival system.

- Obtain real-time concurrences and verifications from remote locations.

- Directly download updates and deviation approvals if revisions are needed to complete the work package.

- Directly access supplemental information such as training videos, operating experience, similar historical work packages, and corrective action reports.

- Provide real-time task status to work execution centers, eliminating the need to call field workers to obtain updates.

- Validate results based on real-time plant data, historical results, and engineering acceptance criteria.

This project will develop prototype work packages that can be executed on the mobile technologies for field workers. Target work packages will be selected from the areas of operations, maintenance, chemistry, radiation protection, and security. The work packages will be tested in a host utility NPP, exercising all of the capabilities of the mobile technologies and interconnectivity among those technologies. Human factors evaluations will be conducted during these tests to determine the gains in productivity and human performance, as well as identifying and mitigating any negative human factors that are introduced. The final product will be a technical report on how to deploy this concept for a wide range of work package-based plant activities using mobile technologies.

\section{Pilot Project $\quad 3.2 \quad$ Title: $\quad$ Automated Work Packages \\ No:}

Purpose:

To improve worker productivity and human performance by automating field work packages using mobile technologies.

Scope: $\quad$ Select representative work package-based plant activities from the plant functional areas, develop prototype work packages, test usage of the automated work packages in NPP field activities, conduct related human factors evaluations, and develop an implementation strategy for wide-scale deployment for NPP field activities.

Deliverables: - $\quad$ (2014) Develop automated work package prototype technologies for NPP work processes with associated study of field trials at an NPP.

- (2015) Develop human factors evaluations and an implementation strategy for deploying automated field activity work packages built on mobile technologies, resulting in more efficient and accurate plant work processes, adherence to process requirements, and improved risk management.

$\begin{array}{llll}\text { Schedule: } & \text { FY 2014 to FY 2015 } & \text { Cost: } & \text { TBD } \\ \text { Host Utility: } & \text { TBD } & \text { Project Status: } & \text { Not started }\end{array}$




\subsubsection{Augmented Reality for Nuclear Power Plant Field Workers}

NPP field workers are often in a plant environment where information critical to successful completion of their activities, and even their well-being, is not visually obtainable, such as:

- Temperature of surrounding components

- Whether a valve is open or closed

- Proximity to reactor trip-sensitive equipment

- Proximity to temporary hazard boundaries (e.g., radiography or overhead load paths)

- Plant data (pressure, flow, and set points) from nearby components

- Strength of radiation fields and location of hotspots

- Oxygen-deficient environments.

Without the ability to visually acquire this information, plant workers must have this information already provided in their work packages or they must rely on others to supply this information during the activity through the available communication channels. This is time-consuming and often does not result in an adequate understanding of the actual field conditions.

Technologies are emerging that will enable a NPP field worker to "see" this information in a dynamic and context-based way. These technologies will allow the worker to visualize otherwise invisible information that will enable them to make informed decisions about their activities and their personal proximity to hazards. As an example, this might include smart safety glasses that can superimpose a transparent color-shaded representation of a radiation field directly into the worker's field of view. Similarly, plant data could be superimposed directly onto the components in the worker's field of view, allowing the worker to "read" the data by merely looking at the components.

This capability would be made possible through use of wireless communications to supply information from the plant computer and other sources, in combination with technologies that can determine the worker's location, orientation, and field of view. Further, the information provided would be context based because the worker's purpose for being in that location would be known to the information system. In this way, only data relevant to that purpose would be automatically pushed to the worker. However, the worker could request any other information desired. In addition, it would be possible to visualize hazards, such as heat-stress work environments or confined spaces with the potential for hazardous gases. Stay-time clocks could be presented visually to the worker with appropriate alarms.

These capabilities would create a whole new dimension in the concept of an "intelligent plant worker." They can be combined with the concept of automated work packages to produce extraordinary efficiencies in conducting plant activities and keeping the worker safe. There would be secondary benefits to knowing the location and environment each worker was in. For example, this would greatly simplify accounting for personnel in emergency situations such as containment evacuations and security events. It could enable remote monitoring of radiation dose and allow for optimized dispatch of field workers supporting concurrent work activities such as quality control inspectors. It could enable the concept of "picture procedures" in which images of the actions required by a procedure step are superimposed on the equipment being manipulated via the worker's heads-up display.

This project will develop the needed technologies to create augmented realities for NPP field workers and will test these technologies first in the HSSL and ultimately in a host utility NPP. Studies during testing will include both technical and human factors evaluations. The final product will be a technical report on how to implement these technologies in conjunction with the previously developed mobile technologies for NPP field workers. It also will provide guidance for integrating the augmented reality technology with compatible automated work packages. The Halden Reactor Project is already developing these types of technologies, including those that can determine the location and orientation of a field 
worker. This project work will be coordinated with Halden to take full advantage of their efforts in augmented reality technologies.

\section{Pilot Project No： $\quad 3.3 \quad$ Title: $\quad$ Augmented Reality for NPP Field Workers}

Purpose: $\quad$ To improve worker productivity, safety, and human performance by implementing augmented reality capabilities that allow the worker to visualize abstract information in the context of plant activities.

Scope: $\quad$ To develop the augmented reality technologies, test them in both the HSSL and actual NPP field settings, conduct related human factors evaluations of the technology, and develop a technical report for implementing the technologies and integrating them into appropriate automated work packages.

Deliverables: $\quad$ - (2016) Develop and demonstrate augmented reality technologies for visualization of radiation fields for mobile plant workers.

- (2017) Develop and demonstrate augmented reality technologies for visualization of real-time plant parameters (e.g., pressures, flows, valve positions, and restricted boundaries) for mobile plant workers.

- (2018) Publish a technical report on augmented reality technologies developed for NPP field workers, enabling them to visualize abstract data and invisible phenomena, resulting in significantly improved situational awareness, access to context-based plant information, and generally improved effectiveness and efficiency in conducting field work activities.

$\begin{array}{llll}\text { Schedule: } & \text { FY 2015 to FY 2017 } & \text { Cost: } & \text { TBD } \\ \text { Host Utility: } & \text { TBD } & \text { Project Status: } & \text { Not started }\end{array}$

\subsection{Integrated Operations}

Many industries have taken advantage of new digital technologies to consolidate operational and support functions for multiple production facilities to improve efficiency and quality. This concept is often referred to as integrated operations. It basically means using technology to overcome the need for local support, thereby allowing the organization to centralize certain functions and concentrate the company's expertise in fewer workers. These workers, in turn, develop higher expertise because they are exposed to a larger variety of challenges and issues than if they supported just a single facility. It allows the organizations to outsource selected functions where beneficial, while maintaining immediate access to the services even if provided remotely. The concept also enables standardized operations and economy of scale in maintaining centralized functions rather than duplicate capabilities at each location.

The Halden Reactor Project has been quite active in this concept for the Norwegian off-shore oil platforms. The oil companies have developed integrated operations to move large parts of their platform operations and support to centralized on-shore locations. This has resulted in dramatic improvement in the efficiency of operations and the quality of life for the participating workers. While there remains a need for sufficient staff on the platforms to conduct the hands-on work, virtually any activity that can be controlled or monitored through the digital systems is a candidate for integrated operations.

Likewise, for years, airlines have maintained centralized flight operations monitoring centers, due to the impracticality of providing this as an on-board service. Data links are used to stream in-flight performance data to the centers to be monitored by systems experts. The experts are able to confer 
directly with the pilots on any immediate operational concerns. Otherwise, minor issues can be documented and addressed at the next convenient opportunity.

NPPs have a similar opportunity to improve support functions by developing an integrated operations concept. Indeed some steps in this direction have already been taken by utilities that have implemented a centralized online monitoring center for plant components equipped with remote monitoring capability. However, there are many more opportunities to consolidate support services across the fleets using digital technologies that enable work to be performed just as effectively as if it were onsite. Furthermore, the concept can be extended beyond the utility organization to create seamless interfaces with suppliers, consultants, and original equipment manufacturers. In this way, an operating company could build a virtual organization of trusted partners rather than having to provide operations-critical services in-house.

\subsubsection{Advanced Online Monitoring Facility}

Sustainability for the U.S. LWR fleet is dependent on the preservation of plant assets far beyond the original life of 40 years. With most utilities pursing life extension to 60 years (with the possibility of 80 years), long-term plant asset management will have to be a prominent focus of the utility's technical staff.

Technologies are being rapidly developed that can provide early indication of component degradation. Moving beyond empirical models of the degradation factors, physics-based models are now being developed that can mimic the effects on the overall component in response to degradation in one of the subcomponents. This provides a capability to move beyond mere monitoring of the condition to the diagnosis of the degradation mechanism and the prognosis of the remaining useful life of the component and give the utility a window of opportunity to take remedial actions. These types of technologies are being developed under pilot projects described in Section 4.6.The purpose of this project is to integrate these new monitoring capabilities into a concept of fleet asset management based on a centralized online monitoring facility. The underlying information structure would be part of the digital plant architecture as described in Section 4.2.1.

The architecture would support the real-time acquisition of condition monitoring data from every type of source. This would include fixed sensors embedded in components such as in "smart pumps." It would also collect data streamed from mobile technologies used by field workers (see Section 4.3.1). This would include data from hand-held condition monitoring technologies such as thermal imaging, vibration monitors, and acoustic probes.

The architecture would organize the information in a manner that could be used for a variety of purposes. In addition to being available for the centralized asset management facility, it would be made available to the plant engineering system health program, troubleshooting and root cause teams, original equipment manufacturers and technical consultants involved in component support, and the data historian and plant records function.

This project will develop a prototype advanced online monitoring facility based on the state-of-the-art information technologies and collaboration facilities. It will demonstrate the following:

- Employ new visualization capabilities to create a better understanding of the condition of degrading components

- Have video conferencing capability for direct collaboration with plant staff in a variety of settings (e.g., the control room, the outage control center, or engineering support groups)

- Have access to industry databases on failure signatures and associated component data to assist in diagnosing component degradations 
- Support the concept of integrated operations in that it will be able to remotely support a number of operating plants as effectively as if it were onsite.

The prototype advanced online monitoring facility will initially be developed in the HSSL where technology developments and human factors studies can be conducted in a test environment. Following that, a production facility would be developed at a host utility location for actual production testing. Based on this initial experience, a technical report would be written to provide recommendations for industry wide implementation.

\begin{tabular}{|c|c|c|c|}
\hline Pilot Project No: & \multicolumn{3}{|c|}{ Advanced Online Monitoring Facility } \\
\hline Purpose: & \multicolumn{3}{|c|}{$\begin{array}{l}\text { To develop the underlying information technologies to support an advanced } \\
\text { centralized online monitoring facility for long-term plant asset management. }\end{array}$} \\
\hline Scope: & \multirow{2}{*}{\multicolumn{3}{|c|}{$\begin{array}{l}\text { Develop the specific digital architecture to collect and organize data from all types of } \\
\text { sources of condition-monitoring data, develop a prototype advanced online } \\
\text { monitoring facility in the HSSL, provide guidance and associated technical and } \\
\text { human factors studies for an initial production online monitoring facility at a utility } \\
\text { host location, develop a technical report for industry-wide implementation. } \\
\text { - (2015) Develop and demonstrate (in the HSSL) concepts for an advanced online } \\
\text { monitoring facility that can collect and organize data from all types of monitoring } \\
\text { systems and activities and can provide visualization of degradation where } \\
\text { applicable. } \\
\text { - (2016) Develop and demonstrate (in the HSSL) concepts for real-time information } \\
\text { integration and collaboration on degrading component issues with remote parties } \\
\text { (e.g., control room, outage control center, systems and component engineering } \\
\text { staff, internal and external consultants, and suppliers). } \\
\text { - (2017) Develop a digital architecture and publish a technical report for an } \\
\text { advanced online monitoring facility, providing long-term asset management and } \\
\text { providing real-time information directly to control room operators, troubleshooting } \\
\text { and root cause teams, suppliers and technical consultants involved in component } \\
\text { support, and engineering in support of the system health program. }\end{array}$}} \\
\hline Deliverables: & & & \\
\hline Schedule: & FY 2015 to FY 2017 & Cost: & TBD \\
\hline Host Utility: & TBD & Project Status: & Not started \\
\hline
\end{tabular}

\subsubsection{Virtual Plant Support Organization}

Because of the complexity of plant systems and the large number of components in NPPs, utilities maintain a very large staff of highly trained operators, engineers, technicians, and other types of specialists to ensure safe and successful operations. Considerable ongoing investment in the form of training and development is made in this workforce to enable them to maintain the unique and aging technologies in the plants. Like the technologies, the workforce as a whole is relatively older compared to other industries in that many of today's workers began their careers in the early days of commercial nuclear power.

At present, the nuclear industry has arguably the most experienced workforce in its history. This is undoubtedly a significant factor in the operational success that the industry has enjoyed over the last decade or so. However, this is an unsustainable path because, like the aging II\&C systems that must be 
replaced, the aging workforce is on the brink of a substantial retirement wave, and a significant portion of the workforce will have to be replaced in a relatively short amount of time.

Going forward, there are concerns whether the commercial nuclear industry will be able to attract the needed engineers and technicians given the looming shortage of technically trained workers in this country. In addition, the model of having career-long employees who develop deep expertise is not likely to be as successful in the future with what appears to a new generation of workers who will be more prone to change jobs.

A better model would include the ability to build a virtual plant support organization that is seamlessly connected through advanced II\&C technologies. A virtual support organization is a combination of a NPP's own organization plus external organizations to which have been delegated direct support roles in operating and maintaining the plant. The term "virtual" implies that the organization is interconnected through a seamless digital architecture for data exchange, communications, and collaboration as opposed to having to be located onsite. This allows the NPP to tap into far greater resources and expertise than can be practically maintained at the NPP facility.

In general, this is an extension of the concept introduced with the advanced centralized online monitoring facility. It will allow specialty organizations, both within the utility and outside companies, to assume the responsibilities of a portion of the ongoing operations and support of the plants. Some examples of these types of operational and support roles would be as follows:

- An onsite demineralized water production plant could be owned and remotely operated by the original equipment manufacturer of the equipment, with minimum onsite support for hands-on maintenance.

- Condition monitoring could be performed by remote experts in vibration analysis, oil sample analysis, and loose parts monitoring analysis rather than having to maintain this specialized expertise within the general plant engineering staff.

- II\&C system monitoring and diagnostics could be performed by the manufacturers of the system, with a small onsite support staff to replace circuit boards once faults were isolated to the specific component.

- Radiation monitoring could be performed remotely using data-linked monitors and video cameras to observe workers in the radiation control zones.

- Chemistry analysis could be performed remotely using in-line instruments that take either batch or continuous samples.

- System test results could be reviewed and validated by a remote engineering staff that directly receives data from system performance tests.

- Portions of the plant support systems could be monitored, or even remotely operated, by a centralized staff. This would exclude safety-related systems and those systems that are major transient initiators such as the main feedwater system. However, there could be a significant reduction in burden on the control room for having many of the auxiliary systems under centralized operations. Examples would include auxiliary steam systems, hydrogen purification skids, oil purification skids, chemistry systems, and radwaste systems.

A virtual support organization would be a significant step toward the concept of integrated operations for the LWR fleet. The workforce required to conduct the plant work activities could be appreciably 
reduced in number, resulting in a secondary proportional reduction in organizational support functions (e.g., number of supervisors, human resources specialists, trainers, and recruiters). This concept would move the NPP operating model away from a labor-centric model to a technology-centric model. This could greatly enhance LWR fleet cost competitiveness because technology is generally a declining cost factor while labor is always an increasing cost factor. By purchasing only the services a plant needs, rather than maintaining a full-time staff for all technical functions, considerable cost savings could be achieved.

The following are examples of specific benefits of a virtual organization:

- Specialty organizations could attract and maintain experts much more effectively than could individual operating companies. The experience base of a specialty organization would be much deeper in that they would see phenomena and problems across the entire industry and not just a few plants.

- The monitoring capabilities of a third party (or even a fleet-centralized service) would be more uniform over time because it would not depend on the work schedules of one or two on-site experts.

- The NPP would be relieved of continual hiring, transferring, and training of replacement workers for these positions as inevitable attrition occurs.

- In the case of having some plant auxiliary systems monitored or remotely operated by support organizations, there would be a net safety benefit in allowing the control room and on-site operations staff to concentrate more on safety-significant portions of the plant.

This project will develop the underlying technologies that will enable development of a virtual support organization. The information structure to do this will be built into the digital architecture for a highly automated plant (see Section 4.2.1). Human and organizational factors will be incorporated into a technical report for integrating external organizations directly into line functions of the plant organization, as enabled by data sharing, communications (voice and video), and collaboration technologies that will compose a seamless work environment. These technologies will first be created and studied in the HSSL, where it will be possible to evaluate the dynamics of a remote organization conducting key plant support functions. An open standard for data sharing technology will be demonstrated for this architecture to promote a fair and competitive market for external services.

The project will identify which plant functions are priorities for outsourcing using the virtual plant support organization concept. The project will work with a host utility NPP to implement some trial instances of remote support. Evaluations of these initial examples will be the basis for a technical report on how to implement the virtual plant support organization on an expanded scale.

\footnotetext{
Pilot Project No: 4.2 Title: Virtual Plant Support Organization

Purpose: $\quad$ To address long-term plant staffing challenges and technical expertise shortages by developing the concept of a virtual plant support organization built on a technology platform that enables real-time integrated operations.

Scope: Develop an open standard for the digital architecture and the communications and collaboration technology platform that would enable an external organization to provide real-time operational and support services to the plant, prototype this technology platform in HSSL, determine which plant support functions are suitable for outsourcing under this concept, work with a host utility NPP in trial implementation of a limited virtual plant support organization, and develop a
} 
Deliverables:

Schedule: Host Utility: technical report for expanded implementation.

- (2018) For chemistry activities, conduct a study and publish a technical report on opportunities to provide remote services from centralized or third-party service providers, based on advanced real-time communication and collaboration technologies built on the digital architecture for a highly automated plant. Demonstrate representative remote activities with a host NPP.

- (2019) For maintenance activities, conduct a study and publish a technical report on opportunities to provide remote services from centralized or third-party service providers, based on advanced real-time communication and collaboration technologies built on the digital architecture for a highly automated plant. Demonstrate representative remote activities with a host NPP.

- (2020) For radiation protection activities, conduct a study and publish a technical report on opportunities to provide remote services from centralized or third-party service providers, based on advanced real-time communication and collaboration technologies built on the digital architecture for a highly automated plant. Demonstrate representative remote activities with a host NPP.

- (2021) Publish human and organizational factors studies and a technical report for a virtual plant support organization technology platform consisting of data sharing, communications (voice and video), and collaboration technologies that will compose a seamless work environment for a geographically dispersed NPP support organization.

FY 2018 to FY 2021
Cost:
TBD
Not started

TBD

\subsubsection{Management Decision Support Center}

Operational decision-making is a foundational element of safe nuclear operations. Processes for decision-making are formal and rigorous in all levels of the nuclear utility management structure. Nuclear managers are required to be technically competent and actively engaged in the issues facing their nuclear facilities such that they can effectively participate and be held accountable in the ongoing operational decisions.

Plant functional managers typically serve in both standing and special-purpose decision review boards that are formally invoked for significant plant issues. One such example required by a nuclear utility's Quality Assurance Program is the Plant Operational Review Committee, or a similarly titled group. The Plant Operational Review Committee is required by the licensing basis to have a broad range of technical expertise and competence in plant issues and is required to review a number of different types of plant issues and provide a recommendation to the plant manager on the advisability of recommended actions. There are similar groups that are appointed for other special purposes, such as to provide oversight of operational decision-making and risk management.

On a more informal basis, the plant management typically meets early every weekday morning to review current operational concerns and to ensure that all work plans are well-coordinated and meet risk management expectations. This is yet another forum for operational decision-making on the adequacy of the daily work plan and the response to emergent problems. A similar daily management meeting is held during outages to address the issues arising from the ongoing work.

Another category of management decision-making pertains to the emergency response organization. These are the decisions on how to classify events, mitigate the consequences of events, and provide protective actions in a nuclear emergency. These deliberations occur in the dedicated emergency response 
facilities, namely the Technical Support Center, the Operations Support Center, and the Emergency Operations Facility, the latter of which is offsite and sometimes serves the entire fleet.

What all of these decision-making processes and forums have in common is the critical need for accurate and timely information on which to base the operational decisions made by the plant managers. There are many examples in the industry where a plant management team made decision errors, not due to lack of competence among the managers, but simply because the managers did not have an accurate picture of what actually was happening in the plant and so did not fully appreciate the consequences of their decision(s).

To improve understanding in these settings, technology will be introduced that provides a better visual picture of the situation, such as real-time video taken at the location of the problem. In other cases, where pictures of the problem are not practical (e.g., core power imbalances due to dropped rods), simulations and symbolic presentations of the issues will be developed.

The concept of a management decision support center would address these needs by employing advanced digital technologies to improve the quality of operational decision-making. It would be a dedicated facility where all regular and special management oversight meetings would be held. (The exception to this would be the emergency response facilities, which have to be maintained in a state of readiness. The technologies of the management decision support center also would be separately implemented in the emergency response facilities.) The following are examples of the types of technologies that would be implemented:

- Multiple large screen displays that can handle many different data sources at a time

- Video streaming capability directly onto any of the large displays, including video conferencing

- Access to all data and screens from the plant computer and Safety Parameter Display System

- Real-time images of the main control room control boards, with real-time data refreshing

- Ability to run the plant simulator for the scenario of concern

- Real-time plant risk assessments and defense-in-depth measures

- Severe accident management guidelines and extensive damage mitigation guidelines

- Access to all plant process applications (technical specification logs, operator logs, schedules, work orders, and test results)

- Access to all plant documentation through the electronic document management system

- Access to NPP field worker mobile technologies for streaming of activity-related information Access to outside data sources such as weather, media, regulatory information, and external databases

- Decision support and resource allocation software

- General presentation capabilities.

This concept also could be applied at the fleet level where decisions involve multiple NPPs or involve decision processes between the plant and fleet-level management. Collaboration tools would allow information views to be pushed to other participating centers so that there would be a shared context for discussions and decisions.

Obviously, this project will build on many of the capabilities that are developed in other pilot projects, but will focus them on the unique aspects of nuclear management decision-making. The project will team with a host utility to identify the needed capabilities for such a facility. The digital architecture pilot project will address the information requirements of this facility. The facility will be prototyped in the HSSL to demonstrate and evaluate the various capabilities. Human factors studies will be a key part of the evaluation to ensure the information presentations are well designed for comprehension and do not 
result in information-overload. Protocols for managing the information resources during a management decision-making meeting will also be developed. Following the laboratory demonstration, a management decision support center will be implemented at the host utility NPP for trial usage. Field studies will assess any needed corrections to the concept or implementation. A technical report will be developed for industry-wide implementation.

Pilot Project No: 4.3 Title: Management Decision Support Center

Purpose: $\quad$ To improve the quality of operational decision-making by developing a dedicated facility that is equipped with advanced digital technology capable of real-time display and integration of all information that is pertinent to the decisions.

Scope: Identify the needs and sources of information for operational decision-making, develop the digital architecture to accommodate these sources, prototype a management decision support center in the HSSL and conduct relevant technical and human factors studies, develop protocols for managing the information sources and displays during a decision session, implement a decision support center at a host utility NPP, and develop a technical report for industry-wide implementation.

Deliverables: - (2019) Develop and demonstrate (in the HSSL) concepts for a management decision support center that incorporates advanced communication, collaboration, and display technologies to provide enhanced situational awareness and contingency analysis.

- (2020) Develop and demonstrate (in the HSSL) concepts for advanced emergency response facilities that incorporate advanced communication, collaboration, and display technologies to provide enhanced situational awareness and real-time coordination with the control room, other emergency response facilities, field teams, the Nuclear Regulatory Commission, and other emergency response agencies.

- (2021) Publish human and organizational factors studies and a technical report for a management decision support center consisting of advanced digital display and decision-support technologies, thereby enhancing nuclear safety margin, asset protection, regulatory performance, and production success.
Schedule:
FY 2019 to FY 2021
Cost:
TBD
Host Utility: $\quad$ TBD
Project Status: $\quad$ Not started

\subsection{Outage Safety and Efficiency}

Nuclear plant refueling outages are perhaps the most challenging periods of time in the ongoing operations of the facilities. There are usually more than 10,000 activities to be accomplished in a typical duration of 20 to 30 days. Enormous expenses are incurred related to the cost of the outage work and plant modifications, including supplemental workforce, which sometimes totals over 1,000 contractors. Schedule delays drive these costs up proportionately. In addition, the utility incurs additional costs for replacement power for the time the nuclear plant is out of service.

Nuclear safety is a particular challenge during outages due to the degraded configurations the plant is sometimes in to accommodate work on the systems. In fact, the majority of the annual planned incremental core damage frequency of the plant's probabilistic risk assessment is incurred during outages. There also is a special regulatory risk because the plants are challenged to meet shutdown technical specifications and "maintenance-rule" risk mitigation measures. 
Finally, an outage is especially challenging from the standpoint of industrial safety in that the risk of plant workers getting hurt is highly elevated due to the types of activities that are conducted.

Managing nuclear outages in a safe and efficient manner is a very difficult task. In fact, the early history of refueling outages was one of significant cost and schedule overruns, as well as troubling nuclear safety challenges. This led utilities to develop formal outage organizations dedicated to planning and executing both their refueling and forced outages. They also built outage control centers that co-locate the activity managers for all of the major site organizations so that they can closely coordinate their activities. In addition, the utilities maintain a number of other work execution centers that control critical elements of the work, such as safety tagging for system and component isolations, nuclear risk management coordinators, and similar functions needed to address other constraints on how the outage is conducted. As a result of these practices, today's outage performance today is substantially improved from what it once was. Outage cost and durations are considerably lower than in the past. Nuclear safety also is greatly improved. However, there remain some significant opportunities and challenges for the industry as follows:

- Further reducing the duration of refueling outages remains the largest opportunity to improve plant capacity factors and increase the economic value of the facilities.

- In spite of impressive gains in shutdown safety, there are still too many serious safety challenges, such as loss of residual heat removal and unintended additions of positive reactivity.

- Regulatory violations continue to occur due to subtle configuration control issues that result from unintended interactions between different work activities.

In spite of the impressive organizations and facilities that have been implemented to improve outage performance, outage management generally relies on very basic technology of radios, telephones, and stand-alone computer applications. There is some growing usage of remote video for point applications and activity monitoring. Utilities have not made widespread usage of mobile technologies for controlling and communicating with field work, collaboration technologies for coordinating issues across the broad organization, and advanced configuration management technologies to improve safety and regulatory performance.

There is no question that improved technology for outage management would provide a step change in a utility's ability to conduct outages in a safe and efficient manner. DOE is uniquely positioned with its HSSL, human and organizational factors expertise, and knowledge of NPP outage practices to demonstrate and provide guidance for application of advanced digital technologies in order to achieve substantial economic value and nuclear safety improvement through outage performance improvement.

\subsubsection{Advanced Outage Coordination}

The amount of information that must be processed by the outage control center (OCC) is staggering. OCC managers must obtain the status of ongoing work activities, project the expected progress of the activities, and then adjust near-term activities for gains or losses in the overall schedule. Accurate work status is difficult to obtain due to communication barriers with field work, particularly in hard-to-access areas of the plant. Also, work status sometimes reflects an overly optimistic outlook by those performing the work. (Figure 10) The term "real-time truth" is used by some

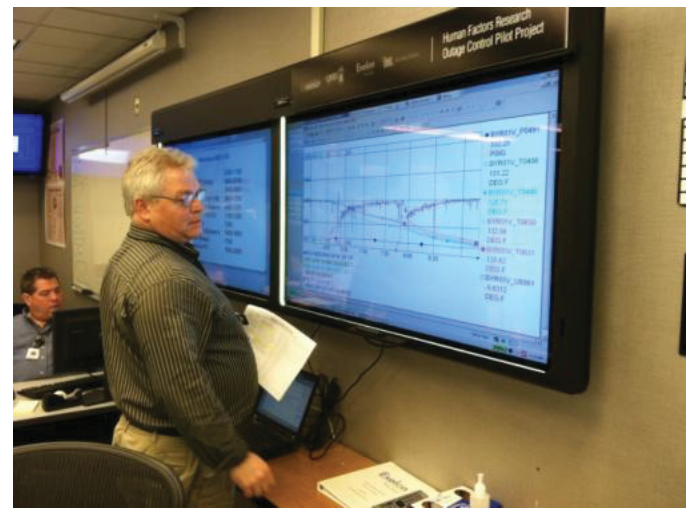

Figure 10 Remote collaboration technology in use during a refueling outage at Byron Nuclear Station to obtain accurate work status 
outage managers to refer to this need for the true status of the work-in-progress.

The outage managers also deal with a continual stream of emergent issues, caused by deviations in the expected progress of the planned activities, or new problems that arise (e.g., equipment failures, unexpected interactions between work activities, and other unanticipated outage conditions). The outage managers have to quickly assess the impact of the new issues on the overall outage plan and schedule, consult with knowledgeable individuals on the nature of the problems and possible solution options, determine the solution that results in the least impact on the overall outage objectives, and communicate changes to plans and schedules to the affected activity managers.

These typical outage management activities rely on telephone calls, impromptu meetings, "white board" solution sessions, manual transcribing of agreed-upon changes into a number of work process systems (e.g., work orders, schedules, risk management, radiation work permits, safety tagging, and warehouse parts), and communication throughout the organization using outage status meetings, email, and direct telephone contact. This process is repeated tens of times per shift for the duration of the outage.

This project will assess the needs of outage management and identify technologies that will greatly improve communications, coordination, and collaboration activities that are needed to minimize the impact of challenges to the outage plan and schedule. It will focus on capabilities that facilitate natural human interaction, while ensuring a high degree of situational awareness and shared understanding. Further, the technologies will be integrated in a way that minimizes the effort to keep all work management systems synchronized with changing plans.

The project will also develop dynamic interfaces for information coming from mobile field workers, the plant control and information systems, and the fluid information developed in the OCC and other control centers as the greater organization develops solutions to emergent outage problems (Figure 11). Human factors assessments of the use of the technology will be conducted to validate that the benefits are actually obtained and new problems are not introduced by technology usage. The results of the project will be a demonstration of the integrated technologies and a technical report for industry-wide implementation.

This pilot project was conducted with Exelon Nuclear (Byron

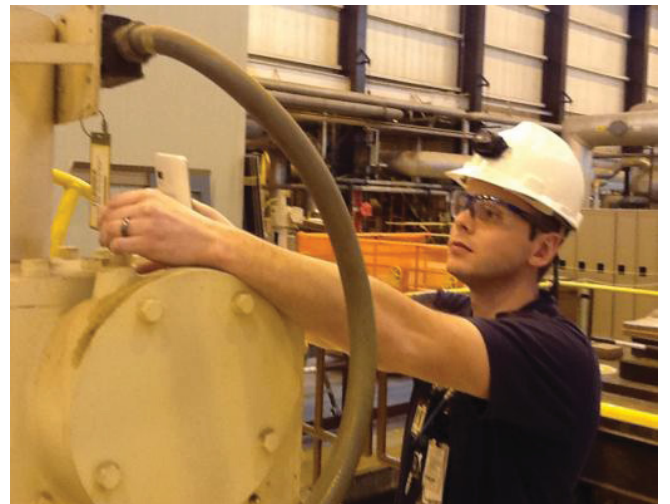

Figure 11 Operator uses hand-held technology to verify correct component identification at Byron Nuclear Station. Nuclear Station) serving as the host utility. It was completed at the end of FY 2012.

\section{Pilot Project No： $5.1 \quad$ Title: Advanced Outage Coordination}

Purpose:

Scope:

Deliverables:
To improve outage performance by introducing technologies that facilitate communications, coordination, and collaboration in obtaining critical activity status, managing the enormous flow of information through the OCC, and resolving emergent problems in an efficient and effective manner.

Determine technology needs for outage coordination improvement, prototype technologies, implement technologies in the control centers of a host utility NPP for use in refueling outages, conduct associated technical and human factors studies, and develop a technical report for industry implementation.

- (2012) Publish a technical report on strategies for nuclear plant outage work status capabilities that facilitate communications, coordination, and collaboration in obtaining accurate outage activity status and managing the flow of information 
through the OCC. (Complete)

- (2012) Publish a technical report on resolving emergent issues during nuclear plant outages, enabling the resolution of emergent problems in an efficient and effective manner, resulting in improved work efficiencies, production success, and nuclear safety margins. (Complete)

$\begin{array}{llll}\text { Schedule: } & \text { FY 2010 to FY 2012 } & \text { Cost: } & \text { (on file) } \\ \text { Host Utility: } & \text { Exelon Nuclear } & \text { Status } & \text { Complete }\end{array}$

\subsubsection{Advanced Outage Control Center}

The OCC is the central command and control point for executing NPP outages. It is staffed 24/7 during outages and accommodates 15 to 20 managers and coordinators from the site and fleet organizations supporting the outage. These positions are typically grouped according to organization and informally interact with one another to coordinate their specific work activities and problem resolutions. Various types of meetings are held on a regular schedule each shift to communicate outage status, share information on upcoming activities and emergent issues, and verify with each organization that they are prepared to support the upcoming activities.

Many of these organizations represented in the OCC also maintain functional support centers at their own site locations to provide the specific services they conduct. For example, radiation protection operates a center to develop and assign radiation work permits and authorize and brief workers who are to enter radiation control zones. For example, Radiation Protection typically operates a center to develop and assign radiation work permits and authorize and brief workers who enter radiation control zones. Operations maintains centers to prepare safety tagouts, conduct risk assessments, and track plant configuration changes. There are similar support functions set up in the other organizations such as Chemistry and Engineering. One of the key tasks of the OCC coordinators is to ensure these functional centers are aware of changing needs as determined in the OCC and are responding accordingly. The coordinators typically have to leave their positions in the OCC several times a shift to attend coordination meetings back in their functional support centers and are not available for coordination with other OCC positions during those times.

In consideration of all of these coordinating activities, there is a significant need for advanced technologies to facilitate the information flow into, across, and out of the OCC. These will include technologies to conduct interactive meetings with participants in other locations, including on the job sites in the plant. These technologies will allow the entire OCC to share information as it develops in response to an emergent issue. They will allow the OCC coordinators to meet electronically with their respective functional support centers without having to leave the OCC. They will update all affected work management systems as decisions were made in how to resolve a problem. Finally, they will provide the overall outage managers with the true status on the progress of work and the implementation status of outage plan changes from the OCC managers and coordinators.

These technologies will be integrated into an advanced OCC specifically designed to accommodate and maximize the value of the technologies, while preserving the features of the existing OCCs that facilitate human interaction. Where appropriate, these features will be extended into the workspaces of the functional support centers to accommodate their interface with the OCC.

This project will integrate these technologies into a prototype advanced OCC using HSSL. It will be set up to facilitate the display and processing of information and collaboration within the OCC or with parties remote to the OCC. This prototype facility will be used to simulate outage coordination functions so the technology and associated human factors can be evaluated. It will test interaction with all required sources of information needed by the OCC, including mobile technology operated by NPP field workers, 
plant control and information systems, other control and functional support centers, and information sources external to the plant. As a final product, a technical report will be developed for industry wide implementation of the advanced OCC.

\section{Pilot Project No: $\quad 5.2$ Title: Advanced Outage Control Center}

Purpose: $\quad$ To improve management of NPP outages through development of an advanced OCC that is specifically designed to maximize the usefulness of communication and collaboration technologies for outage coordination and problem resolution activities.

Scope: Identify the required communication and collaboration technologies, develop a prototype advanced OCC in the HSSL, conduct associated technical and human factors evaluations, and develop a technical report for industry implementation.

Deliverables: - (2013) Develop technologies for an advanced OCC that improves outage coordination, problem resolution, and outage risk management.

- (2014) Develop human factors studies and publish a technical report for an advanced OCC that is specifically designed to maximize the usefulness of communication and collaboration technologies for outage coordination, problem resolution, and outage risk management.
Schedule:
FY 2013 to FY 2014
Cost:
TBD
Host Utility:
Arizona Public Service
Project Status:
In-Progress

\subsubsection{Outage Risk Management Improvement}

Significant efforts are expended to manage the nuclear risk of an outage. The utilities conduct preoutage risk assessments, based on a very detailed review of the outage schedule, to identify where combinations of outage work and equipment out-of-service could result in degraded conditions with respect to nuclear safety or regulatory compliance. Probabilistic risk assessment studies are conducted to quantify the incremental core damage frequency as a result of the outage activities and system unavailability. These studies are usually presented to site and fleet management, the site Plant Operational Review Committee, and the NPP's independent Nuclear Safety Review Board for concurrence that the outage is planned safely and that reasonable measures have been taken to reduce the added risk of conducting the outage.

During the outage, the plant configuration is monitored continuously to ensure that it conforms to the approved safety plan. Deviations must be assessed and approved by management committees and, in some cases, the Plant Operational Review Committee. In virtually all outage meetings and job briefings, the current nuclear safety status of the plant is communicated, including information on the specific equipment that is being relied on to meet the requirements of the nuclear safety plan. In addition, Operations and the outage organization implement several layers of physical and administrative barriers to prevent unintended interaction with the systems and equipment credited for nuclear safety.

In spite of all these efforts, nuclear safety challenges still occur too frequently. While some of these are due to failure of equipment being relied upon for safety, the majority occur due to human error. These typically involve some form of interaction between work activities and plant configuration changes. Some of them are very subtle and are extremely challenging to detect in advance. Nevertheless, they are not acceptable and represent clear opportunities to improve nuclear safety during outages.

This pilot project will investigate methods to improve real-time plant risk management and configuration control during outages as a function of work activities and plant system alignments. It will 
develop a means for combining actual plant status information with intended component manipulations embedded in procedures and work packages that are underway. This information will, in turn, be compared to design information (e.g., piping and instrumentation diagrams and one-line diagrams) to identify the set of possible interactions. Finally, the information will consider the technical specifications (and other licensing basis requirements), probabilistic risk assessment information (e.g., accident precursors), and ongoing risk mitigation plans to report possible interactions of concern. The project will demonstrate the techniques and underlying technologies to perform this type of outage safety analysis. The project deliverables will include the new technologies and the guidelines for integrating them into outage preparation and execution activities.

\section{Pilot Project No： $\quad 5.3 \quad$ Title: $\quad$ Outage Risk Management Improvement}

Purpose:

Scope:

Deliverables:

\section{Schedule:}

Host Utility:
To improve nuclear safety during outages by detecting configuration control problems caused by work activity interactions with changing system alignments.

Develop and demonstrate new technology to detect configuration control interactions and develop guidelines for implementing the technology.

- (2015) Develop and demonstrate (in the HSSL) technologies for detecting interactions between plant status (configuration) states and concurrent component manipulations directed by in-use procedures, in consideration of regulatory requirements, technical specifications, and risk management requirements (defense-in-depth).

- (2016) Develop and demonstrate (in the HSSL) technologies to detect undesired system configurations based on concurrent work activities (e.g., inadvertent drain paths and interaction of clearance boundaries).

- (2017) Develop a real-time outage risk management strategy and publish a technical report to improve nuclear safety during outages by detecting configuration control problems caused by work activity interactions with changing system alignments.

FY 2015 to FY 2017

Cost:

Project Status:

TBD

Not started

\subsection{Centralized On-Line Monitoring and Information Integration}

As NPP systems begin to be operated during periods longer than originally licensed, the need arises for more and better types of monitoring of material and component performance. This includes the need to move from periodic, manual assessments and surveillances of physical components and structures to centralized online condition monitoring. This is an important transformational step in the management of NPPs. It enables real-time assessment and monitoring of physical systems and better management of components based on their performance. It also provides the ability to gather substantially more data through automated means and to analyze and trend performance using new methods to make more informed decisions concerning long-term plant asset management. Of particular importance will be the capability to determine the remaining useful life (RUL) of a component to justify its continued operation over an extended plant life.

The foundation for monitoring in the U.S. nuclear industry is built around signal processing techniques and advanced pattern recognition (APR) programs that are technically mature and commercially supported. The application of this technology is in the early stages of implementation in the nuclear power industry. The implementation rate is slow due to the necessary level of investment and 
infrastructure development required to integrate monitoring programs within the operating and business environment.

APR provides highly sensitive anomaly detection of current condition or behavior for targeted components. Much of the value of online monitoring comes from early warning of imminent component failures. Commercial APR products rely on the continuous input of well-correlated plant data, typically available only for active components, to provide this early warning. After the initial warning, an investigative review identifies the actual failure mode (fault) and cause, and then suggests appropriate corrective actions. The investigative review can involve plant staff, consultants, and field experts in predictive maintenance. In these cases, the diagnostic process can be manually intensive and can consume available warning time and extend damaging operating conditions. While APR systems are effective at identifying equipment operating in conditions which may shorten the equipment's remaining life, APR technology is limited to identifying operating data values that are "not normal" in comparison to a historical baseline. Commercially available APR products cannot perform the next essential step of diagnosing the underlying cause for the abnormal data values. This diagnosis step relies entirely on a staff of highly trained specialists to troubleshoot and diagnose the underlying problem and to recommend a corrective action response. Furthermore, the remaining useful life of the monitored asset cannot be accurately determined by APR technology. In addition, there are long term failure modes that are not detectable with APR technology.

Hence, current APR technology has limited capability in providing directly useful information to life cycle management and long term asset management. Commercially available APR technologies in their current form are unable to detect long term failure modes; thereby restricting their applicability for the purpose of long term monitoring and management of nuclear assets, and in particular for passive assets evaluated on an intermittent basis using nondestructive evaluation (NDE) measurement techniques.

The development of diagnostic and prognostic capabilities would provide an automated means of directly identifying equipment condition from the signature of the initial warning. This would support analysis of longer term component behavior, related risk, and remaining useful life. Further, it would provide verification of asset condition as evidence of design qualification and economic viability. This will enable early detection of degradation conditions that can be addressed before they significantly contribute to life limiting damage. This early detection of degradation is one of the more significant factors in extending component lifetime. A more timely response to the causes of degradation can also significantly improve nuclear safety and prevent collateral damage to other nearby components and structures. Finally, these new capabilities will reduce costs for manual diagnostic work.

EPRI is active in various research and demonstration projects for maturing prognostic and health management (PHM) technology to help assure the long term, reliable operation of the nation's fleet of nuclear power plants. EPRI's current research includes developing a Fleet-wide Prognostic and Health Management (FW-PHM) Software Suite software solution designed for compatibility with existing nuclear power plant troubleshooting and asset management.

The open-architecture FW-PHM software, as shown in Figure 7, has four main components: the Diagnostic Advisor, which identifies possible faults by comparing asset fault signatures with operating data; the Asset Fault Signature Database, which organizes asset fault signatures collected from across the industry; the Remaining Life Advisor, which estimates how long an aging or faulty asset will continue to provide reliable service; and the Remaining Useful Life Signature Database, which organizes asset remaining life signatures collected from across the industry.

No commercial products are available that perform the full functionality intended for the FW-PHM Suite. The Suite's four primary functional modules are built on a common reference database of diagnostic and life models for power generation assets. 


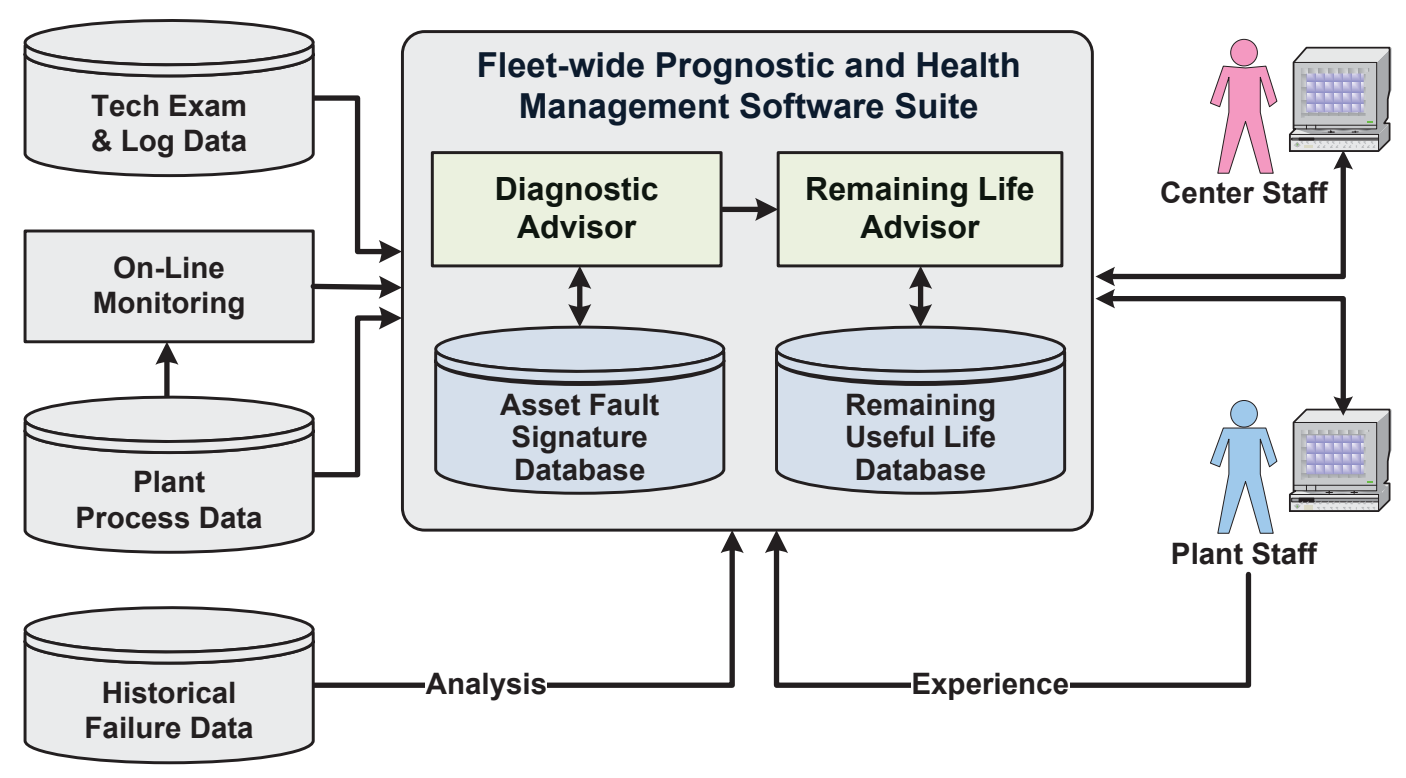

Figure 12 Fleet-wide Prognostics and Health Management in an Online Monitoring Environment (diagram courtesy of EPRI)

The FW-PHM Software Suite includes specific knowledge capture capabilities that learn diagnostic and prognostic information from in-service experience in industry-deployed applications and structure this information for pooling and analysis by EPRI, government and industry experts. The information acquired by this means can be used by these experts in combination with EPRI's extensive library of reference documents to create and maintain an industry-wide database of verified diagnostic and RUL models for nuclear power plant assets.

The FW-PHM Software Suite software is, at present, a research grade product available to EPRI members that have sponsored its development. The Suite's databases are, at present, populated with limited knowledge derived from various preliminary pilot applications involving a small set of nuclear and fossil plant equipment and from technology demonstration projects. EPRI has identified the long term need for on-going research to develop the diagnostic and remaining life prediction models for power generation assets that will populate this industry-shared database of models; as no one utility or vendor alone could compose such a comprehensive model reference collection. In fact, a collaboration of the industry, EPRI, the national laboratories, and universities is needed to accomplish the research and development effort to identify a model or a set of models required (for a particular component) to create verified diagnostic and remaining useful life models to support PHM processes and provide accurate, substantiated input to life cycle management and long term asset management capabilities. In particular, diagnostic and remaining useful life models for passive nuclear assets require significant future research, which should include formulating the resulting diagnostic and life models and their basis information for inclusion in the FW-PHM Software Suite's knowledge database.

A gap exists between the current state of technology development and the effective application of diagnostics and prognostics to nuclear plant assets. To address this gap, the following research tasks have been defined.

1. Complete the development of a monitoring infrastructure at the operating and management levels of the nuclear power industry. 
2. Develop an organizational structure that defines the contributing research organizations, their roles, resource availability, and utility hosts. This includes EPRI, national laboratories, universities, utilities, and technology developers.

3. Continue the R\&D of the diagnostics and prognostics technology for adaption to the nuclear power industry.

4. Develop the component specific models, analytical methods and the supporting data requirements needed to support diagnostics and prognostics analysis.

5. Obtain access to the real physical assets in service in a nuclear power plant and determine the critical measurements needed to support the analysis.

6. Develop additional monitoring methods such as transient analysis to support RUL analysis.

7. Identify environmental conditions detrimental to aging mechanisms including fatigue monitoring and assessment.

8. Identify component specific failure and aging mechanisms/precursors.

9. Identify measurement and sensor requirements to support analytical methods.

An effective means to accomplish portions of the above research tasks is through the development of pilot projects. These projects will be structured around a narrowly defined set of objectives to accomplish specific tasks that require access to real time plant assets and operational data. There are significant limitations to bench-top modeling and scaled down component behavior analysis in the progression of technologies from proof of concept to real world component applications. The utilization of real physical components and operational data is required to develop the technologies beyond the lab. The process of applications engineering and research is not within the capabilities of the utilities, or the engineering staff at nuclear power plants. What is required to support the needed research are host utilities having the initiative and resources to provide access to major components while not detracting from staff support of on-going plant operations. This has been and continues to be a significant limitation in the R\&D process. Given access to these assets, research efforts can be undertaken that will address the above tasks.

EPRI will provide the lead role in developing on-line monitoring capabilities through their continued development and support of the FW-PHM Software Suite software, in addition to their other OLM research activities. DOE will support EPRI by conducting the pilot projects to develop the diagnostic and prognostic analytical framework for representative active and passive component/structures whose extended life supports LWR sustainability.

In regard to the "centralized" aspect of the project concept, it is expected that utilities will find that a central monitoring function within their nuclear fleet will be the most efficient way to implement this technology. Indeed, this has been the practice of some of the early adopters of the APR technology. This concept work for centralized monitoring will be accomplished through Pilot Project 4.1, Advanced Online Monitoring Center, as described in Section 4.4.1. DOE will also serve the role of integrating the OLM information into the overall digital information architecture such that it will provide information beneficial to other plant activities.

\subsubsection{On-Line Monitoring of Active Components}

The pilot project will perform research and working with industry partners to identify and characterize critical faults that lead to catastrophic failures in Emergency Diesel Generators (EDGs) and Generator Step Up (GSU) Transformers. DOE will formulate this information in the fault signature framework used by the FW-PHM Software Suite prior to implementing the fault signatures in FW-PHM and thus populating the asset fault signature database. The objective will be to develop the diagnostic and prognostic analysis framework for these components, including the ability to predict the RUL. These 
capabilities will enable industry to implement on-line monitoring for these components and will establish the methodology for industry to extend the concept to other active plant components where aging and degradation mechanisms must be managed for extended life.

The pilot project will work with industrial partners to evaluate the effectiveness of the fault signatures. Additional work will be performed to identify prognostic models applicable to the selected components. This will be accomplished by consulting with subject matter experts from industry, national laboratories, and universities in addition to performing literature searches. The prognostic models will be implemented in a form compatible with the interfaces of the FW-PHM Software Software, and will then be used to populate the RUL database.

For each of these component types, a technical report will be published that describes the technical basis and analysis framework to enable on-line monitoring for these components. These technical reports, along with the results and experience from the pilot projects, will be used to develop guidelines for utilities to implement centralized on-line monitoring and information integration for the components/structures important to plant life extension. The reports will also include the identification of additional sensor development and monitoring capabilities needed to enhance the monitoring capabilities for these components. All implemented signatures will be delivered to EPRI for evaluation and possible inclusion in the master database that is shared with EPRI members.

Pilot Project No： $6.1 \quad$ Title: On-Line Monitoring of Active Components

Purpose: $\quad$ To extend the life of large active plant components (EDGs and GSUs) by detecting long-term aging and degradation mechanisms, determining the underlying causes, and predicted remaining useful life of the components.

Scope: Develop and demonstrate the diagnostic and prognostic analysis framework for the selected components.

Deliverables: - (2012) Publish an interim technical report on the online monitoring technical basis and analysis framework for large power transformers.

- (2013) Publish a technical report on measures, sensors, algorithms, and methods for monitoring active aging and degradation phenomena for large power transformers, including the diagnostic and prognostic analysis framework to support utility implementation of online monitoring for the component type.

- (2014) Publish a technical report on measures, sensors, algorithms, and methods for monitoring active aging and degradation phenomena for emergency diesel generators, including the diagnostic and prognostic analysis framework to support utility implementation of online monitoring for the component type.

$\begin{array}{llll}\text { Schedule: } & \text { FY 2012 to FY 2014 } & \text { Cost: } & \text { TBD } \\ \text { Host Utility: } & \text { Exelon Nuclear } & \text { Project Status: } & \text { In-Progress } \\ & \text { Duke Energy (Progress) } & & \end{array}$

\subsubsection{On-Line Monitoring of Passive Components/Structures}

A pilot project will be conducted involving two passive components or structures representative of those for which extended life is highly-important to LWR sustainability. The intent is to target a large and economically important plant assets for which the science of managing long-term material degradation is yet unsolved. Candidates identified by the LWRSP Materials Aging and Degradation (MAaD) Pathway include the reactor vessel, fatigue in piping, medium and low voltage cables, and containment concrete base mat. These components and structures were selected based on importance to utility decision-making 
in pursuing additional life extension (beyond 60 years) and the prospects for research success within the timeframe of this project. The MAaD Pathway will be responsible for developing the scientific basis for modeling the degradation mechanisms and determining the types of sensors needed to monitor the degradation. It is possible that new types of sensors will have to be fabricated for this purpose. DOE would devise the signal processing capabilities to convey the sensed parameters to the monitoring system.

The objective of the pilot project will be to develop the diagnostic and prognostic analysis framework for these components, including the ability to predict the RUL. These capabilities will enable industry to implement on-line monitoring for these components and will establish the methodology for industry to extend the concept to other active plant components where aging and degradation mechanisms must be managed for extended life.

Using the EPRI FW-PHM Software Suite, the pilot project will develop the data bases and analytical models needed to process sensor signals to derive parameter estimates of specific aging and performance features and to characterize the state and condition of materials. The data bases include the asset fault signature data base and the RUL data base. The analytical models will be those needed for the diagnostic and RUL advisors.

For each of these component types, a technical report will be published that describes the technical basis and analysis framework to enable on-line monitoring for these components. These technical reports, along with the results and experience from the pilot projects, will be used to develop guidelines for utilities to implement centralized on-line monitoring and information integration for the components/structures important to plant life extension.

The on-line monitoring technologies for the components/structures investigated in this pilot project, along with those from the active on-line monitoring pilot project, are again meant to be representative of the larger class of similar components and structures for which enhanced long-term monitoring is critical to ensuring extended life. The scope of these two pilot projects is sufficient to demonstrate the benefit of the technology and to validate the methodology of building the diagnostic and prognostic analysis framework. Based on this work, the nuclear industry will be able to extend these capabilities to the remaining components and structures of interest. To facilitate this additional work, the guidelines produced in these pilot projects will include a survey of additional sensors, NDE-technologies, and signal processing techniques, to the extent known, that will need to be developed for these other important components/structures.

Pilot Project No: 6.2 Title: On-Line Monitoring of Passive Components/Structures Purpose: To extend the life of large passive plant components/structures by detecting longterm aging and degradation mechanisms, determining the underlying causes, and predicted remaining useful life of the components.

Scope: Develop and demonstrate the diagnostic and prognostic analysis framework for the selected components.

Deliverables: - (2014) Develop diagnostic and prognostic models for large passive plant components based on the information integration framework.

- (2015) Publish a technical report on measures, sensors, algorithms, and methods for monitoring active aging and degradation phenomena for a large passive plant component/structure, involving nondestructive examination-related online monitoring technology development, including the diagnostic and prognostic analysis framework to support utility implementation of online monitoring for the component type.

- (2016) Develop diagnostic and prognostic models for second large passive plant 
components based on the information integration framework.

- (2017) Publish a technical report on measures, sensors, algorithms, and methods for monitoring active aging and degradation phenomena for second large passive plant component structure, involving nondestructive examination-related online monitoring technology development, including the diagnostic and prognostic analysis framework to support utility implementation of online monitoring for the component type.

$\begin{array}{llll}\text { Schedule: } & \text { FY 2014 to FY 2017 } & \text { Cost: } & \text { TBD } \\ \text { Host Utility: } & \text { TBD } & \text { Project Status: } & \text { Not started }\end{array}$

\subsection{Publications of Guidelines}

To ensure appropriate transfer of technology to the nuclear power industry, guidelines documents will be published for each of the areas of enabling capabilities, incorporating the specific technologies and technical reports produced under each of the pilot projects for the respective areas. EPRI has agreed to assume responsibility for development and publication of these guidelines, using their standard methods and utility interfaces to develop the documents and validate them with the nuclear industry. The LWRS Advanced II\&C Pathway will support this effort by providing the relevant information and by participating in the development activities.

The following milestones have been established to produce the guidelines for each area of the enabling capability:

Highly Integrated Control Room (refer to Section 4.1)

- (2016) Publish interim guidelines to implement technologies for a highly integrated control room.

- (2019) Publish revised interim guidelines to implement technologies for a highly integrated control room.

- (2022) Publish final guidelines to implement technologies for a highly integrated control room.

Highly Automated Plant (refer to Section 4.2)

- (2017) Publish interim guidelines to implement technologies for a highly automated plant.

- (2021) Publish final guidelines to implement technologies for a highly automated plant.

Human Performance Improvement for NPP Field Workers (refer to Section 4.3)

- (2014) Publish interim guidelines to implement technologies for human performance improvement for NPP field workers.

- (2016) Publish revised interim guidelines to implement technologies for human performance improvement for NPP field workers.

- (2018) Publish final guidelines to implement technologies for human performance improvement for NPP field workers.

Integrated Operation (refer to Section 4.4)

- (2018) Publish interim guidelines to implement technologies for integrated operations.

- (2020) Publish revised interim guidelines to implement technologies for integrated operations.

- (2022) Publish final guidelines to implement technologies for integrated operations. 
Outage Safety and Efficiency (refer to Section 4.5)

- (2015) Publish interim guidelines to implement technologies for improved outage safety and efficiency.

- (2018) Publish final guidelines to implement technologies for improved outage safety and efficiency.

Centralized Online Monitoring and Information Integration (refer to Section 4.6)

- (2015) Publish interim guidelines to implement technologies for centralized online monitoring and information integration.

- (2018) Publish final guidelines to implement technologies for centralized online monitoring and information integration.

\section{Research and Development Support Functions}

\subsection{Human Systems Simulation Laboratory}

The Department of Energy has developed a reconfigurable control room simulator at the INL, known as the Human System Simulation Laboratory (HSSL), which is used to conduct research in the design and evaluation of advanced NPP control rooms, intelligent operator support systems, and advanced operational concepts. This facility provides the means for science-based studies of new technologies and concepts of operation. It supports human factors research, including human-in-the-loop performance, human-system interfaces, advanced human performance modeling, and analog and digital hybrid control displays. It is also used in the development and evaluation of human-machine interface (HMI) technologies for existing and advanced NPP control rooms and other command and control centers.

The HSSL provides the simulation, visualization, and evaluation capabilities needed for pilot projects involving development and evaluation of advanced technologies for the main control room and other control centers, as depicted in Figure 13. As such, the new technologies will first be staged in HSSL for proof-of-concept prior to demonstration at host utility NPPs. HSSL facilities will be configured in a variety of settings according to the functional context of each type of plant control center.

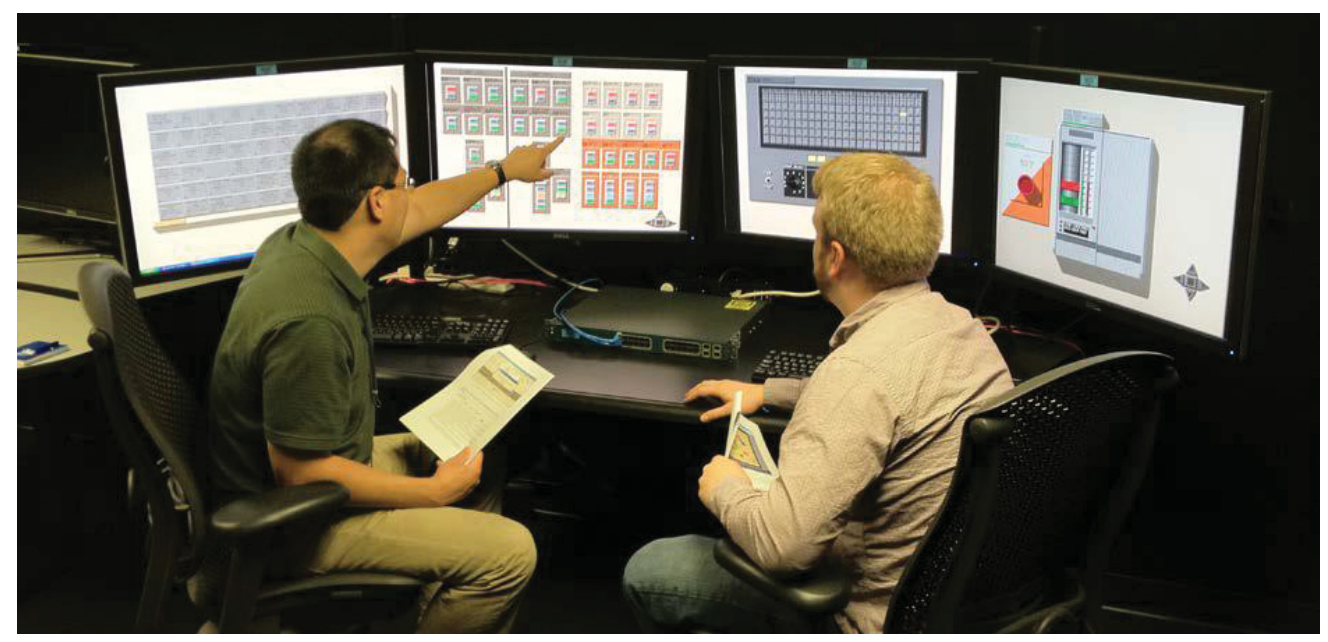

Figure 13 Human Systems Simulation Laboratory used to evaluate advanced control room technologies 
The HSSL has the ability to mimic current control rooms in order to develop and evaluate prototypes of new digital function displays for the existing analog control environment. [7] The HSSL features 15 bench-board-style touch panel control bays (Figure 14). These bays provide a realistic representation of the panels found in the current LWR control rooms and are fully-functional in terms of simulator operation. The touch panels provide operators the ability to manipulate the control panel devices just as they would in the actual control room. The HSSL currently employs two plant-specific simulators from U.S. nuclear utilities and several generic plant-type simulators.

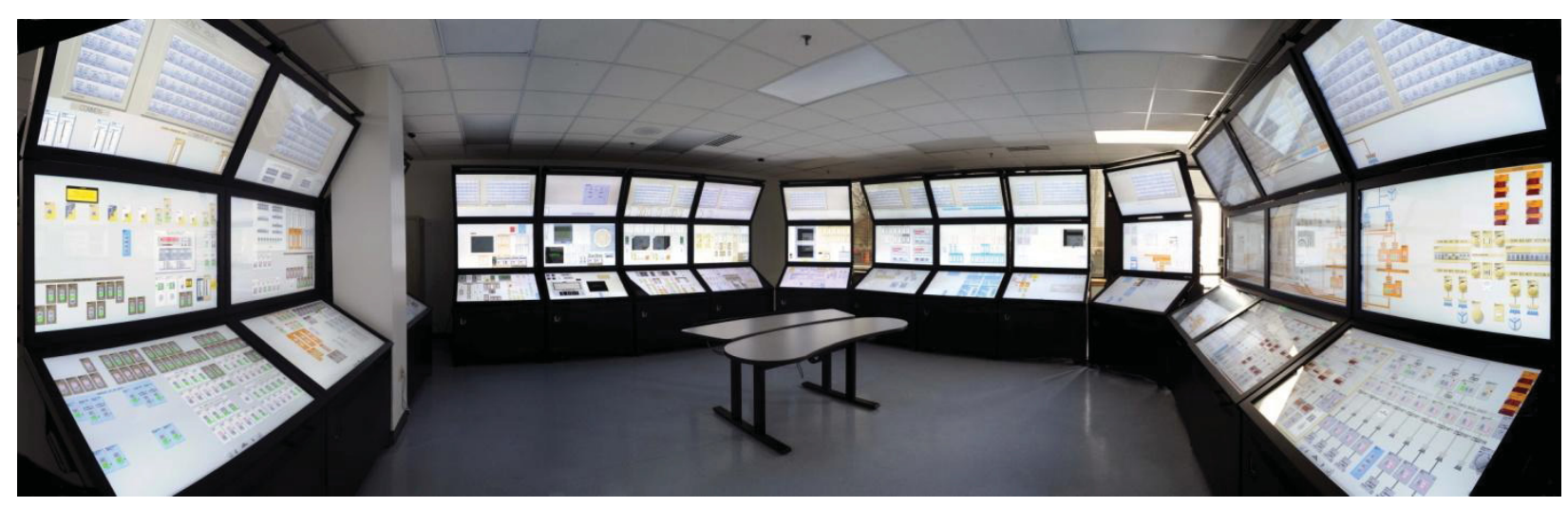

Figure 14 Human Systems Simulation Laboratory configured with bench-board style control bays for realistic simulation of current light water reactor control rooms

As a reconfigurable simulator, it is possible to augment the simulations of the current LWR analog control panels with digital panels that represent future control room upgrades. In this manner, various stages of hybrid control rooms (i.e. those with a mixture of analog and digital HMI) can be staged and studied from a plant control and human factors standpoint. It is also possible to introduce new concepts of operations based on higher levels of plant automation, advanced operator interfaces, and advanced alarm filtering. Because the HSSL is not based on or limited to the systems or technologies of any individual technology vendor, it serves as a neutral test bed for the implementation of new digital control room system technologies and to conduct human-in-the-loop experiments to evaluate the effect on human performance. The HSSL is thus a plant- and technology-independent environment for full-scope as well as part-task evaluation of operator performance in various control room configurations.

In general terms, the HSSL is used for:

1. Human-system performance relationships between the reliability of the operator, the time available to perform an action, performance success criteria, and the influence of the performance characteristics of the plant or system on task performance and outcome(s).

2. Usability of the human systems interface, which includes the effectiveness, efficiency, safety, and reliability with which an operator can perform specific tasks in a specific operational context (e.g., normal or emergency). This includes the effect on human performance with different technologies and different human-system interface configurations.

3. Human performance expressed as physical and cognitive workload under different operational conditions.

4. Situational awareness with a given human-system interface and control configuration under different operational conditions.

5. Crew communication effectiveness with given technologies under different operational conditions.

Human performance with different staffing configurations and a given control room configuration. 
Of specific interest to the modernization of LWR control rooms, the HSSL can be used to conduct the studies required under NUREG-0711. These include workshops on Functional Requirements Analysis, Function Allocation, Task Analysis, and Operational Sequence Analysis. The facility is equally suitable for human performance measurement in other NPP control centers such as an outage control center, a centralized online monitoring center, and emergency response facilities.

The HSSL will continually be upgraded with new capabilities as the research program progresses. A major upgrade will be implemented in 2013, which will enable research on function allocation, staffing, situational awareness, and workload in multiple-unit control rooms. Over time, this will result in an HSSL of highly complex and sophisticated features that will enable realistic modeling of the tasks and functions required of the various plant control centers. It is envisioned that HSSL will be the leading facility in the United States for validation of new operational concepts and technologies for the LWR fleet, thereby ensuring that NPP modernization of II\&C systems is based on demonstrated and validated scientific principles.

\subsection{Cyber Security}

Cyber security is recognized as major concern in implementing advanced digital II\&C technologies in NPPs in view of the considerable security requirements necessary to protect these facilities from potential adversaries, as well as to protect company-proprietary information. The members of the UWG have emphasized the need to ensure that cyber security vulnerabilities are not introduced through the adoption of these advanced digital technologies. Furthermore, their respective companies have internal cyber security policies and regulatory obligations that must be upheld in the implementation of the project technologies.

To this end, a project task has been created to address cyber security issues arising from the technology developments in the pilot projects. DOE has significant expertise and resources that have been developed to address security concerns of the laboratory as well as those of many security-critical U.S. government facilities. Further, DOE's experience in identifying, characterizing and mitigating cyber security threats is highly-applicable to the type of concerns that would be potentially created in technology areas of the pilot projects.

A cyber security plan assessment template will be developed to identify threat vectors potentially introduced by the new technologies. All pilot projects will be given these assessments to identify the issues specific to its technologies, characterize the degree of risk, and recommend effective mitigation measures. The assessments will be discussed individually with the host utilities for the pilot projects as well as the UWG in general.

Responsibility for cyber security resides ultimately with the utilities that implement the technologies from this research program. They must ensure that their own policies and regulatory commitments are adequately addressed. However, the resources, expertise, and experience of INL in cyber security will provide a sound information basis to guide utilities in prudent technology implementation practices and mitigation measures.

\subsection{Quality Assurance}

Quality Assurance (QA) requirements for this research program are defined in INL/EXT-10-19844, Light Water Reactor Sustainability Program Quality Assurance Program Document. This QA Program is based on the requirements American Society of Mechanical Engineers (ASME) NQA-1-2008, 1a-2009, 
"Quality Assurance Requirements for Nuclear Facility Applications." It covers all of the R\&D activities of the program, including any QA requirements applicable to the technologies and related concepts developed and implemented under the pilot projects.

The ultimate responsibility and authority for the QA Program rests with the LWRS Program DOE-NE Federal Director. The LWRS Program Technical Integration Office (TIO) Director has responsibility for the developing, maintaining, and performing oversight of the QA Program. The LWRS Program TIO QA Manager is responsible to the LWRS TIO Director for assisting in the development, issuance, maintenance, and oversight of the QA Program. This includes review and concurrence with the quality requirements specified in each work package associated with a research activity, and the performance of assessments/audits of the research activities.

A specific QA plan is developed for the Work Package associated with each pilot project, employing an assessment matrix that examines each task in the project to classify it according to the type of research it represents: basic, applied, or development. These research types correspond to a graded approach to quality assurance in which the requirements appropriate to each type are applied. Depending on the type of research, requirements imposed include personnel training and qualification, calculations and analysis, document control, records management, work management, design control, modeling and software development and management, test planning and control, data acquisition/collection analysis, procurement document control, and peer review.

The research activities associated with the pilot projects are subject to assessments/audits of QA requirements implementation by the LWRS Program management. Program managers are required to identify and correct problems with the implementation of the QA Program requirements.

\section{Research and Development Cooperation}

A systematic engagement activity is underway with NPP owner/operators, suppliers, industry support organizations, and the NRC. Together, these engagement activities are intended to ensure that R\&D activities focus on issues of challenge and uncertainty for NPP owners and regulators alike, the products of research can be commercialized, and roadblocks to deployment are systematically addressed.

\subsection{Utility Working Group}

The Advanced II\&C Systems Technologies Pathway sponsors a Utility Working Group (UWG) to define and host a series of pilot projects that, together, will enable significant plant performance gains and minimize operating costs in support of the long-term sustainability of the LWR fleet. [8] At this time, the UWG consists of 13 leading U.S. nuclear utilities. Additional membership will be pursued for the UWG with the intent to involve every U.S. nuclear operating fleet in the program.

To achieve the full potential of digital technology to improve performance, the industry must work together to collectively transform the operating/support model, using these same practices of rapidly adopting proven innovations across the industry. The UWG will foster this digital transformation in a manner that reduces technical and financial risk, while providing a pathway to this new operating/support model. It also will cooperate with the major industry support organizations to facilitate all aspects of the transformation. 
The UWG is directly involved in defining the objectives and research projects of this pathway. The UWG meets regularly several times annually. Criteria have been developed for identifying, prioritizing, and selecting potential advanced II\&C pilot projects performed by this pathway.

The pilot project partner will make the results of the R\&D available and accessible to other commercial nuclear utilities and participate in efforts to support deployment of systems, technologies, and lessons learned by other NPP owners. Host utilities regularly make presentations in key industry technical meetings to describe their motivations and efforts in the pilot projects and to communicate important findings to the industry.

Participating utilities in the UWG currently includes Constellation Energy, Southern California Edison, South Texas Project, Exelon, Entergy, Duke Energy, Pacific Gas \& Electric, Arizona Public Service, Southern Company, Progress Energy, Tennessee Valley Authority, Luminant, and Xcel. Additional membership will be pursued for the UWG with the intent to involve every U.S. nuclear operating fleet in the program. Also participating in the Utility Working Group is the Electric Power Research Institute (EPRI) and the Halden Reactor Project, each of which is described below.

\subsubsection{Purpose of the Utility Working Group}

The purpose of the Utility Working Group (UWG) is to define and sponsor research projects that will collectively enable significant plant performance gains and minimize operating costs as part of the larger national effort to ensure long-term sustainability of the LWR fleet. The UWG Charter is as follows:

- Develop agreements with host utilities to demonstrate near-term beneficial digital applications that improve performance at lower cost.

- Obtain funding for these projects through a variety of means such as government grants and industry shared research funding.

- Coordinate project development among research organizations associated with the U.S commercial nuclear industry, to the degree practical, to minimize duplication of effort.

- Sponsor research on a long-term vision of the nuclear power plant operating/support model based on substantial digital technology integration, and sponsor research on methodologies to identify the cost-beneficial opportunities to transition various plant support functions to a digital technology infrastructure.

- Communicate the work of this research program to utility and support industry decision makers to build a collective vision for a transformed plant operating/support model based on digital technology.

- Coordinate with major nuclear industry support organizations (e.g., NEI, EPRI, and INPO), to the degree practical, in the pursuit of complementary digital technology developments such as appropriate regulatory requirements, technology applications and guidance, and standards of excellence in digital implementation.

\subsubsection{Opportunity for Collective Improvement}

The U.S. nuclear power industry is somewhat unique in how similar each nuclear utility conducts its operations. In fact, the success of the industry as a whole is largely due to the open, sharing nature of the industry wherein new beneficial practices are rapidly adopted throughout the operating fleets. In turn, these operating practices become somewhat of de facto expectations by the industry and the regulator as a whole. This has created significant inertia in the present operating/support model, with limited divergence by individual nuclear plants. This has constrained digital technology to a role of supporting the present operating/support model rather than transforming it. 
To achieve the full potential of digital technology to improve performance, the industry must work together to collectively transform the operating/support model, using these same practices of rapidly adopting proven innovations across the industry. The UWG will foster this digital transformation in a manner that reduces technical and financial risk, while providing a pathway to this new operating/support model. It will also cooperate with the major industry support organizations to facilitate all aspects of the transformation.

The UWG is directly involved in defining the objectives and research projects of this pathway. The UWG meets regularly several times annually. Criteria have been developed for identifying, prioritizing, and selecting potential advanced II\&C pilot projects performed by this pathway.

The pilot project host will make the results of the R\&D available and accessible to other commercial nuclear utilities and participate in efforts to support deployment of systems, technologies, and lessons learned by other NPP owners. Host utilities regularly make presentations in key industry technical meetings to describe their motivations and efforts in the pilot projects and to communicate important findings to the industry.

\subsubsection{Special Interest Groups}

The UWG sponsors two special interest groups in the areas of:

- Control Room Modernization

- Human Performance and Process Improvement.

The purpose of the special interest groups is to provide a means of focused engagement for utilities in the areas of their interests and provide the means of broad peer review of the technologies developed by the research program.

- The special interest groups hold separate conference calls and meetings to review specific technology developments, particularly in association with demonstrations at a host utility. This facilitates direct communication and collaboration among utility representatives with similar development responsibilities and provides a much broader base for identifying utility requirements, such that the developments will have broad applicability across the LWR fleet.

- Additional special interest groups will be formed as new areas of technology development are undertaken through the future pilot projects.

\subsection{Electric Power Research Institute}

EPRI participates in the research program in a collaborative research role. EPRI has conducted numerous R\&D activities over the past several decades in support of NPP digital implementation and related issues and has made relevant reports and guidelines available to this research pathway. EPRI technical experts directly participate in the formulation of the project technical plans and in the review of the pilot project results, bringing to bear the accumulated knowledge from their own research projects and collaborations with nuclear utilities.

EPRI has agreed to assist with the transfer of technology to the nuclear utilities by publishing formal guidelines documents for each of the major areas of development, as described in Section 4.7. This will provide a major benefit to the research program by engaging the EPRI-sponsored industry groups and utility contacts where technical interests match up with the pilot project technologies and concepts. 
For several years, EPRI has sponsored a utility advisory group on "Productivity Improvements through Advanced Technology, which is addressing digital technologies of common interest. EPRI has enabled an open dialogue between this group and the research program, including the UWG, through joint meetings and shared documentation. This arrangement provides a number of important benefits.

- It assures that the end-state vision for plant modernization is shared by a significant portion of the LWR fleet.

- It assures the near-term technologies are immediately beneficial while they comprise the longterm building blocks of a more comprehensive digital environment.

- It greatly reduces the risk of implementation for any one utility, given that the proven abilities of DOE stand behind the soundness of the technologies and that the oversight of the working group provides a competent peer review.

- It allows the utilities to move forward together in transforming their operating model to fully exploit these technologies, providing a transparent process for coordinating efforts with the major industry support organizations of EPRI, INPO, and NEI.

- It increases the likelihood that the technology implementations will receive favorable regulatory reviews due to DOE's, EPRI's, and NRC's agreement to collaborate on research efforts conducted within the LWRS and LTO programs.

\subsection{Halden Reactor Project}

The Halden Reactor Project is a jointly financed R\&D program under the Organization for Economic Cooperation and Development - Nuclear Energy Agency and is comprised of national organizations in 18 countries, including licensing and regulatory bodies, vendors, utilities, and research organizations. The program is executed by the Norwegian Institute for Energy Technology at its Halden establishment in Norway. [9]

The programs from the Halden Reactor Project extend to many aspects of NPP operations; however, the area of interest to this $\mathrm{R} \& \mathrm{D}$ program is the man-machine-technology research program that conducts research in the areas of computerized surveillance systems, human factors, and man-machine interaction in support of control room modernization. Halden has been on the cutting edge of new NPP technologies for several decades and their research is directly applicable to the capabilities being pursued under the pilot projects. In particular, Halden has assisted a number of European NPPs in implementing II\&C modernization projects, including control room upgrades.

Membership in Halden Reactor Project will be maintained over the course of this research program to leverage the wide spectrum of advanced capabilities developed for nuclear operations and support.

The II\&C Pathway will work closely with Halden to evaluate their advanced II\&C technologies to take advantage of the applicable developments. In addition to the technologies, the validation and human factors studies conducted during development of the technologies will be carefully evaluated to ensure similar considerations are incorporated into the pilot projects. Specific Halden developments of interest to the pilot projects are as follows:

- Advanced control room layout

- Computer-based procedures

- Advanced, state-based alarm systems 
- Integrated operations

- Plant worker mobile technologies.

In addition, INL will enter into a bilateral agreement in areas of research where collaborative efforts with Halden will accelerate development of the technologies associated with the pilot projects.

\subsection{Major Industry Support Organizations}

The LWR fleet is actively supported by major industry support groups; namely EPRI, the Nuclear Energy Institute, and the Institute of Nuclear Power Operations. All of these organizations have active efforts in the I\&C area, including technical developments, regulatory issues, and standards of excellence in conducting related activities. It is important that these organizations be informed of the purpose and scope of this research program, and that development activities be coordinated to the degree possible. In the case of EPRI, even though they are a partner in development activities, there are opportunities to collaborate with other major programs they sponsor such as the Instrumentation and Control Program and the Nuclear Maintenance Application Center.

It is a task of this research program to engage these organizations to enable a shared vision of the future operating model based on an integrated digital environment and to cooperate in complementary activities to achieve this vision across the industry with the maximum efficiency and effectiveness.

There are additional industry support groups (such as the Pressurized Water Reactor and Boiling Water Reactor Owners Groups) that need similar engagement for more focused purposes. These groups sponsor I\&C working groups that will similarly benefit from communications about the research program and coordination of activities where warranted.

\subsection{United States Nuclear Regulatory Commission}

Periodic informational meetings are held between DOE Headquarters personnel and members of NRC management to communicate about aims and activities of individual LWRS Program pathways. Briefings and informal meetings will continue to be provided to inform staff from NRC's Office of Nuclear Regulatory Research about technical scope and objectives of the LWRS Program.

\subsection{Suppliers}

Ultimately, it will be the role of nuclear industry II\&C suppliers to provide commercial products based on technologies developed under this research program. In the absence of an industry-wide II\&C modernization strategy, products currently offered by these suppliers reflect the more limited approach of fragmented, like-for-like digital implementations as driven by the market. As a collective vision for an improved operating model based on an integrated digital environment takes hold within the LWR fleet, leading suppliers will seize the market opportunity to provide products that enact this vision. 
An engagement strategy for nuclear industry II\&C suppliers will be conducted with the following tasks:

- Communicate to suppliers the objectives of the research program and the specific technologies and operational concepts that are being developed and validated through the pilot projects.

- Obtain input from suppliers on how they are developing their products with respect to this market.

- Set up a mechanism for ongoing communications.

- Facilitate a long-term commercialization strategy for the program's developed technologies.

\subsection{Department of Energy Nuclear Energy Enabling Technologies Program}

The DOE Office of Nuclear Energy sponsors a crosscutting technology R\&D program addressing common II\&C needs in all Office of Nuclear Energy-sponsored programs. This program, the Advanced Sensors and Instrumentation crosscut, is conducting research that is intended to address gaps and needed capabilities for II\&C technologies in all Office of Nuclear Energy-sponsored R\&D programs.

II\&C related technologies are or will be needed to meet some of the long-term sustainability goals that are beyond the scope of LWRS Program research activities today. This includes improved technologies to support fuels and materials research that are capable of providing higher quality data during in-pile irradiations (planned to be coordinated in other LWRS R\&D pathways). It also includes technologies that will enable some of the vision elements of the II\&C research pathway. Examples of these include digital technologies that can reduce the highly labor-intensive aspects of plant maintenance (such as inspections, tests, and surveillances of sensors and controllers). In addition, digital technology introduction still presents a challenge for most plants because of the considerable regulatory uncertainties - both real and perceived - to obtain approvals, creating significantly higher costs and schedule uncertainty.

The current fleet of LWRs still employs many of the same technologies and algorithms in balance of plant control as when the systems were originally commissioned. Because of the amount of system noise and measurement uncertainty, set point regulation imposes a high burden on plant margins and creates a control structure that is inflexible. Consequently, control system behavior is deterministic and cannot easily or rapidly account for small system disturbances or significant external transients without quickly reaching protection system set points. This results in more 'unavoidable' shutdowns and runbacks than would be necessary if installed control systems could be made more resilient and better able to cope with anticipated transients. Advances in control systems technologies would enable a range of operational improvements that would support higher rates of plant availability and reduced thermal cycling on major plant components caused by rapid plant shutdowns.

Two significant issues confront the massive communications architectures that are required to transmit signal and control data from and between the more than 100,000 individual plant components. The first relates to the material aging of copper cables for medium and low-voltage cables, especially the performance of insulating material. Although research is underway to understand and propose mitigations to counter the effects of material aging and degradation, a diversification of communications approaches may reduce the amount of amelioration that is eventually necessary once a solution is found. In addition, many plant components are not physically 'wired' to the control system and exist outside the awareness of the control system and the operational staff. This introduces significant challenges in maintaining a desired plant configuration and requires substantial manual efforts to periodically assess and verify 
configuration status. In both cases, wireless communications technologies may one day be substituted for many physical cabling. In concert, power harvesting technologies would help realize the goal to have all components physically coupled to plant control systems without imposing additional requirements for power cabling.

Finally, the reactor accidents at Fukushima Dai-ichi have raised a number of issues regarding the ability of current II\&C technologies to withstand the environmental and accident conditions of severe accidents. Currently, emergency operating procedures and severe accident management guidelines in U.S. NPPs require access to reliable information from sensors and controls in order to manage anticipated transients. However, the severe accidents at Fukushima Dai-ichi highlight the potential for loss of all instrumentation and the ensuing difficulties in implementing emergency actions as a consequence. Further research is needed to understand the root causes of instrument failures, alternative approaches to estimate plant conditions, and to determine alternatives to accident management and recovery. 


\section{References}

1. Light Water Reactor Sustainability Program Plan, Fiscal Year 2009, September, 2008

2. Nuclear Energy Research and Development Roadmap, U.S, Department of Energy, April 2010

3. Dominion News Release, Dominion to Close/Decommission Kewaunee Power Station, October 22, 2012

4. NUREG/CR-6883, INL/EXT-05-00509, The SPAR-H Human Reliability Analysis Method, Idaho National Laboratory, p. 19 (2005)

5. D. Robb, J. Gartner, Taking the Long View of Nuclear Plants, EPRI Journal, Spring, 2009, pp. 11-13

6. L.J. Bond, S.R. Doctor, D. B. Jarrell, J.W.D. Bond, Improved Economics of Nuclear Plant Life Management, p. 2 (2008)

7. R.L. Boring, V. Agarwal, J.C Joe, J.J. Persensky, INL/EXT-12-26367, Digital Full-Scope Mock-up of a Conventional Nuclear Power Plant Control Room, Phase 1: Installation of a Utility Simulator at the Idaho National Laboratory, Department of Energy Light Water Reactor Sustainability Program, Idaho National Laboratory, p. 25 (2012)

8. K. Thomas, F. Lipinski, E. Quinn, B. Hallbert, J. Naser, Development of a New Working Group on Advanced Instrumentation, Control and Information System Technology for the LWR Sustainability Program, Seventh American Nuclear Society International Topical Meeting on Nuclear Plant Instrumentation, Control and Human-Machine Interface Technologies, p. 4 (2010)

9. Halden Reactor Project web page, www.ife.no/hrp 


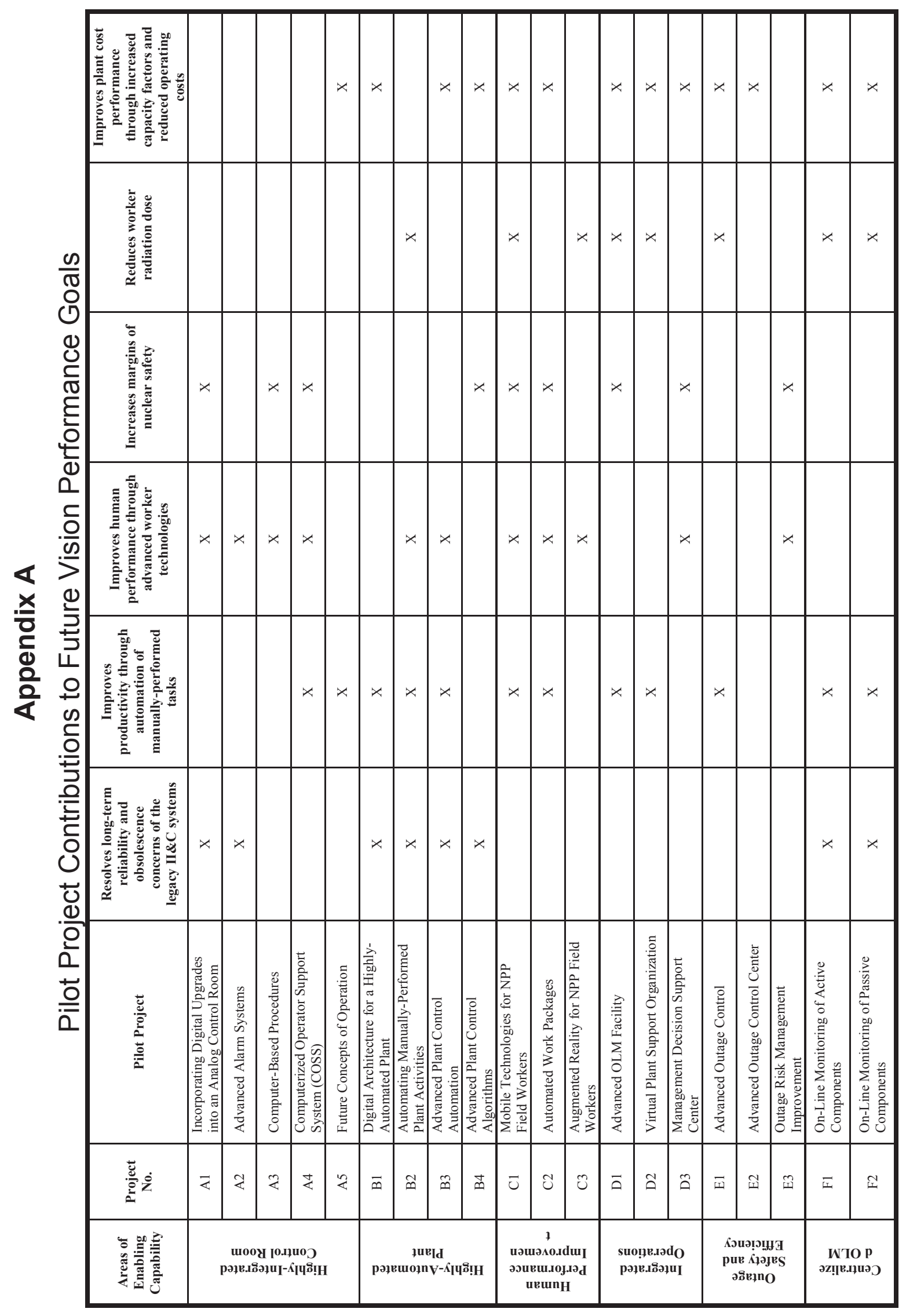

